OFINTENINAT EDITION.

\author{
PATHOLOCICAL \\ HORSP-SHOBNG \\ $\mathrm{BY}$ \\ J. B. COLBMAN, M. R. C. V. S.
}




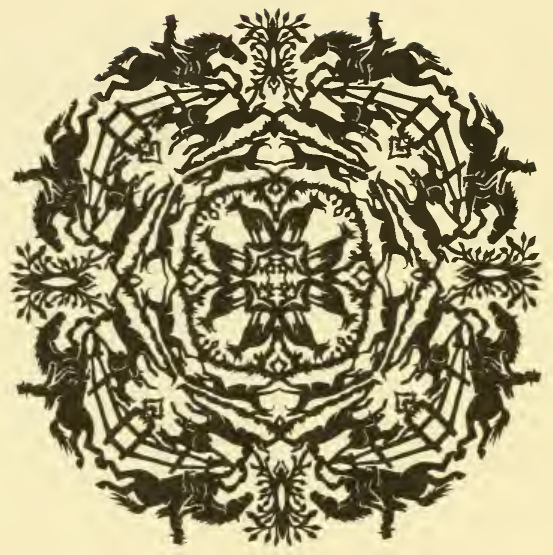

JOHN A.SEAVERNS 
Webster Family Library of Veterinary Medicine Cummings School of Veterinary Medicine at Tutts University 200 Westboro Foad North Grafton MA 01536 



"NO FOOT. NO HORSE."

\title{
PATHOLOGICAL HORSE-SHOEING:
}

\author{
A THEORY AND PRACTICE
}

OF THE

\section{SHOEING OF HORSES.}

BY WHICH

EVERY DISEASE AFFECTING THE FOOT OF THE HORSE MAY BE ABSOLUTELY CURED IR AMELIORATED, AND DEFECTIVE ACTION OF THE LIMBS EFFECTIVELY CORRECTED.

THE RATIONALE OF WHICH IS FULLY

EXPLAINED AND DESCRIBED.

EMIERACING ALSO

AN OUTLINE OF THE ANATOMY AND PHYSIOLOGY

OF THE

FOOT OF THE HORSE,

AND A CUPIOUS GLOSSARY, FORIULARY AND INDEX.

IFY

JOSEPII BRINE COLEMAN, V. S.,

Member of the Royal College of Veterinary Surgeons, and member of the Veterinary Medical Association of London, England.

IIAY BE HAD OF ALL BOOKSELLERS.

C H I CA G O :

Published by the Author, at the Offlce of Henky Fish \& Co., Phinteks and Publishers, 46 Clakk Street.

1876 . 


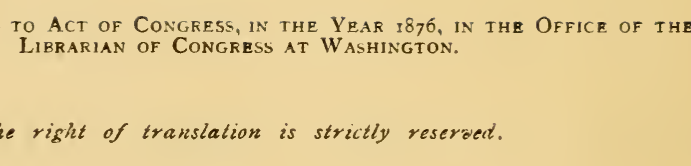




\section{N D EX.}

Anatomy and Physiology of the Foot of the Horse-General Remarks...... I6

Definitions .................... 18

External Structures of the Foot....... I8

The Wall ..................... 18

Composition of ................. I9

Form of .................... 19

Shape of ...................... 20

Bars, Braces, or Buttresses of......... 20

Laminated Internal Surface of ........ 2 I

Epidermis or Cuticle of ............ 22

Coronary Concavity ............... 20

Angle of Inflection, Abnormal........ 2 I

Horny Sole and its Functions ........ 23

Peculiarities of Structure ........... 24

Horny Frog and its Functions ......... 24

Peculiar Properties of.............. 25

Internal Apex of ................. 25

Remarkable Appendix to ............ 25

Coronary Frog-band ............... ${ }_{26} 6$

Fleming's Description of........... 27

Internal Tissues of the Foot-Its Parts

Particularized................ 28

Bone, Chemical Constitution of ........ ${ }_{2} 8$

General Characteristics of............ 29

Bones of the Foot ................. 30

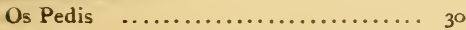

"A Mockery, A Delusion, and A Snare." 3 I

Pedestal of the Column............. 32

Remarkable Construction of .......... 32

Essential Importance of the Foot ..... 32

Os Coronæ ..................... 33

Os Naviculare.................. 33

Stellate Ligaments of ............. 34

Cartilaginous Structures of the Foot.... 35

Lateral Cartilages ................ 35

Inferior Cartilages................ 35

Articular Cartilage ................ $3^{6}$

Remarkable Characteristics of ........ 37

Buffers and Gilding Surfaces... ....... 37

A Knotty Question................. 38

Ligamentous Textures of the Foot ..... 39

Coronary Ligament............... 39
Functions of.................... 39

Reasons versus Ipse Dixits........... 40

Periosteal and Endosteal Membranes... $4 \mathrm{I}$

Sensitive Laminæ................. 42

An Undetermined Question.......... 43

Interperiosteal Pad ................ 43

Relative Weights Sustained by Fore and

Hind Limbs .................. 44

Facilis Decensus Avernus ........... 45

Sensitive Sole ................... ${ }_{46} 6$

An Erroneous Conception Exposed..... 46

Mr. Fleming, Rise and Explain ....... 47

The Solar Zone.................. 47

Sensitive Frog $\ldots \ldots \ldots \ldots \ldots \ldots \ldots \ldots, 47$

Functions of ................. 49

Characteristic Structure of ........... $4^{8}$

Importance of Healthy Condition of.... 4y

Structure Indicates Function ......... 49

Maximum and Minimum of Lateral Movements ...................... 50

Summary of Views ................ 50

Tendons and Tendinous Textures-Particularized................... 5I $^{\mathrm{I}}$

General Character of .............. 5 I

Important Anatomical Fact.......... 52

Flexor Tendons ................. 52

Remarkable Mechanical Arrangements of 53

Three-fold Functions of . .......... 54

Extensor Tendons................. 54

Accessories of ................. 55

The True Suspensor ............ 56

Low Instep, Frequent Source of Lameness 54

Antagonizing Forces............... 56

Secret of Knee Action.............. 57

Tendinous Expansions.............. 57

Lesser Ligaments of the Articulations... 57

Synovial Membranes ............... $5^{8}$

Diseases of, and their Sequela......... $5^{8}$

A Common Error Corrected.......... 58

The Circulatory System of the Foot..... 60

Arteries ...................... 60

General Remarks Upon. ........... 60

Characternstics of ............... 61 
Microscopic Anatomy of ............ $\sigma_{i}$

The Plantar Arteries, Description of.... $\sigma_{2}$

The Plantar Capillaries.............. $6_{4}$

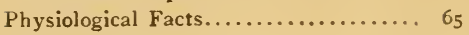

Veins ......................... 66

Micros copic Anatomy of............ 66

Anatomical Arrangement Described.... 68

Veins of the Foot Have No Valves.. .. 67

The Reason Why................ 68

Lymphatics of the Foot............ 69

Scavengers or Sanatory Agents ....... 70

Lymphatic Glands................ $7 \mathbf{r}$

Nerves......................... $\eta^{\tau}$

General Remarks Upon Nervous System 7 I

Nerves of the Foot ............... 72

Distributive Arrangement of ........ 72

Is the Equine Foot an Organ of Special

Sensation ?.................. 73

Prima Facie Reasons ................ 74

Analogical Argument.............. 74

An Objection Anticipated ........... 75

Experientia Docet................ 75

Relative Sensibility of the Equine Foot . 76

Causes of Impaired Action........... 76

Sub-acute Laminitis .............. 77

Acute Laminitis.................. 77

General Causes-Diverse Effects ...... 78

Injuries from Nailing on the Shoe ...... 78

Source of Pain in the Foot.......... 79

External Sources of Pain in the Foot.... 80

Muscular Spasms, or Cramp ......... 80

Non-Inflammatory Affections......... 89

The "Ragged Edge" .............. 80

Possible Cause of Stringhalt.......... 8 8

Secreting Structures of the Foot-Particularized................. $8_{2}$

"Ample Room and Verge Enough".... 82

Constitution of Secreting Villi ........ 83

Fluid Elements of the Foot Particularized $8_{3}$

Physical Properties of the Blood....... $8_{3}$

Important Physiological Facts ........ $8_{3}$

Red and White Blood-Cells.......... 84

Chemico-vital Changes in the Blood .... 84

Judicious Mechanical Expansion....... 85

The "No-Contraction and Non-Expansion Heresies...................

Preliminary Remarks.............. 86

Facts versus Theories.............. 87

Contraction as a Morbid Condition...... 88

The Reviewer Reviewed.............. 88

Age not the Gage of Experience...... 89

"Be Just and Fear Not"............ 89

Essence of Gamgee................ 89

The Case Stated ................ go
An Important Omission Supplied ...... gI

"Language the Key to the Sciences"... gI

Authorized Definitions............... 92

What Does Atrophy Mean ? ......... 92

Value of the Word Atrophy.......... 93

Facts versus Fallacies.............. 93

Varieties of Feet-How Produced....... 94

Effects of Dry Atmosphere ........... 94

Varieties and Effects of Contraction..... 95

The Invariable Cause of Quarter-Crack. 95

The Diseases of the Foot of the Horse-

Contraction-Symptoms and Treat-

ment ....................... 97

Positive and Negative Evidence........ 97

Preparation of the Foot.............. 98

Form ....................... 99

The Best Kind of Shoe............. 100

Nail-holes and Nailing............. r.

Acute Laminitis-Acute Rheumatism-

Acute Founder-Proximate Causes

of......................... 103

Symptoms and Treatment .......... I02

A Puzzling Problem ............... 104

The Cure, "That is the Question ".... 104

Octogenarian Veterinarians........... 104

The Kind of Reception............. 105

Special Points in Shoeing for Laminitis.. I05

Broad's Laminitis Shoe............ . 106

A Point of Importance ............ 106

The Rolling Motion Expedient ........ 106

Depletion, When Desirable .......... 107

Constitutional Treatment............ 107

Chronic Laminitis-Chronic Founder-

Pumiced Foot................. 108

Authorized Errors Combated........... 108

Support the Sole................. r 108

"Stubborn Facts " versus "High A uthor-

ity" ...................... 109

A Demonstrable Fact............... I09

The Why and the Wherefore ......... 109

Common-Sense Shoeing the Desideratum 1 10 How to shoe the Pumiced Foot......... I 10 Navicular Disease-Causes and Symp-

toms ....................... III

Rheumatic Symptoms ............ 112

Treatment...................... 113

Ringbone-Etiology and Pathology .... II 13

Treatment ..................... 113

Sidebones-Ossification of the Lateral

Cartilages-Etiology and Pathology. 114

Treatment .................... 115

Corn-Causes and Symptoms .......... 115

The Old Theory .................. I16

The Writer's Theory .............. II5 
Contraction, or Lateral Pressure, the Cause of Corn................. I 16

Treatment of Corn............... I16

Concomitants of Contraction ........ 117

No Bar-Shoes Necessary for the Cure of Any Corn .................... II

Suppurating Corn ............... II

Nothing Like Expansion of the Quarters to Cure Corn ................. 118

Toe-Crack and Quarter-Crack-Etiology and Pathology................ 118

Contractionists, and Non-Contractionists 119 Solid Proofs Wanted, Not Fallacious Arguments

The True Rationale of Quarter-Crack ... Centers of Rotation, or Motion........ I 120 Correlative Movements.............. r2I

Rationale of Treatment............. 12I

A Sine Qua Non ................ 142

An Exploded Fallacy............... 122

Quarter Before, Toe Behind..... . .... 125

The Cause, Par Excellence ............ 123

What to Do, What Not to Do.......... 123

False Quarter-Shelly Foot-Seedy Toe. 124

False Quarter .................... 124

Treatment... .................... 125

Shelly Foot.... .................. I2 $^{2}$

Treatment......................... 125

Seedy Toe-Special Characteristics...... 126

General Treatment .................. 127

Grease - Scratches - Chapped Heels-

Thrush-Etiology and Pathology ... 128

Fatty Follicles and Their Functions..... 128

Crowding and Dwarfing the Tissues..... 128

Difficult to $M$ isunderstand........... 129

The Machinery out of Gear............ I29

Bad Enough at That ............... $1_{30}$

Treatment of Grease or Scratches....... 130

Treatment of Thrush.............. 131

The All-Important Adjunct... ........ I $_{3} 1$

Treatment of Canker................ $1_{31}$

Some Cures Contrary to All Expectation 13I

Atrophy of the Foot-Dry Rot......... 133

Contraction, Both Cause and Consequence .................... I33 $_{33}$

General Principles of Treatment.... ... 133

Accidental Injuries............... 133

Calking the Instep................. 134

Characteristics of Quittor............. 134

A Remarkable Resemblance............ $I_{34}$

The Most Powerful Adjunct .......... I 35

Tetanus or Lucked-Jaw-Etiology and Pathology ................... 135

Mysterious Intertransmutations of Disease ${ }_{13} 6$
Facts of Pathology................. 1.37

Concurrent, or Predisposing Causes..... 137

Invaluable Adjunctive Measure......... 138

Stringhalt--A Mysterious Malady...... 139

Notes and Queries.................. 140

Peculiar Mechanism of the Hock-Joint . . 140

Does Stringhalt Constitute Unsour.dness? I4I

Professor Spooner's Hypothesis ........ $14^{\mathrm{x}}$

Percival's .. Opinion................. 142

Microscopical Research.............. $14^{2}$

Professor Spooner's Final Judgment ..... ${ }_{142}$

Physiological Attribute of the Hock-

Joint....................... 14

Busteed's Belief.................... 143

Professor Spooner's Strictures.......... $r_{43}$

Dr. Busteed's Claim as a Discoverer.... 144

Experimental Facts... .............. 144

A Curious Coincidence............... $\mathbf{1}_{44}$

The Writer's Suggestion............. I45

Summarized Statement of Author's The-

ory....................... 147

Summary of Changes ............. 147

Incipient Contraction.............. 147

Advanced Contraction............. 147

Ussification of Lateral Cartilages........ 147

Laminitis .................... 147

Drop-Sole, or Pumiced Foot .......... 147

Navicular Disease ................ 148

Ringbone...................... 148

Corns ... ..................... $\mathbf{1}_{4} 8$

Quark-Crack...................... 148

Toe-Crack ...................... ${ }_{14} 8$

False Quarrer .................. 149

Shelly-Foot .................... $\mathbf{1 4}_{49}$

Seedy-Toe ...................... $\mathbf{r}_{49}$

Scratches ..................... 149

Thrush of the Frog,.............. r 49

Canker of the Sole.................. 149

General Atrophy of the Foot ......... 149

Accidental Injuries ................ 149

Treads ......................... 149

Bruises........................ 149

Injuries from Calking.. ............ $\mathbf{1 4 9}$

Quittors...................... 149

Suppurating Corns.................. $\mathbf{1}_{49}$

Picking Up Nails................. $\mathbf{1}_{49}$

Injuries Connected With Shoeing...... 149

Constitutional Complaints ... ......... 149

Tetanus, or Locked Jaw............ 149

Pneumonia ..................... 149

Pleurisy ..................... 149

Gastritis ...................... 149

Enteritis ..................... J49

Gastro-Enteritis................ 149 
Skin Affections..................... 149

Sweeny, or Atrophy of Muscles........ 150

Irregularities of Gait and Action ....... 150

Conclusion

$15^{1}$

FORMULE :

Poultices and Poultice Boots......... 152

Fomentations for Different Forms of Injury ........................ 153

Lotions for Various Purposes......... I 154

Liniments and Embrocations for Sprains, Bruises, ete................. ${ }_{5} 6$

Liniments and Salves for Canker, Thrush, etc ..................... 157

Powders for Scratches, Canker, Thrush, etc ...................... ${ }_{159}$

Powders for Cleaning Foul Ulcers, etc... I 60

Blistering Applications for the Removal of Splents, Spavins, Ringbones, Sidebones, Bony Enlargements, Thickened Tendons, etc............. I6r
Hoof Dressings-Their Use and A buse.. 162

Hoof Stimulants ................ $16_{3}$

Hoof Salves................... $16_{4}$

Hoof Stoppings for Sole and Frog....... $16_{4}$

Constitutional Treatment............ 166

Preliminary Remarks.............. 166

Glossary...................... I70

Special Notification............... 179

Testimonials ................... I $8 \mathrm{I}$

How to make a Book.............. I8 1

The Play without the Part of Hamlet... I8r

Acknowledgments ................ 182

Unexceptionable Testimony.......... 182

Letter from Addison Doughty......... 182

Letter from R. C. Anthony ........... $18_{4}$

The Dilator.................... 186

The Book and the Instrument-Terms.. 187 


\section{APOLOGETIC AND EXPLANATORY.}

The author of this work is fully conscious of some errors of omission as well as commission to be found within its pages, although he deems them of minor importance, when compared with the really valuable and useful practical information it contains, upon a much neglected but highly important branch of veterinary science and art. It was intended that its pages should have been enriched with first-class engravings illustrative of the doctrines and the practice taught. These, however, the exigencies of professional duties, and other circumstances, would not admit of being executed in a manner that would be deemed satisfactory to the public, or the author, within the limits of time at the latter's disposal. He trusts that his desire for the issuance of his work during the most momentous celebration of human progress of modern times, may, to some extent, further excuse this omission, as well as the reduction of the original price-Five Dollars with illustrations, to Three Dollars without them. It is the author's intention to fully complete his work in a future edition, and to make it worthy in every respect of the age of enlightened progress in which we live; of the great epoch now being celebrated; of the Country, par excellence, which as yet, has exhibited the highest developement combined with the greatest utilization of speed in the noblest of all animals, the Horse; and of the important protessson to which he has the honor to belong. 



\section{N TRO DUCTORY.}

HUMANE SOCIETIES AND IMPROVED HORSE-SHOEING.

Amongst the various secondary objects which Humane Societies, the world over, propose to themselves to attain in order to carry into effect their highest benevolent intentions towards the inferior order of created beings, which are associated with, or subject to, the service of mankind within the different spheres of civilization, there is none I deem of more transcending importance to the best interests of society, in subserving the noble aims, greater and lesser, which those societies have in view, and the well being of the quadruped under consideration, than improved methods of shoeing horses, whether for the purpose of preventing disease and lameness, or for removing or ameliorating those abnormal conditions when present. The full measure or complement of all that is possible in these directions, ought to be accomplished.

The writer of the following pages on pathological horseshoeing, deeply impressed with this view, as well as actuated by a profound conviction of personal duty, earnestly desires to enlist the active sympathies and assistance of the above societies in every civilized community on behalf of what he regards as his mission of mercy to the victim of the most unaccountable ignorance of his necessities, in the management of one of his most essential organs of usefulness; yet, withal, an indispensable and invaluable adjunct of civilization everywhere.

About three.years since, the Scottish Society for the Prevention of Cruelty to Animals, awarded prizes "for the best and most practical essays on horse-shoeing, in connection with the comfort and soundness of the horse." Upwards of forty essays 
were sent in, the chief prize being awarded to G. S. Fleming, Esq., of London. Mr. Fleming's essay contemplates only the correct principles upon which a sound foot should be shod. It left untouched the wider and more important question as to how the feet of horses in a diseased and semi-diseased conditions should be shod; more important because of horses in actual service at the present time, I do not think that one in twenty may be said to have a perfectly sound foot; and still more important, inasmuch as the methods or principles involved in restoring a diseased foot to healthy conditions, will point, infallibly, to the manner in which it should be shod to preserve healthy conditions, while no amount of ordinary horse-shoeing for the sound foot will teach methods of shoeing for the unsound foot. The term, pathological shoeing, refers to shoeing diseased feet; physiological shoeing, to shoeing the sound foot.

Some prefatory remarks to Mr. Fleming's essay, made by the Secretary of the S. S. P. C. A., have a peculiar appropriateness here. He says : "It is a painful reflection, that the advance of civilization seems ever to be accompanied by certain evils, and in no instance is this more marked than in the terrible amount of suffering unnecessarily endured by the Horse. This animal, pre-eminently the most useful to man, is the one upon which is inflicted, either wantonly, or through sheer ignorance, or thoughtlessness, the greatest amount of cruelty. The records of all humane societies, show that of prosecutions for cruelty to animals, an overwhelming majority refer to the horse, and of these a large proportion are for working horses, while suffering from lameness in one form or another. So frequent are such cases, that observers have concluded that its prevalence must result from some specific cause; and not unnaturally attention has been directed to the various modes of management practiced relative to the horse's foot, to the manner of shoeing, and in particular to the way in which the hoof is prepared for the shoe." Here, then, is an illustrious precedent, if any were needed, in the most progressive city in the world, whose collective characteristic is to lead rather than to follow; for the Chicago Branch of the Illinois Society for the 
Prevention of Cruelty to Animals, upon which to take action upon a question of extreme moment, directly to the well-being of the horse, whose natural rights it is the morally and legally recognized guardian and advocate; and, incidentally, to the main objects to attain which, the society has been called into existence, and to society at large. I respectfully suggest, that a committee of this Society be appointed to inquire into the value of the modes of treatment enunciated in this work. This can readily be determined by testimony and experiment. I am prepared to show by the testimony of gentlemen, owners of horses, and of well known horsemen of this city whose horses I have treated, and some of whom, moreover, I have instructed in my processes and plans of treatment, that the majority of all the diseases incidental to horses' feet are curable by the means I recommend, and many of them by no other means; that they have the merit of being simple and easily acquired, and their application easy, by any man of intelligence; that there need be no pain consequent upon their application, but that, in many cases, they occasion an immediate relief of pain and lameness. By experiment, I propose to prove beyond a peradventure, that in all the varieties of foot affections, with but very few exceptions, the immediate effect is beneficial, and the ultimate result in a vast majority of lamenesses from diseases of the foot, an absolute cure, if simple rules concerning management and shoeing are observed during the progress of recovery. If this can be shown to the satisfaction of a committee of this Society, can a doubt exist as to the course the latter ought to pursue in regard to an endorsement of the treatment recommended and taught in this work? 


\section{PREFATORY.}

The publication of this work has arisen out of the expression of a want on the part of my pupils for a remembrancer, or guide, in the application of the principles and practice of the treatment I have adopted and recommend for the adoption of others, as the most rational, and the most successful of any that I am acquainted with, or even heard of.

The first intention was to limit its issue to my pupils who had been fully instructed in the theory and practice of the views it embodies. A fuller consideration, however, of the benefits that would accrue to society, aye, to the world at large, in the diminished sufferings, a fuller utilization, and in the enhanced pleasure and profit arising from the employment of one of the most useful of the domestic animals, namely, the horse, has determined the writer to give a wider dissemination to his views and methods of treatment for the diseases incidental to the foot of that animal; to devote his entire energies to the work of personal instruction which he has begun, and by rescuing those operations from the domain of empiricism and selfish secrecy, to give them their legitimate place in the category of useful medical appliances.

It is a fact but too patent to the observation of every thinking person having any interest of humane sentiment, pleasure, or pecuniary profit in the well-being of the horse, that the footdiseases of this animal are out of all reasonable proportion, in excess of those affecting him in other respects, and that the foot of the horse and its diseases, notwithstanding the numerous ponderous volumes that have appeared from time to time since the establishment of the Royal Veterinary College of London, England, over three-quarters of a century since, is still the least understond, and the best, or worst abused organ of the whole animal economy. 
Every humanitarian who embraces within his merciful regard every creature whose existence is not inimical to his own, whose common feelings of sympathy for the speechless victims of modern civilization, constitute a platform of union and effort, for the one common purpose of preventing, or mitigating those sufferings, as far as they have the authority and power conferred by the law to do, will assuredly be interested in any painless, or even comparatively painless process. of treatment by which the sufferings of horses which arise from the morbid condition of their feet, may be materially abridged; that in some instances acts almost magically in the relief of pain, and in all cases exerts its ameliorating influence gradually, but surely, and perceptibly, day by day.

The scientific veterinarian owes a positive duty to society and to the profession of which he is a member, besides having a personal and pecuniary interest therein, to investigate any, and every mode of operation that promises to enable him to cope more successfully than he has hitherto done with the morbid conditions of the pedal extremities of the animal of whose physical welfare he is the recognized protector and physician, which seem to have baffled and defied the acutest veterinary pathologists of every age and country to account for and to overcome. Has he not an all important interest, the value of which can scarcely be estimated, in a theory, and such a practical verification of it, that throws a clear and unexpected light upon causes of morbid conditions heretofore obscure, and a theory and practical measure moreover, the truth and value of which he can so readily demonstrate for himself in a variety of cases, and be master of its application in a few hours?

Hitherto, I confess, I have been extremely reticent upon the subject of my modes of treating diseases of the feet of horses. Now that I have assumed the role of teacher, and have devoted my time and energies to the vocation of teaching, I am willing to impart the special information I possess freely and unreservedly to every veterinary practitioner of whose ability I am satisfied to do justice to the operation I recommend. 
It is not less the duty and the interest of the horse-shoer, who aspires to superiority in his important and useful calling, to acquire a correct, if not a profound knowledge of the nature and functions of the structures he is called upon to operate, in order-

I. That he might the more intelligently co-operate with the owner of the horse, or the veterinary surgeon having a case in his charge.

2. That he may justly be entitled to the confidence of his employer who may be unable, or unwilling, if able, to give any special directions in the matter.

3. That he may be able to distinguish between normal and abnormal developments, or healthy and unhealthy conditions, to become familiar with, so as to be able to detect readily the first advances of a departure from healthy conditions, or the natural conformation of the organ it is his particular province to conserve and protect; and moreover that he may have, and be able to apply that special knowledge which will enable him to counteract and check such advances.

The shoeing-smith who possesses these qualifications has in his hands a powerful lever of personal advancement in his calling, and the whip hand of his fellow craftsman not so well informed, upon the road to distinction and wealth.

A clear understanding of the subject can be gained by any intelligent smith in the course of a few hours private, or other instruction, by the aid of specimens, diagrams, etc. His opportunities for demonstration are of course the best; as he can be instructed and initiated into the modus operandi in his own workshop. Every smith, if possessed of candor, after witnessing the results of the operation for Contracted Feet, Corn, Quarter-crack, and in Founder and Navicular Disease are so pleased and surprised that they exclaim in the spirit, if not in the precise language of the philosophic Hamlet :

"There are more things in heaven and earth, Horatio, Than are dreamt of in our philosophy."

I claim no special merit on the score of originality as to the facts and the main feature of the practice on which my methods 
of treatment are based. There is nothing new in the practice of dilating the foot for a contracted condition of that organ, though I incline to the opinion that something new will be found in its application, and in the theory which embraces and explains the etiology and the rationale of cure of every specific disease of the foot, and throws new light on some of the mysterious constitutional maladies of the horse.

The process, limited to the correction of contraction, was recommended by La Fosse, a celebrated French equine pathologist, over a century since, and his successors at the Veterinary College of Toulouse, have issued a brochure on the subject within the last decade; still, however, limiting its utility to contraction. Horse-shoers everywhere, but especially in the country districts, occasionally pry open the horns of the shoe with a common smith's tongs.

I have experimented and investigated, and have found that there is literally no disease, and scarcely a condition of the equine foot to which it is not applicable, whether it is for the prevention or cure of disease, or for the correction of faulty action, and per consequence, the development of speed.

This universal applicability has revealed the true character and causes of some diseases about which controversies have raged and spent themselves in vain for the last three quarters of a century, as far as a solution of the questions in dispute was concerned, and of others which have hitherto been very difficult of cure, but of which the difficulties are now completely overcome. In short, the long sought for theory, which most writers on veterinary pathology have thought would in time be found, that would explain and harmonize many conflicting opinions and recorded observations upon these matters, and show the true sequence of the causes and effects which produce the various disorders of the foot of the horse, in the writer's opinion, has been found, and is now submitted to the judgment of the veterinary profession and the world-for the first time. 


\section{ANATOMY AND PHYSIOLOGY OF THE FOOT.}

GENERAL REMARKS.

To attain anything like a full and clear conception of the economy of the foot of the horse, its various component parts, whether internal or external; their structural organization, and the uses for which they are designed; the laws that govern healthy function; the phenomena of disease, and the rationale of cure, should be studied very attentively. "There is no royal road" to the perfect mastery of this subject; but it is one whoever travels with diligence, whether for pleasure or profit, will soon be led to a strong vantage ground of usefulness to society, that will enable him to accomplish an incalculable amount of benefit for the horse, and therefore for his owner, and incidently to advance in manner and degree, but little suspected, the best interests of humanity and civilization.

Anything more than a brief outline of the anatomy of the integrant parts of the foot, whether internal or external, would lead me far beyond the limits assigned me by the scope of this work or the patience of my readers. Indeed, I would much prefer the discussion of hypotheses, the investigation of causes, and the practical application of remedies, to the dry details of anatomy. They are, however, not barren of results, since they afford the only foundation upon which the science of therapeutics can be built. If, therefore, we would build for permanence, we must lay the foundation broad and deep in the facts and teachings of anatomy and physiology. 
The importance of a knowledge of the peculiarities of form and structure of the various organs and tissues of which the foot is composed, will be best appreciated when disease has invaded them, and every available means are being employed to combat the invader. On such occasions I am accustomed to say that the case requires, and should have, every chance there is in its favor, however apparently trifling, to expedite recovery. An apparently trifling chance will frequently turn the scale for, or against, the animal's recovery, and the reputation of the practitioner.

The amateur student may not be aware that considerable diversity of opinion exists not only in the great body of the veterinary profession, but even amongst its leading teachers and writers; not only upon the functions of the different organs that compose the foot, but of those of the pedal organ itself.

Even the anatomical structure of the foot, usually deemed a science of fact and of demonstration, so prolific is the foot of the horse in contrariety of views, does not command absolute unanimity of opinion.

As to the specific diseases of the equine foot, there are still wider divergencies of sentiment and opinion concerning their causes and treatment amongst the literary luminaries of the profession. These, however, will be reviewed in the section devoted to the consideration of the diseases of the foot.

It will be seen, by and by, what an important connection there is between a correct knowledge of healthy functions of the several parts of the foot, and the right application of principles for the prevention and removal of its morbid conditions.

A study of the physiological laws can alone afford a satisfactory basis for the consideration of the phenomenal changes which inevitably succeed a violation of these laws. The better the laws of health, and the causes and symptoms of disease are mastered, the reasons for, or against, any line of practice that may be recommended, can be the more judiciously reviewed, and adopted or rejected, with just confidence. 
DEFINITIONS.

The foot of the horse admits of two definitions: the common, and the anatomical.

The common implies the horny extremity of the limb, and the tissues contained within it; the anatomical applies to all the structures beyond the lower joint of the knee.

It is in its common acceptation that I shall use the term foot. I do not for the present propose to enlarge my scope of inquiry beyond the limits implied in this term, except by way of explanation or illustration of doctrine concerning the functions of the pedal organ. Indeed, I fear that I shall be found, even within these limits, to tax the endurance of my readers very considerably, whether professional or not, as I find it impossible to do justice to the numerous topics of discussion that arise out of a consideration of the foot of the horse in its varied aspects of structure and function by any very summary style of treatment.

THE EXTERNAL STRUCTURES OF THE FOOT.

The external structures of the foot, regarded as a whole, is called the hoof. The hoof may be conveniently divided into the wall, sole, bars, frog, and frog-band.

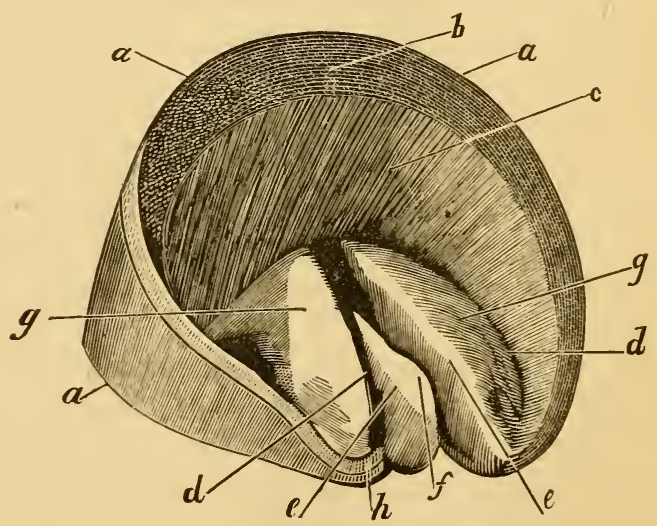

Figure 1.-View of the Hoof when separated from its internal attachments.

a $a$ a. The Wall; $b$. The Coronary Concavity; $c$. The Horny Plates or Laminz; $d d$. The Internal Commissures $: e$. The Horny Frog: $f$. The Internal Prominence of the Frog corresponding to the External Cleft; $g g$. Inner Surface of the Sole $i h$. The Frog-band. 
THE WALL

is that portion of the hoof which is visible when the horse is 'standing. The different portions of the wall, viewed externally, are respectively denominated the toe, the inner or outer toe, the quarters and the heels; terms sufficiently self-explanatory.

COMPOSITION OF THE WALL.

The great body of the wall is composed of a dense fibrous mass, the fibres being bound together by a glutinous material called the horny matrix. The internal surface consists wholly of the horny matrix, and is laminated.

FORM OF THE WALL.

The wall presents some peculiarities of form, which it is not unimportant to be familiar with. These are noticed by Turner in the following paragraph :

"On inspecting the unshod foot of a four-year-old colt (which is fully developed at that period of life), it has been the fashion for veterinary writers to consider its ground surface as a circle. To this I have much objection, having always been struck by the great inequality of its two sides, not only as to the additional thickness of the wall of the outer quarter in comparison to the inner, but the still greater difference in compass or circularity; the outer quarter furnishing far more than is necessary to form the half-circle, while the inside is generally much less than a semi-circle. This bulge, or fine luxuriant growth of the outside quarter is generally most apparent toward the heel, not only forming a much broader basis of support for the superstructure than the inside, but also one of immense strength. The inside column of wall being less strong, and yet placed more immediately under the centre of gravity, it appears to me quite obvious that Nature intended the outer quarter should serve as the main prop of support, whilst the inside quarter, in proportion to the weight and speed of the animal, should expand and oppose concussion." 
THE SHAPE OF THE WALL-DIFFICULT TU DESCRIBE.

As to the question whether the general form of the foot be cylindrical or cone-shaped, I agree with Spooner, that in , some horses no doubt the feet are cylindrical; but as in the great majority of hoofs, and particularly those which we consider the best, the circle at the upper part is less than one at an equal distance lower down, we shall be more frequently correct if we describe it as the "frustum of a cone, the base and summit of which have been intersected by two oblique planes." The fact, however, is, that no mathematical figure can correctly describe the exact shape of the foot, for viewing it in front we may pronounce it conical, whilst at the same time its lateral aspect may be that of a cylinder.

\section{THE CORONARY CONCAVITY.}

On the inside of the upper margin of the wall is to be seen a concavity, about three quarters of an inch in depth, and extending throughout the entire upper circumference of the wall. This is named the Coronary Concavity, and by some the Coronary Ring. This concavity is for the repose of the organ which secretes the fibrous, and therefore the principal portion of the wall, and is called the Coronary Secretary Substance. On the surface of the Coronary Concavity may be seen, by the naked eye, a vast number of minute perforations, which receive the secreting villi of the Coronary substance. Quoting Haycock: "These are the commencement of the horn tubes which are continued from the top to the bottom of the hoof; the hoof, in part, is a series of minute cylinders or hollow tubes. These tubes exist in immense numbers, are placed side by side, and traverse the entire length, or rather depth of the horny mass. The animal, strange as the statement may appear, stands and travels upon thousands of cylinders, all arranged with extreme regularity, and held together by a common glutinous medium, in which is deposited the peculiar pigment giving color to the hoof."

THE, BARS, BRACES, OR BUTTRESSES OF THE WALL.

Another portion of the foot has received the names of Bars. Spooner describes them as a continuation of the wall, being 
similar to it in their structure and appearance. The point where the inflection or doubling inwards of the wall takes place is usually called the angle of inflection. The Bars extend forwards and inwards towards the apex or point of the frog, terminating just before reaching it. The Bars are about the same thickness as the wall is at the quarters, and their greatest depth is about an inch, gradually lessening toward their termination. The bars act as braces or buttresses in forming and supporting the heels of the wall upon which the shoe rests. The wall and bars constitute the boundary of the sole with which they have a strong and intimate union.

NO ANGLE OF INFLECTION IN A NORMALLY SHAPED FOOT.

In a normally healthy foot, the inflection, where the bars spring from the wall, is of a rounded rather than an angular form. Whenever the inflection exhibits a strongly marked angular form, I regard it as a departure from the standard or normal shape, induced by a contracted or shrunken quarter. It is the angular form that produces the condition termed Corn. I, therefore, cannot consider the term, angle of inflection, so frequently used by writers upon the foot, as correct, if applied to a normally shaped foot.

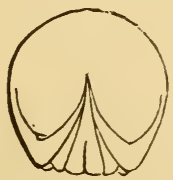

Fig. 2.

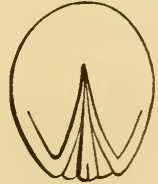

Fig. 3.

Figure 2.-A Foot with open heels and rounded inflections.

Figure 3.-A Foot with contracted heels and angular inflections.

THE LAMINATED INTERNAL SURFACE OF THE WALL.

The entire inner surface of the wall from the lower edge of the coronary concavity to the line of junction of the wall with the sole is covered by a large number of closely set, long, thin, 
narrow leaves, or plates. Their form, and the nature of this substance has given them the name of horny laminæ. In the detached hoof, it will be seen that one longitudinal edge is free, while the other is united to the wall. It is, indeed, a portion of the wall itself, frilled as it were into the form we view it. By means of these plates, averaging about 500 in number, the wall is attached to the internal portion of the foot, namely, to the pedal bone, and it extends to the lateral and inferior cartilages. Besides forming an attaching medium of great strength and tenacity and large extent, they subserve other important purposes which will be referred to a little further on when reviewing these functions more particularly.

THE EPIDERMIS, OR CUTICLE OF THE WALL.

A not unimportant constituent of the wall is its extreme external coating. Physiologists tell us that the normal hoof is covered by a layer of a silicious material resembling that upon the outer surface of straw, and that it fulfils a similar function to the wall of the foot as that of the epidermis or cuticle, to the dermis or true skin. The healthy foot is able to secrete and maintain a degree of moisture compatible with the existence of toughness and resiliency in its outer structures, and any excess or deficiency of moisture is equally pernicious to a healthy foot.

The former is promoted by the injudicious use of the knife and rasp, conjoined with soaking, stopping, poulticing, etc., while the latter is the result of the same unreasoning process of rasping and paring, with the soaking and stopping omitted. Whenever the epidermic covering is removed by the rasp, as is too frequently the case, undue evaporation takes place, and the hoof becomes the very opposite of what it should be, under the combined influences of inordinate exhalation of moisture, and the heat of the sun, or an unusually dry atmosphere. The subject is suggestive of much more that might be said, but must be reserved for future consideration. 
THE HORNY SOLE AND ITS FUNCTIONS.

The horny sole, the organized foundation, the chief weightsustainer of the animal frame, constitutes the whole of the plantar surface, not occupied by the edge of the wall, including its inflections, the bars, and the external frog. Its line of junction with its boundary wall may be traced by a white line or zone, which Mr. Fleming, I believe, has been the first to notice in print.

A detached sole presents the remarkable peculiarity of a deep indentation in the general form of an isosceles triangle, its base being placed posteriorly, and its apex extending fully two-thirds of the distance from its base to the anterior margin of the sole.

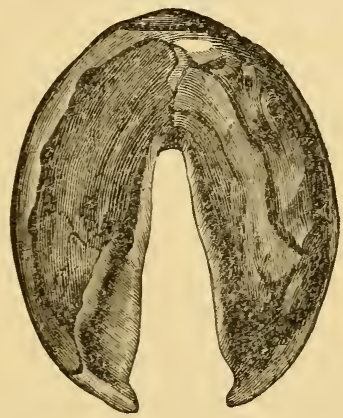

Figure 4.-External View of the Horny Sole.

Microscopic anatomists describe the horny sole as fibrous in its inner substance, the fibres taking an oblique direction forwards and downwards, corresponding to that of the fibres of the wall, and gradually changing into squamous incrustations, somewhat similar to the epidermis of the skin as it approaches its external limits.

The horny sole is secreted by the vascular and sensitive sole, and in the same manner as the wall is secreted by the coronary band, by tufts or villi that penetrate the horny fibres. The wall wastes by attrition when the animal is unshod; the sole. and the frog, by exfoliation. 
Of other peculiarities of construction of the sole, I prefer to give them in the words of an able disquisitionist upon the equine foot, Professor Gamgee, Senr.

\section{THE HORNY SOLE-PECULIARITIES OF STRUCTURE.}

"The sole is thickest at, and is strongly connected anteriorly; and in its two posterior terminations, where it is so strongly inverted by the inflections of the wall, as to be incapable of direct dislocation by any means, whilst the parts remain in their integrity, viz., not cut away or weakened. The inflected wall, which according to prevailing notions is called 'the bars,' constitutes for all essential purposes an inner wall, a continuation of the outer wall; these minor inflections have no such abrupt terminations, as their outer appearance at first sight indicates, or as seems to be the case by the laminated attaching inner surface; the same inflected wall forms the inner boundary of the two lateral divisions of the sole posteriorly, and it is by these that the strength of the sole is contributed, and its arched form perfected."

\section{THE HORNY FROG AND ITS FUNCTIONS.}

The Horny Frog is triangular in shape, and occupies the triangular cleft in the sole. Quoting from Fleming: "In the middle of the posterior part is a cleft, which in the healthy state should not be deep, but rather shallow and sound on its surface. In structure, this body is also fibrous, the fibres passing in the same direction as those of the other portions of the hoof; but instead of being quite rectilinear like them, they are wavy or flexuous in their course, and present some microscopical peculiarities, which, though interesting to the comparative anatomist, need not be alluded to here. The fibres are finer than those of the sole and wall, and are composed of cells arranged in the same manner as elsewhere in the hoof; they are formed by the villi which thickly stud the face of the membrane covering the sensitive frog." 
PECULIAR PROPERTIES OF THE FROG.

The substance of the horny frog is eminently elastic, and corresponds in the closest manner to the dense elastic epidermic pads on the soles of the feet of such animals as the camel, elephant, lion, bear, dog, cat, etc.; and which are evidently designed for contact with the ground, the support and protection of the tendons that flex the foot, to facilitate the springing movements of these creatures, and for the prevention of jar and injury to the limbs. In the horse's foot, the pressure of this thick, compressible and supple mass of horn at the back of the hoof, in a healthy unmutilated condition, and permitted to reach the ground while the animal is standing or moving, are absolutely essential to the well-being of that organ, more especially should speed, in addition to weight-carrying be exacted.

The frog like the sole exfoliates, or becomes reduced in thickness at a certain stage of its growth; the flakes are more cohesive than those of the sole.

\section{THE INTERNAL APEX OF THE HORNY FROG.}

It must be remarked, however, that this exfoliation of the sole and frog only takes place when the more recently formed horn beneath has acquired sufficient hardness and density to sustain contact with the ground, and exposure to the effects of heat, dryness and moisture.

The cleft of the frog penetrates some distance into the foot and terminates in a horny prominence which I am accustomed to regard as the internal apex. This prominence, by its pointed character and upward direction when one or both heels are contracted or shrunken and the frog is of small dimensions, plays a very important part in the production of lameness. This, however, I will not dwell upon here.

\section{A REMARKABLE APPENDAGE TO THE FROG.}

The frog-band or stay was first dissected out and described by Bracy Clark. Mr. Fleming designates it by the more technical 
term "Periople." I at one time shared the opinion of my preceptor in anatomy, that the frog-band was more a matter of fancy than of fact, and that many ingenious carvings could be made out of a horse's hoof. I have, however, a yery well marked specimen in which the band shows its true character without any carving whatever, by the simple process of drying and partial separation. A thin leather strap made to encircle the hoof around its superior border, each end embedding itself into the substance of the frog, it seems to me, may convey an idea of its structure and uses. To my view it is precisely analogous in its purposes to those of the strap that embraces the human instep and gives support to a $\mathrm{clog}$, that is sometime worn, particularly by ladies. A few moments reflection upon the slender character of the attachments of the frog at its posterior portions will show the necessity for the existence of some such an arrangement as this. The following is Mr. Fleming's description of this structure :

"The Coronary Frog-Band, or 'Periople,' is a continuation of the more superficial layer of the skin around the coronet and heels, in the form of a thin, light colored band, that descends to a variable depth on the outer surface of the wall, and at the back part of the hoof becomes consolidated with the frog, with which it is identical in structure and texture. It can be readily perceived in the hoof that has not been mutilated by the farrier's rasp, extending from the coronet, where the hair ceases, to some distance down the hoof; it is thickest at the commencement of the wall, and gradually thins away into the finest imaginable film as it approaches the lower circumference of this part. When wet it swells and softens, and on being dried shrinks, sometimes cracks in its more dependent parts, or becomes scaly.

The fibres composing it are very fine and wavy, as in the frog; they likewise spring from villi which project from the true skin immediately above the "coronary cushion." The use of this band would appear to be two-fold; it connects the skin with the hoof, and thus makes the union of these two dissimilar textures more complete, its intermediate degree of den- 
sity and its great elasticity admirably fitting it for this office; and it acts as a covering or protection to the wall at its upper part, where this is only in process of formation, and has not sufficient resistance to withstand the effects of exposure to the weather. The greatest thickness and density of the band corresponds to the portion of the wall in which the villi or vascular tufts are lodged, and here the horn is soft, delicate, and readily acted upon in an injurious manner, by external influences."

Elsewhere he writes of its uses, and abuses :

"The thin, semi-translucent horn that extends in a somewhat wide, whitish-colored band, around the upper band of the foot, is chiefly intended by Nature, I think, to protect the fibres of the wall from the effects of external physical influences, such as heat and dryness, while they are being secreted, or so immature as to be incapable of resisting these influences; for it will be remembered that the wall is formed at the coronet, and this covering guarantees, not only the integrity of the newly-made horn-tubes, but also maintains the secreting vessels that enter them, in a healthy condition, and competent to supply fresh material for wear. The destruction of this band, and the rasping of the fibres beneath it, is detrimental to the healthy secretion of the wall fibres, and leads to the same result that paring the sole was shown to do: shrinking of the horn tubes containing the tufts of vessels, wasting of these, a diminished supply of horny material in* consequence, and a thin brittle wall that scarcely appears to grow down at all, in depth or thickness, and barely allows a shoe to be attached to it. Sandcrack and other diseased conditions of this part of the hoof are mainly due to this cause." To all of which I yield an unqualified assent, excepting the last clause. Ascribing as I do the chief proximate cause of quarter-crack to contraction of the lower part of the quarter, and outward pressure upon the upper, I am willing only to accept brittleness of hoof, etc., as predisposing or secondary causes. 


\section{THE INTERNAL TISSUES OF THE FOOT.}

ITS PARTS PARTICULARIZED.

Having described the component parts of the hoof, or exter nal portion of the foot, we will proceed to the consideration of the internal structures or tissues of that organ.

The first division of these is into solids and fluids. Of the solid constituents there are bones, cartilages, ligaments, bloodvessels, nerves, absorbents, and secreting glands.

The Fluid elements comprise the blood, synovia, marrow, lymph, and the various glandular secretions.

The Bones consist of the pedal, navicular, and the coronal.

The Cartilages include the articular, the lateral and inferior.

The Ligamentous Structures comprehend the tendons of muscles that are inserted into the bones named, the lateral and other ligaments of the foot-joint, as well as the synovial, capsular, periosteal, and perichondrial membranes, and the fibroelastic structures of the wall sole and frog.

The Blood-vessels embrace the arteries, capillaries and veins.

The Nerves-sentient and motory.

The Absorbents-superficial and deep-seated.

The Secreting Textures-of the wall, the sole, the frog, the frog-band, the solar zone, the sebaceous follicles, and the perspiratory exhalents.

The fluid elements are sufficiently categorized.

\section{DESCRIPTION OF THE BONES OF THE FOOT.}

\section{CHEMICAL CONSTITUTION OF BONE.}

Before entering upon the descriptive anatomy of the bones, a brief allusion to the composition and characteristics of bone substance may not be unprofitable, as assisting to throw light on some of the diseases of bone, of which we have several conspicuous examples in the organ under consideration. 
The two principal constituents of bone are cartilage and phosphate of lime; the proportions of the former being about 29 to 34 per cent., and that of the latter, from 50 to 60 per cent. of the entire bone. The bone-earth may be dissolved out by dilute hydrochloric acid (one part of strong acid to five parts of water). The cartilage remains unaffected and retains the form of the bone. This is really a curiosity which may easily be obtained in the manner indicated.

The following analysis of the bone of a healthy horse is to be found in Bowman's Medical Chemistry. In every roo parts there is

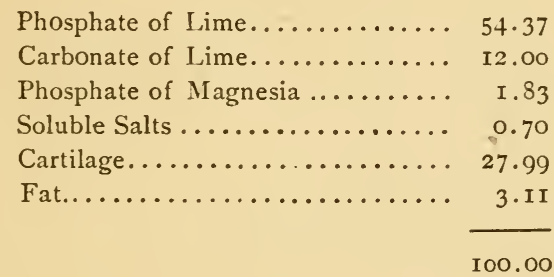

In certain morbid conditions of bone remarkable changes take place in their chemical composition, in which the earthy matters are so deficient that they no longer possess the rigidity and strength necessary for sustaining the weight of the body. A deficiency of the cartilaginous material would render the bone brittle, and liable to fracture upon the slightest occasion. The former condition is called mollities ossium, the latter fragilitus ossium. I have met with examples of both conditions in all three bones of the feet that I have named. In healthy bone phosphate of lime predominates; in exostoses, carbonate of lime is the predominating ingredient.

\section{GENERAL CHARACTERISTICS OF BONES.}

Bone, when recent, is covered by a very vascular membrane called the periosteum. The periosteum is a bed for the ramification of blood-vessels, nerves, absorbents, and is prolonged into the Haversian canals, and connects itself with a similar membrane within the bone named the endosteum. "Bones 
are endowed with vitality, are nourished, grow, waste, and are repaired, and undergo various mutations according to the age of the animal, and they are subject to diseases analagous to the soft parts."-Dadd.

PARTICULAR DESCRIPTION OF THE BONES OF THE FOOT.

Enumerating the bones of the foot in the order of size, the number either wholly or partially within the foot are three, namely :
I. The Os Pedis.
2. The Os Coronæ.
3. The Os Naviculare.

These three bones enter into the formation of the foot-joint.

I. The Os Pedis, Foot or Coffin-Bone.

The os pedis or coffin-bone belongs to the class of irregular bones; it possessing such a remarkable complexity of form. Viewing it in front, its superior outline presents an eminence somewhat like a pyramid in shape, and is therefore called the pyramidal process. This process receives the insertion of the tendon of the Extensor Pedis muscle by which the foot is $c x$ tended during action. Immediately beneath the articular surface that corresponds to that of the navicular bone, the tendon of the flexor pedis perforans is inserted. The office of this muscle, as its name implies, is to flex the foot.

The whole of the anterior surface is very rough, which makes the attachment of its periosteal membrane the more firmly adherent. Large grooves for the protection of the larger bloodvessels, the nerves and the absorbents, as well as holes for their passage into the interior of the bone may be seen upon its lateral surfaces. Its posterior aspect exhibits two surfaces for articulating with the coronal and navicular bones.

The prolongations of the bone backward on either side are called the alæ or wings of this bone.

The inferior, or plantar surface, is comparatively smooth and concave, and its general outline corresponds with that of the 
horny sole, having a deep indentation which affords space for the repose of the principal cushion, or the thickest portion of the plantar cushion of the foot.

In view of the functions this bone is destined to fulfill in the animal economy, it may be instructive to note some of its more salient properties.

\section{"A MOCKERY, A DELUSION, AND A SNARE."}

I. The extreme lightness of this bone in comparison to its bulk is remarkable. This is rendered necessary by its great distance from the moving power. It is said that every additional ounce added to the foot is nearly if not more than equal to a pound at the shoulder. If, therefore, we would economize the vital forces, no more weight should be placed at the end of the foot than is absolutely necessary to insure protection to the integrity of the horny tissues in horses intended for speed. Concussion, the ready apology for heavy shoes, can be better obviated by a 'stout sole' of horn than by a heavy rim of iron. If concussion were the only danger to be guarded against, this could be accomplished better without the intervention of the shoe than with it. I grant that the horse with a thin sole and weak foot generally, and low action, will go better at relatively slow paces, with a comparatively heavy shoe. It does obviate concussion to some extent, and to that extent and under those conditions it is desirable; but reverse those conditions, place heavy shoes upon a sound foot, with unimpaired action, and a well-developed horny sole and frog, and they become " a mockery, a delusion, and a snare" to both the horse and his owner.

These objections to heavy shoes do not apply to the trainers practice of using toe-weights for the purpose of regulating or correcting defective action in trotting horses. In such cases, as well as in diseased conditions, any and every measure that will accomplish the desired purpose, are, of course, proper. They are useful as temporary expedients but should not be regarded as permanent natural or necessary conditions. 
THE PEDESTAL OF THE COLUMN.

2. It is the last bone of the series, which compose the supporting structures of the limb; the pedestal of the column that carries the superstructure. It therefore spreads out in accordance with the principle of mechanics which requires a supporting base of wider proportions than the shaft it sustains, in order to give stability to the vertical position.

\section{A REMARKABLY CONSTRUCTED BONE.}

3. This bone is constructed upon the plan of a double arch. It is a well known physical law that the arched form affords the greater degree of strength with the least weight.

The arched form of the sole resembles the concaved surface of a dished wheel with its concave surface facing the ground.

The archiform parieties of the bone are the best calculated to resist forces acting against it in various directions from which dangers may come, and combines the lightness necessary for speed with the strength essential to endurance, and protection to the exceedingly delicate structures and processes within it.

ESSENTIAL IMPORTANCE OF THE FOOT.

The safety of the horse in his natural state, depending more upon his capabilities for flight than upon the resources of stratagem, this bone appears to have been designed primarily for that object. "No foot, no horse," seems to have been the motto of its Designer. Double walls enguard the brain from external accidents. Arched ribs enclose and shield the heart and lungs from many outward casualties. Scarcely less inferior in importance to the safety of the animal, is the organ of flight par excellence, and that is endowed with a doubly vaulted bone, that receives within the protecting ægis of its recesses a wonderful assemblage of arteries, capillaries, veins, nerves, and absorbents from whence they emerge in various directions to play the part assigned them in the general economy. 
THE OS CORONÆ.

This bone belongs to the class of long bones. It possesses. the peculiarities of having no medullary canal, and of being more broad than long. In a horse of medium size it is about an inch and a half in length, and two inches in width. Its general form is cuboid. It articulates superiorly with the os suffraginis or large pastern bone; inferiorly with the os pedis and navicular bone. Its anterior surface is rounded, its posterior, flattened.

It lies partly within and partly without the hoof.

The tendon of the Flexor Pedis Perforatus is inserted into its upper posterior border, and a little below its insertion is a transverse flattened eminence covered by fibro-cartilage which forms a gliding surface for the tendon of the Perforans.

In blocky, upright feet, this bone is peculiarly subject to the o z -affection known as Ring-bone. It is so short and firmly braced to its position that it rarely becomes dislocated, but is not quite so rarely the subject of fracture.

\section{OS NAVICULARE.}

synonyms-Navicular_Bone-Shuttle Bone.

This bone in its natural position, lies transversely between the wings of the coffin-bone. It averages about two inches in length; half an inch in breadth; and three eighths of an inch at its thickest part. It has three surfaces of articulation, the smallest with the coffin bone, the largest with the perforans tendon and the medial sized one with the small pastern. It is held in position by remarkably strong ligaments, and are respectively named the interosseus ligament uniting it inferiorly with the coffin bone; two anterior, and two postero-lateral, that unite it with the small pastern. Besides these, from either end of the bone proceed three ligaments. As they radiate from the end of the bone as from a central point, they are called the Stellate ligaments.

The insertions of these ligaments embrace about half a circle, the middle ligament going straight from the end of the bone 
to the highest part of the lateral cartilage, the anterior and posterior stellates going respectively to the most anterior and the most posterior edge of the same cartilages.

STELLATE LIGAMENTS AND THEIR USES.

Let us philosophize a moment upon the function of these stellate ligaments. A familiar illustration of their use, I think, may be found in the Stay-straps we see under the bodies of coaches and other vehicles, provided with springs, and intended to be driven at rapid rates, and over rough roads. Their use * is, perhaps, too obvious to need description. A sailor would call them guy-ropes. To my view, these stellate ligaments have a similar function. They materially assist in keeping the fulcrum, that is, the navicular bone, of the main cord that flexes the foot in exact apposition to the gliding surface of that cord; otherwise, rapid motion would be retarded. From whichever direction the disturbing force might proceed, there is a species of guy-rope arrangement to resist it. This is not their only function. Under extraordinary exertion the frog-structures may condense too forcibly and rebound too strongly to be altogether free from danger.

They then possess a regulative function. More, under ordinary circumstances, when there is no excessive action to control, they form powerful auxiliaries to the spring-like movements of the elastic structures. The frog-cushion is the great spring-bed of the foot. The lateral cartilages, one on each side, constitute a pair of springs, that are called into play through the medium of the stellate ligaments. These latter are strong and unyielding, while the lateral cartilages possess the properties of flexibility and rebounding in the highest degree. I think it impossible to conceive, in any organized structure, of means more perfectly adapted to ends than in the structural arrangements of the stellate ligaments. 
CARTILAGINOUS STRUCTURES OF THE FOOT.

These structures include,
I. The Lateral Cartilages.
2. The Inferior Cartilages.
3. The Articular Cartilages.

THE LATERAL CARTILAGES.

The Lateral Cartilages are the two cartilaginous bodies already referred to as receiving the attachments of the stellate ligaments of the navicular bone. They are situated upon the superior margin of the wings of the coffin bone, and their position as regards the hoof is about equally within as without that structure. Their superior portions can easily be felt and manipulated by the fingers in the living subject, and the extent to which they may have lost their flexibility pretty nearly ascertained. Externally they are convex, internally concave. Membranous expansions connect them with the extensor tendon and the coronal bone anteriorly. Posteriorly they become thinner, and are extended downwards and inwards, imparting roundness and flexibility to the heels, and afford considerable protection to those parts against casualties by their characteristic properties of firmness and resiliency.

The portion of these cartilages that lies in apposition to the lamellated structure of the wall has corresponding laminæ for connection therewith. From the inferior extremities of these cartilages, supplementary ones extend, which have been named

\section{INFERIOR CARTILAGES}

and False Cartilages. Mr. Spooner thus describes them: "They are triangular bodies, and somewhat different in structure from the lateral cartilages. They proceed from the lateral cartilages (just as the latter reach the heels of the coffin-bone) in an obliquely forward direction, on the internal and inferior parts of the wings of that bone, and thus afford a smooth surface, which is covered partly by the sensible laminæ, and partly by the sensible sole. The inferior are much more fibrous in their structure than the lateral cartilages, and the latter become 
less cartilaginous toward their upper and posterior part." If the structure of a tissue is any indication of its function, as I believe it will be found to be, then the function of the inferior cartilages is not precisely that of the lateral cartilages, for we find the former much more fibrous in character than the latter; and it is remarkable that the lateral cartilages themselves possess a fibrous border where the stellate ligaments are inserted, and posteriorly where it is connected with the inferior cartilages it assumes a more fibrous character generally. The inference is irresistable, drawn from the structure of these cartilages alone, that the lateral cartilages fulfill the office of a pair of side springs, having the property of yielding and rebounding with every motion of the foot, and aiding and regulating in some measure the vertical movements of the elastic tissues of the frog, through the medium of the stellate ligaments superiorly, while inferiorly it is kept in position, aided, and undue movements controlled by the strong and comparatively unyielding character of the inferior cartilages.

The lateral cartilages are subject to ossification, that is to say, of becoming converted partially or wholly into bone. Enlargements are not unfrequently met with, of one or both cartilages. These are not necessarily ossifications, but they are evidences of a derangement of structure and function, the causes of which will be discussed further on.

The lateral and inferior cartilages are covered by a dense tough membrane called the perichondrium, which performs a similar office for cartilaginous to that of the periosteum for osseous structures.

\section{ARTICULAR CARTILAGE.}

This is sometimes referred to as cartilage of encrustation, because this particular kind is only to be found encrusting or adhering to the articular surfaces of bones. As some theorists on the pathology of navicularthritis deem this disease to have its origin, as a rule, in the disorganization of this structure it may not be uninstructive to learn somewhat of its nature and uses. 
BUFFERS AND GLIDING SURFACES.

Bones are the solid frame-work of the whole body and possess but little elasticity.

These supporting and moving structures being also in sections and destined to move freely upon the ends of each other, would have been peculiarly liable to concussion, and their moving surfaces susceptible to attrition but for the intervention of a substance of such a nature that would fully meet both requirements. Such a substance we have in articular cartilage. It combines those properties in the most eminent degree, that break the violence of concussion, and by its extremely smooth and glass-like surface, with the aid of the synovial fluid as a lubricator enables the moving surfaces to glide on each other with the greatest facility. Its anti-concussive functions may be likened to those of the buffers upon the different sections of a railway train; while its free-gliding purposes may be fitly illustrated by those of the smooth portions of the axle trees upon which the train moves.

ARTICULAR CARTILAGE; REMARKABLE CHARACTERISTICS.

It is remarkable too, that no nerves or blood-vessels are found in articular cartilage, while they are found in all other kinds of cartilage. Why is this? Because it would be incompatible with the exercise of its functions if it possessed either sensibility or vascularity. In the former case, every jar or quick movement would be necessarily attended by pain; and in the latter the vessels would be liable to rupture and extravasation of their contents, when the weight of the animal was thrown upon these structures.

As nutrition and decay are necessary and constant processes, the nutrient blood-vessels that supply these cartilages approach them as closely as possible at their base from the interior of the bone to which they belong, not terminating in the cartilage, but abutting against their base by large numbers of small loops, the cartilage having the property of imbibing their nutrient particles from mere contact with the circular terminations of 
these vascular loops, by the process called cell-imbibition. The cells at first are round, but gradually acquire a flattened form, until, at the wearing surface they become very dense and horn-like in texture. Like as in the hoof and epidermic structtures, the outlying particles are being continually pressed upon toward the external surface, and pass off in the processes of wear or natural decay. In such a case absorbents are unnecessary and therefore none are present. The due secretion of the synovial fluid is necessary to keep the gliding surfaces of these cartilages moist, a condition necessary to the perfect fulfillment of their office in the general organization.

In chronic disease of the navicular joint, it has been ocasionally found that these cartilages have become abraded from attrition, and in some instances the cartilaginous covering of the navicular bone has been found adhering to the perforans tendon, of which that. bone is the fulcrum in its action upon the coffin-bone.

\section{A KNOTTY QUESTION.}

Scarcely any question in the whole range of veterinary pathological inquiry has excited so much animated discussion and such contrariety of opinion as that of the proximate cause or causes of the navicular-joint disease. Few, even amongst the ablest veterinary pathologists recognize more than one general proximate cause for this foot affection; and there is not a tissue entering into the composition of the joint, which has not its advocates for its claims to consideration as the chief tissue involved in this complaint. Some view it as proceeding exclusively from internal and other from external causes. The bones, the cartilages, the synovia or its secreting membrane, the perforans tendon, hereditary predisposition, mal-nutrition, atrophy, concussion, etc., all have their separate claims put forward by one writer after another for the bad pre-eminence of being the chief proximate cause of this equine curse. But I must not digress too far from the main course of my subject or anticipate my own theory too soon. To be able satisfactorily to dispose of conflicting hypotheses, it is important that 
we should thoroughly understand the nature and uses of every tissue that compose the foot. The articular cartilages are subject to abrasion from a lack of synovia; to ossification from perverted nutrition; to ulceration from its propinquity to the ulcerative process in the bone when present, and to adhesion to the perforans tendon, when the latter is the subject of inflammation which is followed by a lymphy exudation.

\section{THE LIGAMENTOUS TEXTURES OF THE FOOT.}

These textures comprise:

I. The coronary ligament.

2. The periosteum and endosteum of bones.

3. The tendons and tendinous expansions of muscles.

4. The perichondrial membranes.

5. The synovial membranes.

6. The ligaments that brace joints.

7. The areolar or connective tissues.

THE CORONARY LIGAMENT.

Sui generis amongst ligamentous textures is the coronary ligament. It is variously designated as the coronary ligament, bànd, or substance. I presume there has been some difficulty, from the peculiarity of its structure, in defining its true place in the category of foot-textures. As it is most frequently referred to as the coronary ligament, I have placed it under the head of ligamentous textures, with the above remark as to its anomalous classification.

\section{IFUNCTIONS OF THE CORONARY LIGAMENT.}

The locale of this ligament is the coronary concavity, just inside of the superior margin of the wall. It is the principal medium of connection between the skin and the hoof. It appears to be transitional in its character, partaking somewhat of the characters of both. Its surface towards the wall is papillated, and each papilla penetrates a horn tube, or fibre, of which the fibrous portion of the wall is made up. It is affirmed by one writer, Mr. Fleming, that the entire wall is secreted by 
this ligament. This, of course, would include the horny laminæ. I dissent from this opinion for the following reasons:

The wall is composed of two kinds of material, the fibrous, and a non-fibrous matrix, which bind the fibres firmly into the solid mass of horn which constitutes the wall of the foot. I am not aware of any secreting structure that secretes more than one specific secretion in a healthy acting condition. But if there should be, it would not be a sufficient reason for attributing the functions of secreting two such widely different substances as compose the walls, to the coronary secreting ligament. Each fibre of the wall is fed by its connecting papilla. Besides, we are not left in doubt as to where the matrix comes from. I think that is just as demonstrable as the source of the horny fibres. The vascular laminæ have not a merely mechanical connection with the non-vascular horny laminæ-but a secreting function, and it is from this source that the homogeneous or non-fibrous portion of the wall is derived. If an experimental proof of this is demanded, examples are numerous enough in cases of False-Quarter, and those cases where the hoof has been torn off by violence and the coronary ligament partially or wholly destroyed. In False-Quarter, for instance, the coronary ligament is injured or destroyed, and we have but a thin non-fibrous horny secretion composing the quarters, frequently too weak to sustain the weight of the animal, which could come from no other source than the vascular laminæ.

REASONS VERSUS IPSE DIXITS.

In cases where the entire hoof has been torn off while the vascular laminæ remain otherwise uninjured, a non-fibrous horny material will be deposited all over the sensitive laminæ in a few weeks. Does this come from the coronary ligament? It can not, as ten or twelve months will scarcely suffice for the growth of horn from the top to the bottom of the foot. I think these experimental facts too well known to need any further exemplification. Mr. Fleming, in his recent work on Practical Horse-shoeing, asserts that the latter view is an error, " as the microscope, physiology, and pathological experience, 
abundantly testify." This is all the refutation he has condescended to give to this alleged error. Supposing it to be an error; it can hardly be expected, that those who are accustomed to do their own thinking, to weigh the opinions of others for themselves, and to rely on their own pathological experience, when they have any, will readily abandon their opinions without a single reason being advanced or a particle of evidence adduced to show that they are erroneous, beyond the mere ipse dixit of any writer, however eminent he may be as an authority in some respects. I repeat, the principal function of the coronary ligament is to secrete the fibrous portion of the wall. It is extremely vascular and highly elastic. The former quality is necessary to supply the demands of rapid wear and tear to which the wall is subject especially in the unshod foot, and to maintain the integrity of the structure it secretes; the latter to adapt it to the expansive and contractile movements of the foot when in action, or when weight is superimposed upon, or removed from the limb. Although in appearance a thickening of the terminal portion of the skin, it has a peculiar and distinct organization to adapt it to its very important purposes. The inner layer is a strong white elastic structure which forms its principal thickness. Upon this reposes a very numerous accumulation of blood-vessels, and external to these a thin coat from which proceed the secreting .villi of the wall. The attachments of these villi in the living structure must be of a very powerful nature, as there is no other visible connection between the hoof and the skin except the areolar or connective tissue, which bind it but in no very especial manner to all the subjacent structures. The growth of the wall is in every respect similar to the growth of the human nail.

THE PERIOSTEAL AND ENDOSTEAL MEMBRANES.

These structures are the dense white-fibrous and non-elastic membranes, the former of which constitutes the external covering, and the latter the internal lining of bones. They are 
connected by prolongations of their substance through small conduits in the bone called the Haversian canals. Their function is to give support to the bone within and without, and to furnish a bed whereon the nerves, blood-vessels, and absorbents can ramify. Bones are most amply supplied with nutrient materials by these means, and their disintegrated particles probably carried away by the absorbents. I say, probably, because some physiologists consider it doubtful, at least, whether absorbent vessels exist in bone. The coronal and navicular bones present nothing exceptional as regards their periosteal coverings, but there is a very remarkable peculiarity concerning the periosteum of the coffin-bone which I think throws much light upon the constitution and functions of the sensitive laminæ, a just appreciation of which has a most important bearing upon the question of shoeing, either in health or disease. Microscopic "anatomy, physiology, and pathological experience," perfectly harmonize in the views I have taken upon this master question of the foot, and the practical measures I have based upon them.

THE SENSITIVE LAMINÆ.

Mr. Spooner says: "The sensitive laminæ are somewhat similar in appearance, but very different in structure to the horny laminæ, with which they are connected by a dove-tailed union, each horny plate being received between two sensible plates, and vice versa. They are firmly attached by means of elastic (?) membranous structure to the irregular surface of the os pedis; and are also continued on the lower position of the side cartilages, where they correspond to the horny laminæ, on the inside of the bars of the foot. The sensitive laminæ, as their name imports, are extremely sensitive and vascular, and as $\mathrm{Mr}$. Percival says, are composed of a double transparent membrane, plaited as it were around the bone, so that one of the sides of each laminæ is in close contact with another, and the other side opposed to a horny lamina. The sensible laminæ used to be considered as highly elastic, and writer after writer having 
copied from each other, without examining for themselves, the error was perpetuated until Mr. Percival demonstrated that the elasticity was not inherent in the laminæ but in the substance connecting them with the coffin-bone which possesses highly elastic properties, and affords a convenient bed for the numerous blood-vessels which secrete the laminæ."

\section{AN UNDETERMINED QUESTION.}

In this connection the late Prof. Spooner, in the course of his lectures, stated substantially as follows: "The precise nature of the union between the vascular and horny laminæ is not yet established. I believe it will be found upon more extended microscopic investigation to be similar to, if not identical with that of the chorion of the fotus, and the tunica decidua uteri of the uterus. The same kind of union also exists between the dermis and epidermis. Whatever doubts may exist as to the histological character of this union, what is certainly known is that the union is a vascular and vital, not a mechanical one, and that it is one of extreme delicacy, and ill-calculated to bear the tremendous burden the weight of the animal would impose upon it."

THE INTERPERIOSTEAL PAD.

It will not be difficult to perceive where this apparent power of elongation comes from, when the peculiar structure of the periosteum of the coffin-bone is fully comprehended. As shown by Percival it is a double membrane, the union of which is attached to the irregular surface of the coffin bone, and the outer presents a plaited or frilled surface. Between this inner and outer membrane, a layer of elastic material is interposed, which, like most other structures of the foot, answers a twofold purpose. It furnishes a nidus or bed for the safe repose of the vessels and nerves that ramify upon the laminæ, and particularly those which are engaged in the work of secreting the horny laminæ. The frilled or laminated arrangement affords abundance of space for these vessels and nerves as they 
proceed to the various points of contact and union with the horny laminæ, and will yet admit of a certain amount of separation of the outer from the inner portion of the membrane, allowing certain movements of the foot to be effected without any undue strain of the filamentous and vascular connections of the laminæ. This elastic material' I shall have frequent occasion to allude to again as the interperiosteal tissue, or pad.

RELATIVE WEIGHTS SUSTAINED BY FORE AND HIND LIMBS.

In further elucidation of the functions of the laminæ, quoting Spooner :

"Let us consider the vast weight supported by each leg, and the manner in which it is distributed. The weight of a moderate sized horse is about twelve hundred weight; this, when the animal is standing is supported by the fore and hind legs in the proportion of two-thirds by the former and onethird by the latter. When the horse is in motion, say trotting, this weight is supported alternately by one hind, and one fore leg, so that each fore leg supports two-thirds of the animal's gravity; to this we must add the weight of the rider, and the increased burden occasioned by the momentum of the horse's action. We shall, therefore, be within bounds when we say that each fore leg alternately bears a weight equal to the animal's entire gravity, all which is borne by the small pastern bone, and is thus distributed to the parts below. A moderate portion is first communicated to the elastic cushion, from whence it is impressed on the lateral and inferior cartilages and posterior part of the frog. The remainder, being the principal portion, is transferred to the navicular and coffinbones, the former of which, by the interposition of the flexor tendon, bears partly on the frog and partly on the sole; and the latter by the intervention of the laminæ, distributes its weight to the wall throughout its whole circumference, and a very slight portion of it is borne by the sole, which may or may not bear upon the ground. Thus at the same moment 
these various actions go on in the foot. The coffin bone descends lower into the hoof, the laminæ, by their elastic connections, permitting it ; the sensible sole is compressed, and perhaps the horny laminæ opposite the coffin bone slightly descends. Well, the horny sole and the anterior part of the frog opposite the navicular bone descend and expand the quarters parallel to them, whilst at the same time, the elastic or sensible frog, being compressed, is forced down upon the horny frog, and contributes to the expansion of the heels; but if the horny frog meets the ground, the cushion, being pressed upon both above and below, enlarges laterally, and expands the upper part of the foot and lateral cartilages."

This quotation is introduced for the purpose of showing the loose views entertained by one of the most influential authorities upon the "Foot of the Horse," regarding the most important function possibly pertaining to that organ, namely, the sustaining or supporting ordination of the sole. He says the sole "may or may not" have a bearing upon the ground. I affirm that it must have a bearing either upon the ground or its equivalent, the shoe, in order to exercise and maintain its functions in a state of efficiency.

\section{FACILIS DECENSUS AVERNUS.}

Descent of the horny sole being regarded as a function, this error renders the acquisition of erroneous views necessary to support it, an easy matter; just as a recognition of its falsity, and the necessity of a supporting function to the sole will have an important influence in producing correct views of other functions. It does not, however, always do this, as I shall show by an illustrious example, namely, Professor Gamgee, senior, who, though strenuously advocating a sustaining function to the sole, denies the contractility and expansibility of the foot functionally or otherwise! Per contra, Mr. Spooner recognizes this latter function, but is loose-jointed upon the sustaining functions of the sole. How passing strange, that men of such mark, and of such "large discourse" upon that ever-fertile topic, the 
foot of the horse, should differ so diametrically upon matters that appear to be of the most simple and demonstrable character, as I think will be seen when we discuss the other functions of the foot.

\section{THE SENSITIVE SOLE.}

Besides the laminal tissues, the periosteum of the coffin bone furnishes a double membrane from its plantar surface to fulfill similar functions for the horny and sensitive soles. Here, also, proceeding from within outwards, we have the basal membrane adherent to the bone, and a secreting membrane sending its papillæ into the internal surface of the horny sole, besides a layer of elastic interperiosteal tissue coming between the two layers of membrane last described - that is to say, it furnishes a bed whereon the nerves, blood-vessels, and absorbents may repose with safety, and yet suffer the necessary elongation and shortening incidental to the movements of the foot without injury; and, being of the elastic variety of fibrous tissues, forms the appropriate elastic medium, when its functions are unimpeded, by which the natural springing and rebounding functions claimed for the plantar cushion, for such it is, are effected.

\section{AN ERRONEOUS CONCEPTION EXPOSED.}

If the above description of the sensitive sole be correct, as I deem it demonstrable that it is, by actual experiment, then the common notion that the horny sole should be cut until it springs or yields under the pressure of the thumb must be founded upon an erroneous conception of the function of the sole, no matter by whomsoever the doctrine may be taught, since this practice neutralizes, to the extent to which it may be followed, the action of the really elastic tissue within the foot, and calls upon tissues that are not elastic to fulfill functions for which they were neither designed nor adapted ; and, moreover, endangers the vascular and filamentous connections of the sensitive and the horny laminæ, as well as those of the sensitive and the horny sole, by causing a greater tension upon those connections than they are able, or were intended to bear. 
MR. FLEMING, RISE AND EXPLAIN.

THE "SOLAR ZONE."

There is a white line that marks the line of junction of the sole and wall. It is undoubtedly the cementing medium of the two portions of the hoof. In some prior observations on the laminæ made by Mr. Fleming, it will be remembered that he stated that the "microscope, physiology, and pathological experience abundantly testify that the horny leaves are not formed at all by the sensitive ones, and that the coronary ligament secreted he entire wall." How, then, does it happen that the source of this "softer and more elastic white zone" is ascribed to "the secreting villi of the lower end of the sensitive laminæ?" If the sensitive laminæ have secreting functions at one part, why not at another? And if not, why not? If they have not, what need is there of any vascular attachment between the two descriptions of laminæ, when a merely mechanical one would do as well? If a portion of the horny wall is not secreted from its sensitive counterpart, perhaps the horny sole and frog are not secreted by their sensitive counterparts; for the inference in one case is just as reasonable as in all three; and if they are not, from whence are they derived? Presuming upon the possibility that Mr. Fleming may alight, in the course of his promiscuous reading, upon these questions, I shall be expecting an answer to them in some future edition of his work on "Practical Horse-Shoeing" or in some other way.

\section{THE SENSITIVE FROG.}

This structure presents a double membranous arrangement, similar in this respect to the secreting organs of the sole and wall. Extensions of a dense white fibrous membrane, almost, if not quite, identical with the periosteal tissues before described, completely invest this substance. Its secreting papillæ penetrate the horny frog, just as those of the sensitive sole are imbedded into the pores of the corneous sole; but they are said 
to be of a finer and more delicate structure than those of the sensitive sole. They also take the same oblique direction downwards and forwards as those of the sensitive sole. Viewing the internal aspect of the hoof, a long, deep, triangular fissure will be seen, with a small eminence springing from its medial line, near the basal end of the triangle. In and over this fissure, and adjacent thereto, the sensitive frog reposes. This sensitive frog may also be regarded as an interperiosteal pad or cushion, only, compared to the others, it is of greatly magnified dimensions. It fills up the whole of the posterior space of the foot not occupied by other substantial tissues. This, the principal spring-cushion of the foot, as to size, is composed of two kinds of ligamentous tissue - the white fibrous and the yellow elastic. The mass of the frog-cushion is composed of the same material as constitutes the sub-cutaneous tissues, usually designated connective or areolar tissues. Towards the posterior portion of the foot these tissues are transformed into a vast fibro-cartilaginous cushion, otherwise known as the sensitive frog. Its eminently elastic properties are due to its yellow elastic constituent, which predominates most in the upper portion of the pad that lies in close contiguity to the perforans tendon and the inferior portion of the coronal bone.

\section{CHARACTERISTIC STRUCTURE OF THE FROG.}

Another remarkable feature of the constitution of the frogcushion, which only the microscope could reveal, is the manner in which these fibrous materials of the sensitive frog are disposed. There is no apparent order in their disposition, but they are interwoven with each other in every conceivable direction, thus forming a dense areolated mass of tissue. These areolæ are exceedingly minute, and it is within these that the yellow elastic fibres called "nuclear" are discovered to exist. It is this variety of fibre that gives elastic properties to an otherwise inelastic substance. The chief characteristic, therefore, of the frog-cushion is firmness, combined with lightness and elasticity, it being endowed with the latter property in every conceivable direction. 
STRUCTURE INDICATES FUNCTION.

These minute particulars as to the structure of the frogcushion - and they could have been made more minute still I deem of importance, as they point unmistakably to its functions. "Men do not gather grapes from thorns, nor figs from thistles;" but they sometimes commit the equally egregious blunder of attributing functions to organs and textures which are altogether foreign to their destined purposes, through imperfect acquaintance with their intimate composition and organization. These considerations, together with the desire I entertain that the sub-structure of my theory and practice in regard to diseases of the feet shall be laid sufficiently broad and deep in the facts of anatomy and physiology must be my apology, if any were needed, for dwelling so long upon the composition and organization of tissues.

\section{FUNCTIONS OF THE FROG.}

The highly important functions of the frog have yet to be considered. The horny frog is evidentiy designed to receive pressure externally, as without this there would be no basis afforded for the resilient movements of the internal springcushion - that is to say, the sensitive frog. The most familiar illustration of this view is the following: Take the springcushion of a carriage, or the spring-mattress of a bed. It will be seen that the spiral spring is fastened by one end to a solid base or frame-work. The full action of the spring is thus obtained; but if the solid base is removed, and a yielding base substituted, the action of the spring is neutralized in proportion to the yielding character of the base; in other words, much of its resilient action is lost, and the body, sitting or recumbent upon either, would sink to a lower level and find less springiness on the seat or the bed.

\section{IMPORTANCE OF A HEALTHY FROG.}

Thus, the sensitive frog is the spring-cushion, and the horny frog its base of action, when these tissues and functions are uninterfered with. 
The horny frog interposes a firm resisting medium between the sensitive frog and the ground. The sensitive frog compresses more readily under the double effect of superior and inferior pressure. It thus lets the weight of the animal down easy upon the other portions of the foot, and the instant the weight is removed in the lifting movement, regains its original dimensions. It is to this expansive or rebounding movement that I attribute the regular, light, easy, corky, springing movements in action that is peculiar to the horse.

\section{MAXIMUM AND MINIMUM OF LATERAL MOVEMENTS.}

The sensitive frog and the fissure in which it reposes are also evidently constructed so as to admit of some degree of lateral movement. The peculiar construction, too, of the sensitive frog adapts it, I think, to receive or to resist pressure in every direction, its areolæ admitting of the maximum amount of rapid condensation with the minimum of the lateral increase of bulk.

\section{SUMMARY OF VIEWS.}

Summarizing the foregoing views - the superimposed weight of the animal superiorly, the solid bases afforded by the horny frog inferiorly, the quarters of the horny wall laterally - these are the solid resistants that call the compressive and the expansive forces of the frog-cushion into play. More elasticity than that which is inherent in these resisting structures, or any interference with the due fulfillment of the functions of any one or more of them, such as contracted quarters and a diseased horny frog, would injure the structure and suspend the functions of the primary organ of resiliency, the sensitive frog, and proportionately will be the impairment of the leg or knee action of the animal subject to such an abnormal condition of things.

The question of the Expansibility of the Foot is too important to be dismissed with a cursory allusion. It will arise for consideration in due course, and will then receive the attention it merits. 


\section{TENDONS AND TENDINOUS TEXTURES.}

Several varieties of these textures are to be found entering into that complex organism, the foot of the horse.

I. The tendons directly connecting the bones with the muscles that act upon them.

2. The tendinous expansions that envelope joints.

3. The tendinous structures that connect bones that are in close apposition to each other in joint formations.

4. The external lateral ligaments of joints.

5. The stellate ligaments of the navicular bone.

GENERAL CHARACTER OF TENDINOUS TEXTURES.

All the above structures have the same general composition, differing only in the arrangement of their fibres. The dense, tough, white, tendinous expansions that embrace the joints, and the inelastic silvery ligaments and tendons that form extensions of muscles, are alike of the white fibrous variety of tissues, and are composed of white filaments, similar in every respect to the fibrous areolar tissues. They only differ in the arrangement of their fibres. They are all, however, arranged in a parallel manner, and, being inelastic, give a firm union to those structures with which they are continuous at their ends. Yet, though they are described as inelastic, they are not absolutely so, as is shown by the fact that a small number of yellow elastic fibres is interspersed among the bundles of white fibres. This undoubtedly imparts some security against the chances of 
a rupture, by admitting of a slight degree of elongation under extremely trying circumstances. Histologists give the name of 'nuclear' to these yellow elastic fibres. The tendons and faschiæ, or tendinous bands, are bundles of filaments of white fibres. The aponeurotic expansions are also filamentous bundles of the same material, strips of which interlace each other, and a quantity of reticular connective tissue giving them a bond of union. It is the toughness and inextensibility of white fibrous tissue that render it so serviceable in attaching muscle to bone, and in connecting bones where they articulate with each other. This tissue is but slightly vascular, and contains fewer blood-vessels in the adult than in the young animal.

\section{AN IMPORTANT ANATOMICAL FACT.}

It is not unimportant to remember that in certain exigencies the division of tendons, faschiæ, and ligaments is unattended with pain, so that these structures are devoid of sensibility. There is no tissue more easily reproduced; and the only con-. dition for effectual reunion is, that the divided ends be brought as close together as possible, in order to prevent any increase in the length of the bond of union. Perfect rest of parts is the best means to insure the healing of a cut or torn ligament or tendon. No other means can be adopted to increase the strength of the white fibrous tissue. This is mentioned, because veterinary surgeons still resort to blistering and firing, in the belief that they insure animals from not lacerating ligaments or tendons a second time.

THE FLEXOR TENDONS OF THE FOOT.

The most important tendons of the foot are those which have their insertion in the coffin or pedal bone; the tendon of the Flexor Pedis Perforans, and that of the Extensor Pedis, and that which is inserted into the coronal bone, the tendon of the Flexor Pedis Perforatus. The latter and the former will be alluded to, for the sake of brevity, as the Flexors, and the other as the Extensor. If we take the Extensor Suffraginis into account, 
we shall then have two Flexors and two Extensors. The largest and most powerful of these tendons is that of the Perforans muscle; the next, that of the perforatus. The two last maintain a very intimate companionship from their origin to their insertion. They are the two largest of the fore limb. The late Professor Dick's favorite theory concerning the navicular disease was, that "injury to this tendon in the synovial capsule of the navicular joint was most generally the primary and proximate cause." The perforans tendon passes under the navicular bone, and is inserted into the posterior pit of the pedal bone. The navicular bone affords a fulcrum, by which means the flexion of the foot is accomplished more easily than could be done without any such fulcrum.

\section{REMARKABLE MECHANICAL ARRANGEMENTS.}

The merely mechanical arrangement governing the action of the flexor tendons or sinewes is of a very remarkable character; but I do not propose to enter into its consideration beyond its immediate influence upon the motions of the foot. Both of these tendons have the same origin, and, though their connection from their origin to their insertion is so intimate, they preserve their individuality throughout their whole course to the foot. Both of them have their accessories above and below the the knee. The perforans is aided by the Ulnaris Accessorius and the Radialis Accessorius above the knee, and a tendon called the tendo-subcarpal below the knee. The perforatus derives assistance from a ligament above the knee, called the Superior Suspensory. At the back of the knee the perforans clasps the perforatus in such a manner as to form a sheath, through which the latter may glide; and at the back of the fetlock joint the latter performs a similar office for the former. Reaching the coronal bone, the perforatus divides itself into two points of insertion, one going to the inner and the other to the outer posterior edge of that bone. The perforans here becomes flat and thin, and adapts itself in width to the length of the navicular bone, against which it presents a hard gliding 
surface. Its rounded terminal insertion measures about four inches, and it spreads out somewhat like a fan, and finds an attachment to the roughened inferior semicircular border of the coffin bone. Such are some of the more salient features of these important tendons, a consideration of which, in all its bearings, would form a subject of considerable interest and prolonged study.

\section{THREE-FOLD FUNCTIONS OF THE FLEXORS.}

Their united function is obviously of a three-fold character. They lift and flex the foot in upward action. In the downward motion their great strength is utilized to diminish the force of the descending weight of the animal, with the acquired momentum in addition, which must be very considerably increased during rapid action. The perforatus and perforans are liable to sprains, to laceration, to rupture, to ulceration, and the latter to adhesion to the navicular bone.

\section{THE EXTENSOR TENDONS OF THE FOOT.}

The extensor tendons are very light and slender in comparison with the flexors. They blend intimately with the faschiæ that enwraps the upper and lower pastern joints. The thickest portion of the extensor pedis is inserted into the coronal eminence of the os pedis. The less thick portion is interwoven with the faschiæ that finds an attachment along the entire superior margin of that bone. The combined general function of the extensors is the extension of the foot and leg.

\section{LOW INSTEP A FREQUENT SOURCE OF LAMENESS.}

A by no means unfrequent source of lameness I have observed to be, pressure upon this tendon, arising from a low instep, which I have found to disappear after lowering and shortening the toe, or raising the heels, or both, as circumstances may render necessary. It comes from lowering the heels unduly, or from allowing the shoes to remain on the feet too long, the toe thereby becoming elevated from inor- 
dinate growth. Injuries to these tendons are less frequent than to the flexors, A very disastrous lesion of the tendon of the cextensor pedis is one upon the part just where it is inserted into the coffin bone, from a severe tread or calk. It is more serious here than a similar injury elsewhere, for the reason, I presume, that the principal point of connection is either weakened, or entirely severed in a case of a severe character.

\section{ACCESSORIES OF THE EXTENSORS.}

The Extensors are not without their adjuncts or accessories. The Extensor Suffraginis is assisted by the Ligamentum Extensorium that springs from the outer part of the capsular ligament of the knee, and the outer metacarpal bone, taking a winding course downwards and forwards towards the fetlock, where it blends with its principal. The Extensor Pedis has a much more complex accessory to aid it, withal, a very important one to understand the arrangement of. It has its superior attachment to the head of the large metacarpal bone on its posterior aspecti, mmediately below its articulating border. It lies between the small metacarpals in close apposition to the large metacarpal, and for two-thirds the length of that bone it is a very powerful undivided ligament. At the commencement of the lower third it divides into two parts, each part attaching itself, one to the inner, and the other to the outer Sesamoid bone. They traverse these bones and leave them somewhat diminished in calibre, and each winds itself around the pastern obliquely to the front where it blends with the extensor pedis. The undivided portion of this curious ligament is said to contain elastic fibres, which therefore would render it extensible in a slight degree when its strength would be severely taxed.

It will be seen that the accessories of the flexors act in a direct line with their principals; while that of the extensor suffraginis proceeds from the side obliquely to the front; and that of the extensor pedis proceeds from behind and winds around to the front to render their assistance. 
THE TRUE SUSPENSION OF THE LEG.

The ligament last described was within the last decade very generally regarded as the principal suspensory ligament of the leg. It is not so regarded now at head quarters or by those who know that a division of this ligament does not result in letting down the limb, while a division of the tendon of the perforans does. The latter, therefore, must be regarded as the true suspensory, and the former has changed its name from suspensory to superior sesamoideal ligament, being named relatively to its connections rather than to its supposed functions. I believe, however, that it has a double function, that besides the inferior suspensory power it possesses when the foot is on the ground, that it operates against an undue extension of the limb, especially in rapid action, and that it is admirably adapted for this purpose by its great strength and slightly yielding properties.

\section{ANTAGONIZING FORCES.}

It seems to me that were there not some antagonizing or controlling force of this kind, in rapid action, the legs would get too much extended, and the body get down too low for the animal to exert his powers to the best advantage. By none of the "locomotive physiologists" have I found this function referred to in the production and contrast of knee action. If this view be correct, this ligament assists the flexors as well as the extensors, by receiving a share of the descending weight during action. Its attachments and properties are eminently adapted for this purpose. I believe, moreover, it is the first to act in the lifting and flexing movement of the leg, and the first to act in limiting or checking the movement of extension and confining that extension within the limits of safety. This question, however, belongs to the region of "locomotive physiology," which I am content to leave to the great mollahs of the veterinary profession and their curious dissertations upon the production of knee action. 
Transcending all other influences upon the action the knee is that of a sound and healthy foot. This is the great producer and modifier of knee action. "Ask the owners and trainers of "Dexter," "Goldsmith Maid," and "American Girl," the secret of their wonderful performances, and if they tell you truly, they will point to a piece of simple mechanism called a foot-dilator, and tell you the whole secret is in the judicious use of that instrument. "A word to the wise is sufficient."

\section{THE TENDINOUS EXPANSIONS}

Are all of the white-fibrous variety of tissues, are very tough and inextensible, and constitute those powerful investing membranes of joints that enclose the articulation as within a capsule, hence the name they commonly receive of capsular ligaments of the large and small pastern and the coffin-joints, the latter being so close to each other are continuous, and powerfully contributes towards the immunity these joints usually enjoy from dislocations, as luxations of these joints are very rare compared to those of other joints.

\section{THE LESSER LIGAMENTS OF THE ARTICULATIONS}

Pertaining to the lower pastern and coffin-joints are all of the same dense tough character as the last described. One class unites the ends of bones where they articulate with each other; and another may be said to brace or tie the joint upon its lateral aspects, so as not to interfere with the hinge-like motion of the joint. The former are therefore called interosseous, and the latter, lateral ligaments.

The small pastern has one interosseus, and two long and two short lateral ligaments.

The coffin-joint has two interosseous, two antero-lateral, and two postero-lateral ligaments. The antero-lateral are continuous with the lateral cartilages.

The stellate ligaments of the navicular bone are of this class. Their functions have been already referred to. 
A COMMON ERROR CORRECTED.

Of three kinds of synovial membranes that exist, the articulatory, the vaginal and the vesicular; the two former are found, one in the foot and the other in very close proximity to it. The articulatory lie in loose folds around the articulatory surfaces, and do not as is generally supposed cover the articulating surfaces. They form circumscribed sacs it is true. Their edges are inserted along the margin of the articulating surfaces, and their office is to secrete the synovial fluid which insinuates itself between the bearing surfaces of the joint. In the coffinjoint one of these membranes encloses the articulating surfaces of three bones, those of the pedal and coronal bones; and the upper and anterior surfaces of the navicular bone; while the inferior surface of the latter bone forms a distinct articulation with the portion of the perforans that glides upon or against it. This latter articulation has a synovial membrane independently of the one above it, and is the one nearest to the internal apex of the frog, which I have strong reasons for thinking presses upward but too frequently, and aggravates the contracted condition of the foot. The example of a vaginal membrane found near the foot, is that which lines the enclosed sac or sheath which is formed by the perforatus for the passage of the perforans, just before it reaches the navicular bone.

\section{DISEASES OF SYNOVIAL MEMBRANES AND THEIR SEQUELAE.}

Synovial membranes are said to be non-vascular and insensitive, except when diseased, when they become the seat of intense pain. They are liable to acute and chronic inflammation, from concussion, blows, and strains, and mechanical injuries, such as the puncture of a nail, broken glass, etc. They may also be affected by rheumatism. Inflammatory adhesions of their surfaces are found in the advanced stages of navicular 
disease, and of conversion of the membrane into cartilage. The lack of a due secretion of synovia leads to consequences of a most serious nature to joints. Abrasion and absorption of - the articular cartilages is the first result, leading in many cases to a species of $d r y$-rot in the bones. A deep furrow may be plowed into the articular cartilage, as is often met with in the astragalo-tibial articulation of the hock-joint, where there is lameness without any palpable or ocular evidence of spavin, incipient, or otherwise. The phrase occult spavin is often made to do duty for occult lameness, arising from the cause alluded to. This lesion will receive fuller consideration under the head of Springhalt. 


\title{
THE CIRCULATORY SYSTEM OF THE FEET.
}

\author{
I. The Plantar Arteries. \\ 2. The Plantar Capillaries. \\ 3. The Plantar Veins.
}

\section{THE PLANTAR ARTERIES.}

\section{GENERAL REMARKS UPON ARTERIES.}

Before describing the course of the arteries of the foot, it may possibly be not altogether uninstructive to non-professional readers to learn something of the nature of that wonderful system forming a part of the general animal economy, through the agency of which every change in the tissues are effected, either for good or ill.

By means of the circulatory system, the waste materials, the worn-out particles of matter are conveyed to their appropriate organs of elimination from the system; and the new, vitalized, and vitalizing, molecules of matter deposited in their place. The value of an adequate appreciation of the facts of physiology having especial relation to the foot and the circulating system, is but little suspected. Believing this, I deem some few facts of this nature of sufficient imiportance to justify the introduction of the following brief notes upon the nature of the arteries as well as of the capillaries and veins which will follow, albeit they may be deemed somewhat advanced for many of my readers. 
CHARACTERISTICS OF ARTERIES.

Branches of arteries leave the main trunk, at obtuse, acute, and right angles.

The united capacity of all the small branches is much greater than the parent trunk.

Arteries do not taper, but diminish in size, by giving off other trunks and branches.

The blood in arteries goes slower the further it is from the heart.

Arteries are placed in the aspect of flexion in limbs, rather than of extension.

As compared with veins, they are deep-seated on the inner surface of the feet and legs.

The coats of the arteries are thick, except in the brain, spinal cord, and the interior of bones.

They are enclosed in a loose cellular sheath to allow of vermicular motion and dilatation.

They terminate in capillaries.

\section{THE MICROSCOPIC ANATOMY OF AN ARTERY}

Reveals the existence of three coats.

I. An external coat made up of areolar tissue, and yellowelastic fibres; the fibres being disposed longitudinally.

2. A middle coat, consisting of muscular and elastic fibres, both arranged in a circular form, so as to form a tube.

3. An internal coat composed of a basement membrane of elastic material, and an epithelial membrane lining the basement membrane.

The coats are all united together by areolar tissue.

Arteries have no valves, excepting one at the entrance to the aorta and pulmonary artery.

An artery is distinguished by its cylindrical form; and bleeding from an artery is known by its pulsatory character.

An artery may be recognized by its dirty yellowish-white color. 
An artery retains its circular form when empty, while a vein collapses.

Arteries frequently anastomose with each other to form complete circles, especially in the brain and feet.

A ligature tied round an artery, divides the middle muscular coat first on account of the circular arrangement of its fibres.

The muscular portion of the middle coat is of the involuntary class of muscles, and acts by means of nervous force, or stimulus, or by electricity. The internal serous coat is very brittle. It possesses neither blood-vessels nor nerves.

Arteries are very extensile, that is, they are susceptible of yielding and elongation, and of returning to their original dimensions.

THE PLANTAR ARTERIES.

The following account of the Plantar Arteries is derived from Spooner, on "The Foot of the Horse."

"The Plantar Arteries at their origin above the fetlock form an acute angle from the apex of which gradually receding, they pass over the joint by the side of the sesamoid bones, and somewhat in advance of the tendons, conforming in their progress to the prominence of the fetlock and the depressions of the pasterns. Below the joint, the artery, still pursuing a straight course, is, from the smaller circumference of the pasterns, compared with the fetlock, again brought very near, and somewhat in advance of the perforatus tendon, and so continues till the termination of the tendon, when the artery itself is hidden from view by the lateral cartilage. It here inclines somewhat forwards, being surrounded by the substance of the cushion, and just within the upper part of the wings of the coffin-bone it enters a groove which conveys it downwards and forwards to the foramen on the posterior concavity of the bone, just under the coffin joint. The artery within the substance of the bone takes a circular direction, and joins its fellow on the other side, from which circumstance it is designated by Professor Coleman the circulus arteriosus. In the course we have 
described, being common to both, the plantar arteries send out many branches to the neighboring parts.

"The first of importance after a few small vessels about the fetlock is called by Mr. Percival, the perpendicular artery, and rises about half way down the os suffraginis, and takes its course forwards and downwards to the coronary substance where it anastomoses with its fellow and forms an arch called the superficial coronary from whence proceed about eighteen small descending arteries whose office it is to secrete the crust.

"The second branch of importance is the transverse artery, which crosses over to the front of the os coronæ, underneath the extensor tendon, and joins the corresponding branch from the other side, forming the Superior Coronory circle, which gives off numerous small vessels, some of which, passing downwards communicate with the inferior coronary artery before described.

"Thirdly, the plantar arteries, having given off these vessels anteriorly distribute others posteriorly, the first of which is the artery of the frog, which rises opposite the pastern joint, and enters obliquely the substance of the sensitive frog, where it divides into two branches, one going to the toe, and the other to the heels of the frog, the latter of which sends branches to the cartilages.

"Fourthly, just as the main trunk reaches the coffin-bone, a Iarge branch, the lateral laminal, is given off, which enters the foramen in the wings of the bone, and then winds around it in a groove to the front of the foot sending branches in every direction to the sensible laminæ, and then enters by a smaller foramen in the antero-lateral part of the bone and joins the circulus arteriosus within it. From this artery a branch is given off which joins the circumflex.

"The Circulus Arteriosus presents a corresponding course within the bone, to that described by its external border, and gives rise to two sets of vessels :

"First.-The Anterior Liminal Arteries, very small and numerous branches which proceed through the foramina of the coffin-bone and are distributed on the laminæ. 
"Secondly.-The Inferior Communicating Arteries, thirteen or fourteen in number, proceed through the foramina in front of the coffin-bone and supply the Circumflex Artery which encircles the toe of the os pedis and from which blood is usually abstracted when a horse is bled in the foot.

"From the Circumflex, proceed the Solar Arteries, thirteen or fourteen in number, which, taking a radiated course towards the centre of the foot, furnish the sensible sole with its requisite nourishment, and form the net-work of vessels from which the horny sole is secreted."

\section{THE PLANTAR CAPILLARIES.}

An extremeiy interesting study is the capillary system, or circulation. It is important to be acquainted with some of its salient features; as much so, indeed, as with the arterial and venous systems of circulation. The great object of the capillary circulation is to minister to the functions of secretion and nutrition, as these operations can only be carried on while the blood is in circulation. The term capillary is used to denote all the minute vessels which pass between and connect the arteries and veins.

It has been estimated that the aggregate area of the capillaries is eight hundred times larger than that of the arteries which supply them.

They are generally uniform in size, varying but a little in different places. They are smallest in the brain, the lungs and spinal cord, and largest in medullary matter, fat, etc. The smallest are about ${ }_{3,500}^{1}$ th and the largest about ${ }_{1,200}^{1}$ th of an inch in diameter. They have but one coat, which is of a homogeneous character. They are nourished by imbibition.

Their course is the same as the fibres of the tissues through which they ramify.

-They commence in arteries and terminate in veins. They anastomose very frequently with each other, and form a network of wonderful minuteness. 
The function of the capillaries is to distribute the nutritive elements to the most minute portions of the tissues.

The arteries themselves are not supplied with nutriment from the biood that passes through them, but by vessels from the collateral branches termed the vasa vasorum. These minute systems within systems remind one of the Hudibrastic conceit:

$$
\begin{aligned}
& \text { "Great fleas have little fleas } \\
& \text { Upon their backs, to bite 'em, } \\
& \text { And little fleas have lesser fleas; } \\
& \text { And so, ad infinitum." }
\end{aligned}
$$

A certain regulative or distributive power exists in the walls of the capillaries, on the tissues which they traverse.

\section{PHYSIOLOGICAL FACTS.}

Though the red cells of the blood pass through them, as a rule, in single file, sometimes the capillaries enlarge to admit several files to pass at once. The velocity of the current is liable to great and sudden variations from local influences, and when the action of the heart is enfeebled, stagnation sometimes takes place, which is often overcome by the vigorous action of the heart.

Impairment of the functions of the blood, by which it is not duly aerated, retards the flow of the blood through the capillaries, the tissues being deprived of the proper amount of their appropriate stimulus. This has been verified by experiment in the lungs. The change in the condition of the blood in regard to the relative proportions of its oxygen and carbonic acid is the only one to which the pulmonary circulation is subservient.

Any circumstance which increases the functional energy of a part, or stimulates it to increased nutrition, will occasion an increase in the supply of blood, irrespective of any change in the heart's action. An undue acceleration of the local circulation constitutes the state known as active congestion, hyperæmia, or determination of blood. 
When inflammation is produced, there is a stagnation of blood and a depression or change of its functions. When blood determines to the head from mental exertion, and the extremities. become cold and livid, the circulation should be equalized by friction and exercise.

In congestion of any organ there is deficient functional energy and retarded circulation. This condition predisposes to inflammation. It is always relieved by promoting the action of the part affected.

\section{THE PLANTAR VEINS.}

\section{GENERAL REMARKS UPON THE VEINS.}

Veins are superficial or deep-seated.

Their inner coat is much more tough than the corresponding coat of arteries. Veins anastomose more frequently with each other than arteries.

Veins accompany arteries in their course, the rule being that large arteries have one vein accompanying them, the middlesized ones, two, and the smaller ones, seldom any.

Like the arteries, the veins have three coats in their structural formation:

I. An external one-fibro-cellular, delicate and loose outwardly, but having a firm attachment to the middle coat.

2. A middle one, a combination of circular muscular and of longitudinally elastic fibres, but of a much thinner substance, possessing, however, less contractile force and greater strength than the corresponding coat of the arteries.

3. An internal serous membrane, consisting of a basement and an epithelial covering.

Veins are more numerous than the arteries, and are more superficially placed.

No veins have been found in the interior of bones. As a rule, veins have valves in their interior. Valves are rendered necessary by the propelling force of the arteries having become lost before the veins are reached. 
When the blood passes from the capillaries into the veins, it runs very slowly, but increases in speed as it reaches the heart. The flow of blood in the veins is assisted by valves where it has to asscend against the force of gravity. The valves are numerous. They open toward the heart. They may be single, double, or treble, according to locality.

There are some important exceptions to this rule. Besides other organs, the veins of the brain and the feet have no valves. They are numerous in the legs above, but there are none below the fetlocks.

The passage of the blood through the veins is facilitated by muscular and other pressure and the aid of the valves, which are the most numerous, where they have the force of gravity to overcome; and yet

THE VEINS OF THE FOOT HAVE NO VALVES.

There must be an important reason for this exception. The following, perhaps, may be advanced as a possible explanation of this remarkable fact: In no other part of the system is there so much liability to disturbing influences upon the circulatory apparatus as under the comparatively hard and unyielding horny encasement of the sensitive part of the foot we denominate the hoof. Excessive dryness or moisture will affect the foot injuriously, the necessary consequences of which would be an abnormal diminution or enlargement of the calibre of the circulatory vessels.

The inference to be drawn from the fact of the veins of the foot having no valves has an important practical value. It is that under all ordinary circumstances the veins of the foot are sufficiently exposed to pressure by the movements of the animal to propel the blood through them; and that the valves so necessary and useful elsewhere in overcoming the force of gravity, would be so liable to get out of order in this organ that they would rather obstruct than facilitate the flow of blood through the veins. The vessels would then became congested; enlargement would ensue, and this would create an internal pressure 
in an outward direction upon the horny textures, similar to what they do when in a hyperæmic condition merely from long standing in the stable or on board a ship. It should also be remembered that the horse was designed for fleetness-indeed, for almost constant action. All else being equal, this constant action would compensate for the omission of valves.

WORK OR EXERCISE A NECESSITY TO MAINTAIN A HEALTHY FOOT.

From these considerations, it would appear necessary that the foot should be in frequent motion, in order to maintain through it a healthy circulation of the nutrient and vitalizing fluid-the blood. And, if these premises be correct, what can be more opposed to the well being of the horse, or be a more frequent predisposing cause of occult diseases of the feet and limbs of horses than tying them up in stalls and depriving them of that exercise which is essential to the maintenance of the healthy condition of the foot primarily; and, secondarily, that of the entire animal system?

\section{THE PLANTAR VEINS.}

ANATOMICAL ARRANGEMENT.

"Having briefly described the arteries of the foot which pass in such a remarkable manner through the bone itself, protected from injury and secure from pressure, we must next describe the veins, which, by being less subject to injury, take their course outside the coffin-bone.

The veins of the sole empty themselves chiefly into those of the laminæ, which increasing in size toward the coronet, are collected together in branches, which take an upward course nrough the coronary substance, and form the superficial coronary veins. From them large branches proceed, which are joined by the deep coronary vein, which is usually double. These vessels when injected with wax present an immense network, spread over the.lateral cartilages, and gradually dimin- 
ishing in number, they at length unite in a single vein just opposite the pastern joint.

The veins of the frog after ramifying over the body of the frog ascend on the inside of the cartilages into the substance of the heel. Diminishing in number, but increasing in size, they become a single vein, which, joining that from the laminæ, together from the plantar vein, which, with the veins that form it, are alike on both sides of the foot. The vein takes its course upward by the anterior side of the plantar artery, but rather more superficially situated, and is joined by a vein called the perpendicular, and by some minor branches, and towards its termination by some larger ones from the fetlock joint."Spooner.

\section{THE LYMPHATICS OF THE FOOT.}

The lymphatic vessels are said, by Percival, to be so minute as to bear no sort of comparison with the veins in point of magnitude.

They are vastly more numerous and have much more frequent anastomsis than the veins.

They are peculiarly tortuous in their course, and are everywhere beset with valves. I have questioned in vain every authority I possess whether the lymphatics, like the veins of the foot, are not an exception to the rule as regards the existence of valves in that organ? Judging from analogy, I should deem it probable that they are. This however, for the present, must remain a moot question:

Their natural divisions are into Superficial and Deep-seated.

The superficial absorbents or lymphatics are distributed in great numbers immediately beneath the skin, and penetrate it at every point, which enables them to absorb moisture from external sources, and to convey it into the interior of the system. The deep-seated absorbents or lymphatics are found ramifying upon the interior tissues, in company with the veins. They are in direct communication with the superficial lymphatics. Their office is to take up, and carry off, in a fluid con- 
dition, the products of disintegration in all the tissues. Like the veins and arteries, they are exceedingly minute at their peripheral extremities, but gradually become less in number, and greater in size until they finally reach the receptaculum chyli, the contents of which being conveyed into the veins, it passes through various depurating organs, by which the effete particles are cast out of the system, and the useful retained and utilized in the regeneration of the various tissues of which the body is built up.

\section{SCAVENGERS OR SANATORY AGENTS.}

The absorbents have been described as the scavengers of the animal system. When the scavengers of a large and crowded city, fail to perform their duties, and the highways and byeways become choked up with refuse matter from the houses, and the air loaded with putrescent effluvia, we know that the general health must suffer, and it may be that the conditions are present for the specific generation of the germs of a disease which may depopulate the city. It is equally certain that when the lymphatics are interfered with and they are hindered in the performance of their duties, by any cause whatever, whether it be mere mechanical obstruction, arising from pressure occasioned by an inelastic and unyielding condition of the horny structures; or by the positive invasion of disease peculiar to its structures, the worn-out particles of the system cannot be conveyed away, and they remain to impair and impede the nutritive materials and functions.

Owing to the want of tonic force in the walls of the absorbents of the extremities, we get those accumulations of fluids that cause the dropsical appearance so well known.

There are other morbid conditions of the lymphatics, such as inflammation of these vessels, etc., which must be reserved for a fuller notice when the diseases having any immediate connection with the foot are under consideration. 
The absorbent or lymphatic glands are small globular bodies varying in size "from a pea to a walnut" that are found lying in the course of the absorbents. They are described as a "contortion of lymphatic vessels," connected together by cellular texture, having neither a cavity nor secreting duct. The vessel appears to enter a contorted mass of vessels, and then pass out again. These glands are linked together by absorbent tubes of intercommunication. The minutest of the absorbent vessels have but a single transparent membrane. As they require force, however, they acquire strength by the addition of another membrane, and finally the large trunks have three membranes.

The lymphatic system is an exceedingly interesting and instructive object of study. They have a more important connection with some diseases of the feet than is generally supposed.

\section{THE NERVES OF THE FOOT.}

GENERAL REMARKS UPON THE NERVOUS SYSTEM.

An eminent authority (Haycock) writes: "The nervous system is one that, if contemplated in all its numerous and important relations, will be found to embrace the most comprehensive inquiries which physiological science can open to the mind of man.

"The horse, like all other highly-organized animals, is possessed of a nervous system, the structure of which is highly complex, and the uses of which are two-fold: First, to place the animal itself in intimate relation with the external world; and, secondly, to place every member and every part of a member in intimate relation with every other member and part of a member. 
"The nervous system may be divided, for the convenience of description into:

I. The brain.

2. The spinal cord.

3. The cranial nerves.

4. The spinal nerves.

5. The sympathetic system.

"It is by means of the brain and its nerves, the spinal cord and its nerves, and the sympathetic system, that the relations I have stated are maintained.

"The sympathetic nervous system is distributed to the heart and to the blood-vessels throughout the body; and also those various organs, the aggregate of which is called the 'organic sphere' of the animal's body.

"The brain and its nerves and the spinal cord and its nerves. preside over the sensory and locomotive spheres of the animal, while, in addition the two systems exchange filaments with each other; and thus the whole is balanced in every part in a manner which cannot fail to excite the wonder and admiration of every beholder."

The importance of a due appreciation of normal and diseased conditions of the nerves in relation to the foot of the horse connot be overestimated. Causes apparently the most trivial, affecting the sensory nerves of the foot produce effects of the most destructive nature to the entire animal economy.

DISTRIBUTIVE ARRANGEMENT OF THE NERVES OF THE FOOT."

Before I advert to some physiolgical and pathological facts. having immediate reference to the nerves of the feet, to which I have to call the attention of my readers generally, and to veterinary surgeons particularly, I will dispose of the merely distributive arrangement of the nerves of that organ.

Quoting Spooner: "The nerves of the fore extremity are derived from the humeral plexus, which is formed by branches from the fifth, sixth and seventh cervical and first dorsal nerves. 
"Below the fetlock, these nerves, like the arteries, are termed the plantar, and they pursue a similar course, on either side, on the borders of the flexor tendons, and a little behind the arteries, and descending within the lateral cartilages, enter the foramen in the cavity of the coffin bone, in company with the artery, and distribute their ramifications through the foramina of the bone to the sole. In this course the following branches are given off :

"I. Just below the fetlock, an important branch, which runs obliquely forward to the lateral cartilages, where it is dispersed in the numerous ramifications, some of them external to the net work of veins, so that we can seldom bleed at this part without dividing a small nerve.

" 2. A large branch is given off, just before the nerve reaches the lateral cartilage, which proceeding backwards, enters the substance of the frog.

"3. Still lower down, a branch winds forward through the foramen in the wings of the cofin bone, and supplies the laminæ.

"The nerves that supply the coronary ligament are derived from the external metacarpal nerve."

IS THE EQUINE FOOT AN ORGAN OF SPECIAL SENSATION?

There are some reasons, I think, for the belief that the foot of the horse is not only the subject of common sensation, but is also endowed with such an extremely delicate and special organization as to entitle it to be considered as an organ of special as well as common sensation. The existence, however, of any special sense of this nature in the foot of the horse is one of inference rather than of positive demonstration; but it is an inference, I think, that is justified by reason and analogy, and, perhaps, by experience.

As to reason: That the foot should possess a special faculty of feeling, or sensation of touch upon its plantar surface, the part in contact with the ground when standing or during locomotion, in order to harmonize its internal functions with its ex- 
ternal relations, by enabling it to receive and to convey impressions of comparative degrees of safety or danger to the brain of the system of which it forms a part, appears to me to be as necessary as the special organization of the ear, the eye, and the other organs of special sensation, designed for the fulfilment of certain functions also in connection with the external relations of the animal.

PRIMA FACIE REASONS.

It appears to me that the impressions of safety or danger could not so well be conveyed to the brain through the agency of the eye alone as through the combined functions of the eye and the foot. Actual contact of the foot with the ground, I take to be a much safer criterion of safety or danger than a merely visual estimate of those circumstances. Both faculties are in perpetual exercise during locomotion; that of sight to measure distances, so as to place the foot with accuracy, whilst that of touch receives the impressions of its good or bad qualities with reference to safety or danger.

I think these may be regarded, at least, as prima facie reasons for the existence of a special endowment of sensibility in the foot of the "noble quadruped."

ANALOGICAL ARGUMENT.

The evidence in favor of this view derivable from analogy I think, may fairly be adduced from the existence of this function in that organ which is the homologue in man of the foot of the horse-the organ of touch par excellance--the human hand. In this the microscope enables it to be demonstrated that, besides the sensation it possesses in common with the skin at all other points, it is endowed with a larger supply of sensitive nerve fibrillæ at their extremities, where external objects are felt, than elsewhere. Just at the points of contact with external objects sensibility is the most acute. 
Anticipating an objection that might be urged to this view of the case, I concede that the respective functions of the hand of man and the foot of the horse are only parallel to a certain extent; that the former has endowments of sensibility denied to the latter, while the latter possesses powers and functions not enjoyed by the former; yet different though they may be in some respects, $\boldsymbol{I}$ yet think there is one particular function they enjoy in common, differing possibly in degree, but not in kind, in which the analogy holds good, and that it may be said of the foot of the horse, as it is of the hand of man, that it is pre-eminently the organ of tactility or touch, and the prime medium of communication between the brain and solid objects of the external world.

\section{EXPERIENTIA DOCET.}

The evidence of experience which I shall adduce may not have much weight with those whose experience with horses in this respect has been limited to what many have been observed among horses whose feet are shod with iron, and traversing only the streets and roads in or near a city.

Those who, like myself, have traveled in sparsely settled countries, as in the interior of Australia, where the foot of the horse is necessarily innocent of iron, and where horses are "shod according to nature," since nature does the shoeing herself, and have spent a large portion of their time on horseback, may possibly be able to recall recollections of "hair-breadth escapes by flood and field," due in a great measure to the sagacity, the instinct or reason (I know not altogether which) of their equine companions, as I can. I confess that my life has been endangered more than once by my not heeding the warning I received of treacherous ground by the animal's reluctance to move forward in a direct line, and by the folly of overcoming that reluctance by whip and spur. 
For myself I am convinced that the foot of the unshod horse, whether wild or subjugated, and traversing the natural surface of the'earth, possesses endowments of special sensibility but little inferior, if any, to those of the palmar extremities of the 'lord of creation' himself. The foot of the shod horse subject to be "cribbed, cabined and confined" in his natural movements, treading only on artificially-formed surfaces, his whole nature but ill-understood by his custodians, and the proper management of his feet in his civilized condition comprehended still less, I regard as vastly inferior in special sensibility to that of the horse which exists under more primitive conditions.

\section{CAUSES OF IMPAIRED ACTION.}

We will now allude to some of the pathological conditions, with which the nerves of the foot have an important and obvious connection. I hold that but a slight degree of abnormal pressure unon the nerves of the foot, whether exerted from within or without, will produce some, it may be but a slight degree of pain, involving necessarily a corresponding degree, or amount, of impaired action in the limb of the foot affected, which must affect, more or less detrimentally the entire system.

As is the amount of pressure, so will be the degree of pain, and the extent of lameness, whether it be slight or severe, in one foot or in more.

It but too frequently happens that the pressure is so slight and so evenly experienced by the two fore feet, and the increase of pressure so gradual and insiduous, that its effects are not discernable by those who are supposed to appreciate and to minister to all the animals physical necessities: until he becomes either an obvious cripple in both feet, or evinces a greater degree of lameness in one foot than the other. 
THE FEVERED FOOT-SUB-ACUTE LAMINITIS.

After a horse has been battering his feet, however sound .they may naturally be, with a thin and unsupported sole, the laminæ suffering the highest degree of tension; the heated organ, stimulated to its highest capacity for the propellance of blood through its millions of tubes, by active, it may be by violent exercise, and is brought suddenly to a stand-still; its rapid circulation is suddenly checked, under the unequal conditions of the blood-vessels within and without the horny textures; there being no valves in the veins of the foot; and the latter being suddenly deprived of its natural stimulus of exercise ; congestion of these vessels ensues, which may be temporary, being overcome by the vigorous action of the heart; or it may be more or less permanent, and become the readily predisposing cause to founder whenever any extra demand is made upon the capacity or endurance of the pedal extremity. But congestion, or morbid fulness of the vessels implies pressure against the walls of the foot remotely. The nerves of the foot are necessarily involved in this pressure, and hence we have the sub-acute inflammatory condition denominated "fever in the foot," which of course may be more or less severe according to circumstances.

\section{ACUTE LAMINITIS-FOUNDER.}

All these conditions of the sub-acute variety may become chronic or remittent in their character, and the foot in some cases become adapted to abnormal conditions, and the peculiar temperament of the animal under the influence of general nervous excitement, and the stimulus of action, may cause him to forget all about his "poor feet."

But when to the above we have a superadded cause in the morbidly contracting or contracted condition of the quarters, it can readily be perceived how a slight internal pressure and its con- sequences would be intensified, under any undue exercise of the functions of the foot, and how the nervous irritation may become so great as to affect the general nervous system, and that morbid condition we call founder, be induced. 
Between the extremes of simple fever, and founder, various structural changes and pathological conditions may be found in the feet of all varieties of breed, and all kinds of feet, whether they be flat, blocky, or of any intermediate form.

In whatever feet the general causes I have glanced at are in operation, however slowly and insiduously, it only depends upon the element of time and the concurrence of certain conditions which may happen at any time unforseen, what the result is going to be; what particular portion of the foot, and in what manner, and to what extent it shall be affected. In one case we may have simple contraction and atrophy or wasting of the internal structures as the ultimate result. Corns and Cracks may be manifested in other cases. In some cases they culminate in acute or sub-acute navicular disease or founder. Thus, it will be clear that the same general causes may produce the whole of these various specific morbid conditions, and the several links in the chain of direct causation be justly adduced, namely: contraction, nerve-pressure, and diminished or vitiated secretions, of the various structures composing the foot, whether they be the hard external, or soft internal, parts, all having to depend entirely upon nerve-stimulus for healthy action.

INJURIES FROM NAILING ON THE SHOE.

The process of nailing on the shoe is by no means an unfrequent source of irritation to the nerves of the foot, which occasionaly eventuates in canker and lock-jaw. Every one of the errors of carelessness or of positive want of skill, in nailing on the shoe, such as driving the nails too near the sensitive tissues, without actually piercing them; absolute piercing of the tissues; driving the nails too high, or too close together; using nails too strong or too weak in the shank; the too frequent insertion and withdrawal of the nail ; and though last not least, injudiciously tight 'closing' or 'drawing up' the nails on a weak or tender foot, no one knows better than shoeing-smiths 
themselves are occasionally productive of the most serious consequences.

The most apparently trivial cause may lead only to temporary lameness, or may be followed by the most destructive onslaughts of canker or of lock-jaw. These diseases will receive a careful and extended consideration under their respective captions in the section upon Diseases of the Feet.

\section{SOURCE OF PAIN IN THE FOOT.}

There are some morbid conditions that cannot be classed among the specific diseases of the equine foot which may be as well referred to here, perhaps, as elsewhere. I allude to pain in the nerves of the various tissues that enter into the composition of the foot. According to "Druitt," "The bones like other parts are subject to that severe and continuous pain which is known by the name of neuralgia." That the pedal bone and its investing membrane is the frequent seat of neuralgic pain, exposed as it is to so many injurious influences, both local and constitutional, I cannot entertain the shadow of a doubt. The same may also be predicated of the synovial and other membranous structures, which are susceptible to acute and sub-acute inflammation from local causes, such as external pressure, concussions, strains, mechanical injuries, and especially penetrating wounds and from constitutional causes, as exposure to cold; contact with the excreta of the stable; breathing a vitiated atmosphere; rheumatic and other blood poisons both inherited and acquired; and perhaps more than all, the powerful sympathy that exists between the feet, the mucous membranes of the lungs, stomach, and intestines, as well as the skin, and the brain.

The foot of the horse is more exposed to all these external and internal influences than the foot of any other animal by reason of its peculiar organization by which the circulation can be so readily impeded, healthy assimilation prevented, the secretory processes perverted, the nerve and other structures atrophied, the nerve-force weakened, and the various kinds and degrees of nervous sensibility augmented or paralyzed. 
EXTERNAL SOURCES OF PAIN IN THE FOOT.

Another seat or source of pain and lameness may be located in tissues, which, though not found in the foot, are yet the source of every movement of that organ. Therefore, whatever impairs the efficiency of the former, must necessarily exert a prejudicial effect upon the latter, just as any painful affection of the feet must have a paralyzing influence upon the muscular organs that control them.

MUSCULAR SPASMS, OR CRAMP.

Druitt thus writes of these diseased conditions: "Pain may arise from muscular spasms, or cramp, or from diseased condition of the nerves, or of the nerve-centres, without the existence of the least inflammation. Such pain may often be known by its coming and going, without apparent cause. It is often intense in proportion to the debilitated condition of the patient. It may last for months without being followed by any of the changes of structure which are commonly called inflammatory." I believe this is equally true of the equine, as the human patient, and that these are just the conditions which have led some veterinary writers to question the accuracy of the term laminitis where there has been no evidence of inflammation in the laminal tissues.

\section{NON-INFLAMMATORY AFFECTIONS. THE "RAGGED EDGE."}

I can readily concur with those writers and concede an occasional primary origin of lameness to muscles that govern the movements of the leg and fool, and hold still, that as a rule it will be found, by the effects of the treatment I pursue and recommend in such cases, that this class of ailments arises primarily from pressure upon the sensitive organization of the foot, and that the muscular organs that govern the movements of the foot are affected secondarily. The effects of the treatment will reveal the true primary seat of the trouble. I think very little observation is necessary to perceive that it is the sub-acute 
condition of pain, arising from pressure upon the delicately sensitive nervous organization of the foot that keeps the afflicted animal so long verging upon the "ragged edge" of misery, that even the atmospheric changes, and the fluctuations of dietetic and other influences, are sufficient to keep it constantly approaching to, or receding from, the line that separates the absolute from the relative disability of the animal for the performance of its duties. A severer degree of pain, a little overtasking of the tissues, an apparently slight accidental injury, or the known sympathy that exists between the skin, the visceral organs, and the feet through the medium of the nervous systems, will often then be sufficient to precipitate a crisis that shall topple the animal over the "ragged edge" into the abysses of positive pain, and misery, or of possible destruction.

POSSIBLE CAUSE OF STRINGHALT.

There is yet another mysterious affection of the nerves whose etiology is of the most doubtful character, and whose origin has been ascribed to various parts of the nervous system, but never before, as far as I am aware, to the region of the foot, or even suspected as having the remotest connection with a disordered condition of the nerves of the foot.

Pressure from within or without, affecting the nervous organization of the foot, and especially, perhaps, those delicate fibrillæ that control the action of the secreting organs, I opine to be $a$ cause, if not the cause, of the affection commonly called Stringhalt, since I have found the relief of pressure by the use of the dilator to relax the severity of the spasmodic action of this affection. It is fortunately not a destructive one except in a few rare instances. This subject will be more fully considered in the Article on Stringhalt. 


\section{SECRETING STRUCTURES OF THE FOOT.}

I. The sebaceous glands of the skin, more numerous in, and around the heels than elsewhere, for the purpose of keeping those parts soft and supple that are subject to extension during motion.

2. The coronary villi, that secrete the fibrous portion of the wall.

3. The secretories of the frog-band.

4. The laminal papillæ, that secrete the non-fibrous portion of the wall.

5. The secretories of the white solar zone.

6. The papillated membrane that secretes the horny frog.

7. The papillated membrane that secretes the horny sole.

8. The synovial membranes that secrete synovia for the purpose of lubricating the gliding surfaces of the joints.

\section{"AMPLE ROOM AND VERGE ENOUGH."}

The location and function of these Secreting Structures have been sufficiently indicated in connection with a description of the various substances they secrete. The following brief reference to the microscopic anatomy of these minute organisms, will perhaps be sufficient to show the extreme delicacy of some of the structures and processes that enter into the economy of the foot of the horse, and to suggest the importance of there being "ample room and verge enough" for the elaboration and secretion of the horny textures. 
All the secreting papillæ and villi are said to be constituted very nearly alike, and to consist essentially of a double membrane, basement and epithelial, with a layer of fine areolated tissue between them both, the inner and outer surface of which is covered by minute villi, so called from the surfaces they cover resembling velvet, or plush. In each villus or papilla, a plexus or little knot of arteries, veins and nerves are found to exist, by which the processes of accretion, of elaboration, and secretion, are carried on. The exact modus operandi of these operations, however, are so complex and difficult to investigate, that they have not yet been fully understood or satisfactorily explained.

\section{THE FLUID ELEMENTS OF THE FOOT.}

I. Blood.

2. Marrow.

3. Lymph.

4. Synovia.

5. Mucus.

6. Substances undergoing transformation into horny tissues.

7. The perspiratory fluid.

PHYSICAL PROPERTIES OF THE BLOOD.

The first, only, of these elements, the blood, demand any special mention beyond that which might have been made when considering the secreting structures, and the enumeration which was necessary to present a complete account of the subst ances that play their part in the complex organism designated the foot of the horse.

\section{IMPORTANT PHYSIOLOGICAL FACTS.}

Anything like a full consideration of the properties and constitution of the blood would carry me further into the domain of physiology than the majority of my readers would be disposed to follow me. There is, however, one view of its physi- 
cal, and one of its chemical, properties that I wish to impress upon the mind of the student, that have an important bearing upon the rationale of treatment.

\section{RED AND WHITE BLOOD CELLS.}

All the constituents of the blood are not absolute fiuids. It contains solid particles, called red and white cells, and, even in a healthy condition of things, when the vessels they pass through have their full natural dimensions, these solid particles can only pass through the capillary vessels in single file. Now I think it is obvious that the very slightest amount of abnormal pressure upon the vessels will impede the passage of these cells; and what is true of the blood vessels and their fluid contents, is equally true of the lymph and lymphatics, and of the secerning organs and their fluid contents. The slightest diminution of the calibre of any of these vessels will interrupt, in some degree, the free and natural flow of their fluids through them, which must be productive of ill effects in proportion to the intensity of the causes.

\section{CHEMICO-VITAL CHANGES IN THE BLOOD.}

The most prominent of these ill effects or morbid conditions I regard as taking place in the constitution of the blood itself. Pathology teaches us that in all inflammatory conditions, whether general or lncal, chemico-vital changes take place in the blood which diminishes its albuminous, and increases its fibrinous constituents. This renders the blood less fluid, and therefore less capable of passing through the minute capillary vessels, whether it be of the brain, the lungs, or the feet. The circulation being impeded in any organ, or from any cause, produces congestion and inflammation. Thus it will be seen how one abnormal action will produce a series of abnormal actions and reactions in other organs besides the feet. These are the merest hints upon a very important element in the question of lameness and its causes; but I hope thcy are sufficient to show, theoretically, the value of a 
- of the horny walls of the foot, whether it be obviously contracted, or whether there is only a suspicion that some slight degree of contraction may exist. Its practical value can only be fully appreciated by those who know, by a profitable experience, that the highest amount of speed of which a horse is capable can only be developed and maintained by a judicious application of the principles of treatment it is the aim of this work to elucidate and to recommend. 


\section{THE "NO CONTRACTION" AND "NON-EXPANSION" HERESIES.}

PRELIMINARY REMARKS.

Having gained a perception of the facts and inductive truths of the anatomy and physiology of the equine foot, we shall be prepared to enter upon the consideration of the pathology and therapeutics-in other words, the diseases that affect that organ and their remedies. With such a preparation, the task is an easy one; but, before I address myself immediately to this task, I feel there is no escape from the performance of a duty which the position I occupy as a teacher has imposed upon me, namely, that of encountering and doing battle with a couple of twin heresies, whose only success has been in disturbing the peace of the profession, such as it was, without in anywise substituting a more solid basis for its repose than it previously possessed. If these no contraction and non-expansion heresies were merely speculative in their character, their adoption or rejection would be of little moment. It will be shown, however, that a long catalogue of calamitous consequences is, and must be, the inevitable consequence of the adoption of these pernicious errors. While sitting at the feet of our modern Gamaliels, it was my duty to listen respectfully to their teachings. So I did, and armed to the teeth with the theories I am now called upon to combat, I went forth into the world to do battle with problems of life and death, and soon found myself but poorly equipped for the occasion, after all; for no amount of plausible theory could extinguish the light of one simple fact 
I had been taught by those who believe in the gospel according to Gamgee, that Coleman, Turner, Bracey Clark, Lawrence Blaine, Percivall, Youett, Miles, Spooner, and other distinguished writers upon the foot of the horse, had all been the victims of a hallucination upon the questions of functional expansibility and morbid contraction, and were "blind leaders of the blind," and their teachings an "ignus fatuus," "mere coinage of the brain," "chimerical," "mythical," and so forth.

It was not until I found myself face to face with pathological problems, upon the correct solution of which depended my "daily bread," that I discovered the real danger of the no contraction and non-expansion heresies; for how could I consistently apply measures or remedies which directly contradicted such views? I was unable to "cope with such cases until I found one fact that was sufficient to dispel the whole brood of crudescent fancies which I had acquired under the influence of the teaching of "eminent authorities." This one fact has been the open sesame to a veritable cave of mystery which a few, indeed, have essayed to enter, but have halted upon its "precincts," and still fewer have been found to penetrate and explore its mysterious recesses.

FACTS VERSUS THEORIES.

Opportunities were soon afforded me of testing the truth of the new or the old doctrines, for there is no middle ground in this question. I was compelled to yield to the irresistible logic of facts. My practice has taken precedence of my theory in this connection. Upon the facts of practice my theory is based. The facts are irresistible and indisputable, and upon these I take my stand, and am prepared to submit my practice to any fair practical test. The theory may be doubted, questioned, nay, utterly annihilated by one better versed than myself in the art of chopping logic. As to the practical facts, however, which are of greater moment than any theory, however plausible, no weapon of logic has ever been constructed that can so much as indent its impenetrable armature. Fortunately, the 
theory and practice which I have yet to unfold in these pages are so simple and so reciprocal each to the other, and so readily demonstrable, that they verify and confirm each other.

\section{CONRACTION AS A MORBID CONDITION.}

THE REVIEWER REVIEWED.

Professor Gamgee, senior, a distinguished equine foot-pathologist, or may I say hippedopathologist, in a reries of ably written articles in the pages of the Edinburgh Veterinary Review, some ten years since, endeavored to, and did to a certain extent, revolutionize all the then prevailing opinions regarding the various functions of the foot of the horse, and their relations to the movements of the animal.

The marked ability with which these questions were treated, and the prestige which accompanied his name must have had considerable influence upon the minds of every one who read those articles, as they had upon mine. Indeed, at the present time, those articles are being extensively quoted and their author's name mentioned as the best English authority in some of the Agricultural journals of this country. There being no middle-ground of compromise; no stand-point that would embrace the old and the new; I forsook the old and embraced the new. Mr. Gamgee became the apostle of a new dispensation in my estimation as regards "THE FOOT AND ITS FUNCTions." But for a brief period only, for the new views were contradicted daily by the facts and observations of experience, nay more, by demonstrations as certainly truthful as any demonstration to be found in the pages of Euclid. Of course, my whilom idol fell from its pedestal, and since then I pay homage only at the shrine of facts, not 'going a cent' upon the authority of a name nor upon the sanctions that are supposed to accompany "hair's grown gray" in professional harness, if they have not a solid backing of facts. 
AGE NOT THE MEASURE OF EXPERIENCE.

An eminent practical surgeon has said, "Years are not the measure of experience. It does not follow that the older a surgeon is, the more experienced and trustworthy he must be. The greatest number of well-assorted facts on a particular subject constitutes experience, whether these facts have been culled in five or fifty years." "It is not the extent merely, but the extent in relation to the quality of the experience that turns the lessons to profit."

"BE JUST AND FEAR NOT."

As I regard the foot and its functions, the final function of locomotion is the aggregate result of a series of minor functions, all acting in harmonious combination. It is possible to have correct views of some of these minor functions, and incorrect views of others. Thus I can consistently credit Mr. Gamgee with having exposed one of the most dangerous errors that have long prevailed with regard to the functions of the horny sole. And, if I were not sufficiently armed with facts, I should hesitate before I entered the lists of controversy with such a redoubtable old swordsman or penman as Mr. Gamgee undoubtedly is. That gentleman, however, must be content to have his utterances reviewed according to the same canons of criticism as those by which he judges the views and opinions of others in the same field of investigation. He has sacrificed distinguished names and reputations upon what he deems the Altar of Truth, in the interests of veterinary science. $\mathrm{He}$ must therefore surrender his own to the sacrificial knife, if it should be demanded in the name of the same goddess, and in the interest of veterinary science.

\section{THE ESSENCE OF GAMGEE.}

Respecting Contraction as a morbid condition of the foot of the horse, Mr. Gamgee denies the existence of any such condition, without any qualification whatever. I will select a few of his utterances upon this subject. "If it be true, as I believe 
it is, that language constitutes the key to the sciences, it must be equally evident that language wrongly used, tends to convey relatively false notions; and that such is the case regarding the word contraction in its common acceptation, in speaking and writing about horses' feet, it will not be difficult to prove. The word 'contraction' is used to describe a narrow or small foot of the horse." "I conceive it expedient to test the value of the word contraction in its relation to the foot of the horse."

"The prevailing notions are alike inconsistent with fact and reason regarding contraction. An imaginary evil has been created, and an indefinite number of equally imaginary measures, to subdue a myth, and in those measures lie the real evils."

"If we could dismiss from our minds the word 'contraction' and all ideas of the inward pressure implied, and adopt instead the word atrophy, we should have a meaning given, to almost all the deranged states of the foot of the horse, whether the cause be want of development through perversion of natural influences, or whether it be the effect of misapplied art subsequently; atrophy, which means wasting, or lack of nutrition, would indicate the true condition of the foot, and lead to inquiry after causes.

"There are many of the most common affections of horses' feet which have yet to be described, and which require the attention their nature demands. Atrophy is the word that clearly indicates these, whether speaking of a particular tissue or several component parts of the same organ."

\section{THE CASE STATED.}

From these extracts it appears to me perfectly clear that Mr. Gamgee objects to the use of the word 'contraction' in its common acceptation when used to denote a commonly diseased condition of horses' feet. 'That the word atrophy would best express almost all the deranged states of the foot of the horse. That the etymological value should be tested to prove this. That the wrong use of a word has led to the creation of an imaginary evil, and equally imaginary measures to subdue a myth, and in these imaginary measures lay the real evil. There 
is no hair-splitting about a word; 'contraction' expresses no real condition of a diseased foot; atrophy, almost every diseased condition.

\section{AN IMPORTANT OMISSION SUPPLIED.}

I looked in vain for the promised "test of value" of the words contraction and atrophy, etymological or otherwise, but not being able to find any in Mr. Gamgee's lucubrations, I have endeavored to supply the omission. This omission was very much to be regretted as "correct language is a key to the sciences," and for the want of this key all our predecessors in this department of veterinary pathology have been creating imaginary evils and imaginary measures, and real evils have been the result, so says Mr. Gamgee.

\section{"LANGUAGE IS THE KEY TO THE SCIENCES."}

We will therefore test the value of the word 'contraction' before we dismiss it to the limbo of obsolete terms, and of the word atrophy before we clutch it to our bosoms as the one thing needful in veterinary nosology. This must be the all-important inquiry according to Mr. Gamgee, since the wrong use of a word has led to such calamities to horses that we in common deplore and attempt to remove or at least to mitigate. Is contraction, then, the meaningless term that Mr. Gamgee alleges it to be when applied to certain diseased conditions of horses' feet? According to 'Webster' the term implies an act, or a state; the act of contracting, or shortening; the act of shrinking or shrivelling; and the state of being shortened, shrunk or shrivelled, or drawn into a narrow compass. Entick's Latin Dictionary informs us that the adjective contractus means contracted, shortened, abridged, drawen, or gotten together, raised, gathered, wrinkled, shrivelled, joined close, riveted, narroze, straight, difficult. These various meanings must therefore give the noun contraction a pretty wide range of application. One can almost imagine the lexicographer to have had a horse's foot in , his 'mind's eye' when he penned the above definition of con- 
tractus, for how could we better describe the condition of very large numbers of horses' feet, than by saying they were draten or gotten together, at the heels, narrowe in the quarters, the inside quarter generally raised above the other, sometimes both quarters unnaturally raised, gathered in, or joined close in the medial frog-fissure, straight or upright quarters; wrinkled and shrivelled walls and heels, and lastly difficult; difficult indeed for the poor horse to travel with such a locomotive apparatus as this, and most difficult usually to heal.

\section{AUTHORIZED DEFINITIONS.}

From these it appears to me that the word "contraction ' not only includes various conditions, whether of diseased horses' feet, or otherwise, but that it has both an active and passive signification, the act of contracting and the state of contraction, which extends its range of application considerably; for have we not evidence of both active and passive contraction in the various forms and stages and degrees in which it is met? In the majority of cases that have come under my notice, I believe the active has preceded the passive; in fact, has produced the passive condition. I therefore cannot coincide with Mr. Gamgee in the opinion that the use of the word 'Contraction' in the common acceptation of that term, is the "source of imaginary measures to subdue myths," and for myself shall, in a general way, abide by the common acceptation of its meaning. When a nice distinction is necessary it will be time to indulge in it.

\section{WHAT DOES ATROPHY MEAN?}

The one essential idea conveyed by it is wasting for lack of nutrition. Atrophy is a very useful word employed in the right place, but its signification is too limited to truly indicate many of the most common affections of horses' feet. It will indicate one condition and no more.

Let us test 
THE VALUE OF THE WORD ATROPHY

a little further. Will atrophy indicate acute or sub-acute local inflammation? Yet this is a condition of the foot, the most commonly met with. Will it suit inflammation of any specific tissue of the foot? I trow not. Will it imply hypertrophy or ossification of the lateral cartilages, Corns, Cracks, or Quittors? These are very common affections of horses' feet. The atrophied foot is comparatively a rare one. It is usually met with when one foot is smaller than the other and is usually found in association with a shrunken and wasted shoulder, and arm. I regard this as an atrophied condition of the whole limb.

It is now ten years since this new gospel was preached, and illustrious converts were made, who abjured the doctrines they had long taught upon this subject. I should like to know what gain to science has resulted from the change of nomenclature introduced by Professor Garngee?

If the use of the word contraction wrongly, has been productive of so much "imaginary disorder and imaginary treatment," surely the truly expressive word for "almost every condition of the diseased feet of horses" must have led to an opposite result? If mere words have the power which $\mathrm{Mr}$. Gamgee ascribes to them, the millennial period for horses ought surely to have arrived by this time. If it has we have not yet been apprised of it in Chicago.

\section{FACTS VERSUS FALLACIES.}

Having, I think, settled the question of fitness of the word contraction, and atrophy, to certain diseased conditions of horses' feet, we will leave the words, which are but signs, to take care of themselves, and discuss the realities they represent. Take another glance at the detached hoof. It has an upper and lower circumferent margin, the posterior terminations of these margins meeting together and merging into a triple-commissured substance called the horny frog.

It has been said that no two human faces are exactly alike. I believe that no two equine feet are exactly alike; not even 
those belonging to the same horse. The resemblances are general, not particular.

VARIETIES OF FEET-HOW PRODUCED.

Professor Gerard, in his Treatise on the Foot, enumerates no less than twenty varieties of feet to be met with either in a natural or diseased state. Spooner, in his Treatise on the Foot, alleges that the various appearances and arrangements of the parts of the foot, "will admit of almost as many varieties as the arrangement of an equal number of the letters of the alphabet." The general causes of these diversities of shape and form arise mainly out of the necessity for affixing a metallic protection, by means of nails, to the foot; affixing it in an unscientific manner, and by neglect and mismanagement in the stable.

The fundamental proximate cause of these varieties of departure from the general healthy form is the inherent property horn possesses, by which a change of form can be induced by the operation of other causes. It is growing more or less rapidly all the time, and from this cause alone an easy shoe to-day may be a tight one in the course of a week or a fortnight, and may be producing a gradual change in form, by a passive resistance to expansion of the hoof from growth, inducing thereby a gradual contraction of its fibres and a consequent gradual alteration in form and structure, of the hoof.

THE EFFECTS OF A DRY ATMOSPHERE.

Experience has taught me that horses' feet are injuriously affected by an unusually dry condition of the atmosphere. They become hard, dry, and contracted, in the ordinary sense of the term, and the most frequent result of these conditions is a split or crack, chiefly in the irside quarter, where the wall is thinnest, and most readily gives way. I believe that of every twenty horses that I treated for lameness in Colorado, eighteen of them were affected with a split hoof, which I could only attribute to the extreme dryness of the atmosphere, a condition 
Mr. Gamgee thinks "the most faciable for the development of horses' feet," and therefore condemns the frequent use of water and other dressings to those organs.

\section{VARIETIES AND EFFECTS OF CONTRACTION.}

Whether active contraction takes place at the upper or the lower circumferent margins first will depend upon circumstances; and whether contraction precedes expansion, will also depend upon other active causes; but I have always found that if one margin be expanded, the other is contracted. For example, when coarctation or contraction of the upper circumferent margin of the wall takes place, there is a corresponding enlargement of the area of the lower one, giving the bell-shaped form of foot. No 'atrophy' can be implied in this condition. It is simply an alteration of the external form, induced by extraneous influences, gaining as much in one direction as it loses in another. I regard it as a stricture or contraction of the hoof, and when it is the cause of lameness, a removal of the stricture removes the lameness. How this stricture can be removed will be shown by and by. It is not an unfrequent source of lameness, and in general it is easily removed, leaving the animal perfectly sound in action. Reverse these conditions, and we have the most frequent cause of lameness, and, moreover, is

THE INVARIABLE CAUSE OF QUARTER-CRACKS.

Let the lower margin of the wall co-arct, or close in preternaturally at the quarters, and there will be a corresponding enlargement of area at the upper margin. The coronary ligament receives an undue amount of pressure, and quarter-crack is the very common result. One of the most common causes of this falling in or wiring in of the quarters is "cleaning out the heels" whenever the horse is shod, and exposing the soft parts to the drying, and therefore contracting, influences of the a tmosphere. Occasionally there is lameness when the crack starts; sometimes there is none. There is obviously here an outward pressure of the internal tissues, which are not permit- 
ted to exert their force at the bottom of the foot, where the wall is strongest, by reason of the wired in or contracted condition of that portion of the quarters. Atrophy of those tissues, producing 'atrophy of the hoof structures, I think would be a very unsatisfactory explanation of the phenomenal conditions under consideration. There is crowding, pressure, enlargement, bursting out, and rupture of the horny investment, but no waasting or shrinking implied at this stage of the malady. I find invariably associated with quarter-crack this contracted lower margin; and as I cannot, for very obvious reasons, consider the crack the cause of the contraction, I assign the cause of the crack to contraction. The cure of contraction is also the cure of the crack, and the cure of the crack is the cure of contraction. The cause and the effect are both removable at the same time. I will make it appear at the proper place that a crack of this nature can be closed up effectually, without a nail, clasp or rivet other than what goes through the shoe, or ligature of any kind. The lameness consequent upon these lesions of the hoof disappear usually within a fortnight. The cracks can never be burst open again while the shoe is properly attached, and remains stronger than the hoof. I have treated hundreds of such cases, and a single failure is unknown to me. Not a mark is made with a knife or firing-iron upon the external surface of the hoof, and it would require an acute observer to detect the existence of a crack, or that anything whatever had been done to the feet. No mean advantage, this, over every other plan of treatment. Even the bar-shoe is dispensed with. 


\section{THE DISEASES OF THE FOOT OF THE HORSE.}

CONTRACTION.

SYMPTOMS AND TREATMENT.

The reader will now be prepared to follow me intelligently in the practical application of the theory with which I should expect he is tolerably familiar.

The evidences of contraction are both positive and negative.

POSITIVE AND NEGATIVE EVIDENCE.

Positive evidence is the shape and contour of the foot. A practiced eye can detect a contracted foot without lifting it from the ground, or seeing the animal move, by standing in front of the animal and noting the inclination of the quartersthat is, whether they incline downwards and outwards, which is normal, or downwards and inwards, which is abnormal. This latter condition is that termed wiring in, and if a horse withsuch quarters is not lame in some degree, he is in a fair way of becoming so, or else, what sometimes occurs, the internal structures of his feet have become adapted to the changed contour of the hoof. These are exceptional cases, however; the former constitute the rule. The touch of the finger or open hand of experience will detect the slightest departure from natural temperature. The normal temperature of the healthy foot is that of the surrounding atmosphere. Any increase or decrease from this criterion is abnormal. Lameness or tenderness, in the absence of any other symptom sufficient to account for its existence, would complete the positive evidence of a morbidly contracted condition of the foot. It is that absence that constitutes the negative evidence in such a case. No crack, corn, bruise, or sprain being detected, the inference is a tolerably safe one that simple contraction is present. I may here inform the student that, having mastered the details of the operation 
for contraction, he has acquired in the main all that is necessary for the safe application of it to all the other diseases of the foot. Some minor details only will have to be described as applicable to each particular case.

It is desirable in all cases where the foot is hard and unyielding to immerse the foot or feet in a warm flax-seed poultice for 24 hours before operating; but this is not essential. The foot can be prepared, the shoe attached, and the poulticing take place afterwards, if certain exigencies, of time or other circumstances, do not admit of the opposite course.

If the foot is in a fair condition for expanding, the foregoing observations do not apply.

\section{PREPARATION OF THE FOOT.}

First, the old shoe being removed, be sure about the existence of corns. Sometimes they lie concealed, and if not detected and disposed of, will occasion disappointment. Being satisfied that there are no corns, and that the case is one of contraction only, proceed to examine the state of the quarters, as to whether they are weak, thin, shelly, and brittle, or whether they are strong, thick, tough, and sound, with reference to their capacities for the reception of nails into their substance, remembering that the shoe has not merely to be attached to the quarters, but that the nails must grip them so firmly, that when the shoe is expanded the quarters will be expanded likewise in the same act.

Passing the nails through the centre of the substance of the wall is not sufficient, however high they may be driven, as they are apt to burst out when force is applied to them. The nail should be pointed fairly within the inner edge of the wall, and take a short firm grip, the nails coming out not higher than one inch from the shoe. Nothing short of this will be sufficient for the purpose. If the capacity of the wall be doubted to stand this kind of nailing, it is better to omit nails in the quarters and apply a shoe with inside clips turned up at the extreme ends of the shoe.

In preparing the foot, the next point to consider is 
FORM.

By form is meant the proper angle or slope of the foot. If the foot is too long at the toe it is equivalent to lowering the heel and increasing the strain upon the flexor tendon. It also lowers the instep, and frequently presses the tendon of the extensor between the hoof and the highest part of the coffinbone, while if it is too elevated at the heels, which again is equivalent to being too low at the toes, a tendency to fall or stumble is promoted by it.

When there is an abundance of horn, and the foot will bear some reduction in size, the reduction should be made in reference to the slope of the fetlock. As a rule, the slope of the foot should be a continuation of the slope of the fetlock. If the heels are low and weak, they must not be made a particle lower, but the strength and thickness of the shoes at heels and toes must be considered with reference to the same points, namely: the just equilibrium of the animal over himself, preferring a slight extra elevation to any undue depression of the heels. When it is remembered that the horse is being shod to correct certain pathological conditions, and that the floors of almost every stable have a sloping surface, it will be seen how much a little extra elevation of the heels will contribute to his standing at ease in the stable, and how injurious the opposite condition must be.

After the pathological shoes have done their work, the use of the same kind of shoe should be continued, omitting the backnailing, and using calks or not, or modifying them to suit the animal's habits of going. As a rule I do not approve of the use of toe-calks except under special circumstances, such as for slow draught work, and during the continuance of frosty weather when their use appears to be indispensible.

I may further remark that I think no shoes should remain upon the feet of any horse, without being removed or renewed, whether the animal is working or resting for longer than twenty days.

To return to the preparation of the foot. After a perfectly level bearing has been obtained for the shoe, not a particle of 
the sole should be removed by the knife, neither fore nor aft. The heels require opening as far as can be done without drawing blood, and the opening in any case should not be larger than is necessary for the Clip to fit into it, and grip the quarters behind what is called the angle of inflection. If nailing should be resolved upon, one nail should be got into this very spot, the others at distances dividing the nailing space between them evenly.

The line of union between the frog and bars should be weakened slightly towards the apex of the frog, but deeply posteriorly into the commissures. The central frog-fissure should be opened a little through the centre from base to apex.

I must here acquaint the student of the intention to cause the principal expansion of the hoof right through the centre. It is not the sides or quarters that is to be torn from their immediate connections as some have imagined, but the hoof is made to expand by widening the area of the large triangular fissure into which the frog is inserted like a wedge. The frog has also a central fissure which makes it easy for it to yield. The frog has then more room, internally and externally, and this is the objective point to attain. Give all the tissues room and that is really all that is needed.

The one necessary condition in the form of the shoe, is that it shall have a flat, even-bearing surface, upon sole and wall alike, extending fully over the anterior two-thirds of the foot

THE BEST KIND OF SHOE.

The convex shoe as understood by horse-shoers, supplies this condition. Such a shoe should be fitted as directed, the heels have a good cover even if a small portion of the frog has to be removed to effect this. The outer superior edge of the shoe should be made to coincide with the outer inferior edge of the wall, right home to the heels.

A short-heeled shoe will spoil the whole thing. Never mind appearances if the shoes are narrow at the heels. The dilator will change all that. 
NAIL HOLES AND NAILING.

In punching the nail-holes due regard must be had to the substance of the wall and its obliquity, as a corresponding oblique direction must be given to the nail-holes. Without this precaution the whole work will be nullified, unless clips are used.

When the shoe is properly fitted, it should be finished in the vice, sharp edges and burrs being removed with rasp or file. An important point (every point is important in this operation), is to weaken the shoe at the point it is desirable for it to yield, when the dilator is applied. By the position of the weak part of the shoe it can be made to yield in any outward direction desirable. If it is desired to expand both sides, the nick in the form of a $\mathrm{V}$ should be made as near the centre of the toe as possible, on its inner edge. If one side only is to be expanded, the nick must be made away from the centre to the side it is proposed to expand. Whether with clips or back-nails, the shoe should be nailed on rather lightly than otherwise.

'Close up' and 'draze' on' very lightly, remembering that the foot has to be immersed in a poultice, and that this will tighten the nails to some extent, and further that the animal is undergoing a surgical operation and is not intended for work until these shoes have been removed and nailing suited to the work or exercise the animal is required to perform, is adapted.

The dilator may now be applied, its arms being inserted within the heels of the shoe, and two or three gradual turns of the screw taken. At every turn of the screw the foot should be surveyed to see that the nails or the clips are acting fairly. The instant the horse evinces the least uneasiness, the expansion should be stayed, the foot placed in a poultice, and another turn or two of the dilator given the next day or the day following. This is continued until good full-sized heels are obtained and the animal is free from lameness. The poultices should be kept on night and day, and except during the time allotted for exercise, which should be given from the first or second day, beginning with half an hour's exercise a day, 
and gradually increasing according to the animal's capability, feeding well the whole time.

In about a week's time, should the lameness not disappear, or the case should not appear to progress satisfactorily, the shoes should be removed and an examination made; the obstacles to progress discovered if possible; a re-adjustment of the shoes effected, and cautious dilation again pursued, not forgetting the persistent use of the softening poultice, both night and day. There is not more than one case in a hundred of simple contraction that will not yield to simple expansion.

In coarse-bred horses the same care should be taken in attaching the shoe, but the same nicely regulated exercise is not so necessary as in the well-bred trotter or runner. Light work for such horses is preferable to standing in the stable.

In very many cases Sweeny or Atrophy of the shoulder muscles is the result of contraction. See Article on Sweeny.

\section{LAMINITIS - ACUTE RHEUMATISM. ACUTE FOUNDER.}

SYMP'TOMS AND TREATMENT.

There are various designations of this disease, the prominent symptoms of which are the extreme painfulness of progression, the high sympathetic fever, and the peculiar attitude assumed by the animal to relieve the fore parts of its feet from pressure, the very opposite symptom of the navicular disease. According to the severity of the disease will be the manifestations of pain, the difficulty of progression, and the extent to which he throws his weight upon his heels. Whether they be hind or fore, or all four, feet, the animal's endeavor is plainly to press as little as possible upon the fore parts of the feet. The fore feet are oftener attacked than the hind ones; less frequently are all the four feet, and more rarely still the hind without the fore feet. It lies down, and is very unwilling to rise when it is down. It wears a very anxious look and painful expression, and sweats very much in a severe case. The temperature of 
the foot is raised, the arteries throb, and the superficial veins become very much distended. The pulse increases in force and number, frequently going up to 80 , and even roo. In slight cases the countenance is tranquil, and he merely shifts his weight from one foot to the other. This latter may be one of the fluctuations of the chronic condition, attracting little notice, but eventually, in most cases, it prepares the way for a subsequent and more violent attack.

PROXIMATE CAUSES OF LAMINITIS.

Some of the immediate causes that contribute to an acute attack of this disease deserve mention. Amongst these I deem over exertion, when the animal is out of tone, and the weather is wet and cold, as a very common cause of this disorder. Fast driving, after standing inordinately in a stable, is very apt to produce it, especially in hot weather, and cold water being given the animal to drink. So that too much or too little work may equally be regarded as causing it.

A horse is often affected in one foot after standing a long time upon it, in consequence of a morbid condition of the other. The standing necessary in such a case is known to be a secondary cause of this disease. Inaction arrests the natural flow of blood through the veins, producing congestion and its consequences.

Wheat, and all kinds of rich food given or taken in inordinate quantities is a well-known cause that leads to laminitis, by clogging the stomach and deranging the digestive processes.

The thoroughbred horse is more often affected than any other class from the latter cause. High feeding and inactivity, so foreign to the natural habits of the animal, leads to that mysterious process called metastasis, affecting the brain, the thoracic and abdominal viscera, and the feet. I entertain no doubt whatever that pneumonia and pleurisy, gastritis and laminitis, and possibly other visceral derangements, as well as those of the skin, are often the products of indigestion.

Elsewhere (see article on Tetanus) I have alluded to the functions of the nervous system, through which the changes of loca- 
tion in certain diseases, of which laminitis in one of its forms is effected. I am equally convinced that the same or another class of diseases, "namely, of the blood, in what is called the 'rheumatic diathesis,' may be inter-communicable between the respiratory, the digestive, and the locomotive organs, through the medium, primarily, of the circulatory system, as well as the sympathetic ramifications of the nervous system. In this view may be found a possible solution of

\section{A PROBLEM THAT PUZZLES MOST WRITERS}

to account for, and an approach to a rational explanation of the modus operandi by which the inter-transpositions of disease of any one organ to any other may be effected; in short, how the process termed matastasis operates.

\section{THE CURE, "THAT IS THE QUESTION."}

The various stages and degrees of development of laminitis are known by the terms early and late, congestive and inflammatory; and although the latter term is objectionable as applied to all morbid conditions of the laminæ, it will be of infinitely more importance than discussing the propriety of the term, to show how the local causes, proximate and remote, that produce this diseased condition can be effectually counteracted, the morbid conditions reversed, and the cure effected in the shortest space of time, and with the least possible loss of the animal's services, no matter what stage of congestion, inflammation, or disconnection of the laminal attachments may have been reached.

\section{OCTOGENARIAN VETERINARIANS.}

I am conscious that I am now stating views which are not in accord with those of all veterinary writers who have written hitherto upon this subject, and that my statements will excite sundry incredulous shrugs of the shoulders, a dubious expression of the lips, or a skeptical elevation of the eye-brows, and perhaps all of these together, on the part of some of our octo- 
genarian veterinarians. "What!" it will be said, "Are we to discard all those principles of treatment of which time and experience has taught us the expedience and suitability, and nail upon a foot already suffering an extreme degree of pain a mass of iron, the mere nailing on of which must have the effect of inflicting a still higher degree of torture? Such a proceeding would be preposterous in the last degree; absolutely absurd, and a piece of downright folly and cruelty. The man who proposes to treat laminitis by any such means is a knave or a fool, or perhaps both, whose descent in the scale of barbarity has reached the very lowest depths of infamous indifference to the sufferings of the "noble horse." "

\section{THE KIND OF RECEPTION.}

This is the kind of reception I expect for my proposal to expand the quarters of a foundered horse, to create pressure on the sole of the foot, to elevate, rather than to depress the heels, and generally to act diametrically opposite to all approved principles of treatment handed down to us by our grandmothers. The general mode of affixing the shoe is the same as in contraction.

\section{SPECIAL POINTS IN SHOEING FOR LAMINITIS}

require, however, to be borne in mind: To guard against any further descent of the sole than what has taken place, rasp the lower circumferent margin of the wall, and prepare the foot and the shoe so that the weight of the animal shall be borne entirely by the sole at its broadest portion.

If the foot is large and flat, a light bar may be placed upon the shoe across the broadest part. The shoe should also be broad in the web, and the quarters only should be expanded. If the foot is medium or small-sized, the bar may be dispensed with, but the shoe should be relatively broad in the web, with its whole bearing 'right on' to the sole. Further descent of the sole is then impossible, and exercise judiciously adapted to the animal's capability, will produce a rapid change in its locomotive powers. 
Moderate elevation of the heels I find to be productive of more benefit than lowering them, as is the practice in the treatment of the inventor of a shoe, denominated

\section{"BROAD'S LAMINITIS SHOE,"}

well known in England. I enjoyed the advantage of being that gentleman's chief assistant for over a year, and am therefore familiar with his principles and plans of treatment. I well remember the obloquy sought to be cast upon his special treatment by those who were not acquainted with its merits, and I anticipate a similar, if not a worse reception for my theory and method of treatment as applicable to the same disease.

A POINT OF SOME IMPORTANCE,

as relieving pressure from the part immediately affected in laminitis, is to omit the nails nearest the toe, one on each side, and with the knife or rasp remove a small portion of the horn, at the toe, extending on each side as far as the nail-holes, so that when the animal's weight is on the ground, a knife or any similar instrument may be passed between the shoe and the toe. Every smith knows what is meant by easing the heels. What I require is a similar easing of the toe. A moment's reflection will reveal the value of this simple expedient when the pain is the anterior region of the foot. When the animal places his foot upon the ground, in such a case, pressure and concussion at the toe is obviated, his weight is borne by the broadest and soundest part of the foot, and some relief from pain in progression is the immediate consequence.

\section{A ROLLING MOTION EXPEDIENT.}

Further, a slight rounding of the shoe from heel to toe, by giving a 'rolling motion' to the foot when in action, and by causing the broadest part of the foot to receive the animal's weight instead of the toe during progression, is also an advantage in bad cases, the value of which will be appreciated whenever the expedient is adopted. Horses given to stumble 
under ordinary circumstances are immensely benefited by giving the shoe this form. It is not a practice, however, that I can recommend for the trotting horse, intended to be driven at the highest rate of speed, as a certain amount of leverage power is necessarily lost by shifting the point of contact with the ground from the toe to the broad part of the foot.

I scarcely need say that the old shoe should be removed and the expanding shoe attached with all the care possible under the circumstances, and the expansion should be gradual, and adapted to the exigencies of the cases. Thorough poulticing is, of course, a prime necessity, to soften the horn and to soothe the pain.

\section{LOCAL BLEEDING DESIRABLE.}

Depletion of the blood-vessels of the affected foot or feet, may be employed or not. It is not, as a rule, an essential proceeding. I must say, however, that I think recoveries take place quicker in extremely acute cases, when about a quart of blood has been taken from each foot before affixing the expanding shoe. This is one of the few cases in which I tolerate bleeding.

\section{CONSTITUTIONAL TREATMENT.}

If the animal suffers much constitutional irritation, sedatives, such as aconite, arnica, belladonna, hyoscyamus, or opium (see Appendix of Forrnulæ) may be administered with advantage; and in extreme cases the same agents may be added to the poultices, applied to the feet. This, however, is rarely required, the relief of pressure given by the expansion of the quarters having an almost magical effect in relieving both the local and constitutional symptoms of pain. Judicious exercise, once, twice, or three times a day for short periods, suitable to the exigencies of the case, as it promotes the circulation s. of new blood through the foot, will restore a healthy tone to the tissues in a surprisingly short time. The foregoing is an outline of the treatment I have found to be as far ahead of Mr. Broad's special treatment, as that gentleman's is in advance of the ordinary professional routine, implied in the phrase "antiphlogistic ineasures to the fullest extent." See Chronic Laminitis. 


\section{CHRONIC LAMINITIS; CHRONIC FOUNDER; PUMICED FOOT.}

\section{AUTHORIZED ERRORS COMBATED.}

There is no material difference in the pathological conditions implied by these terms. The two first are the technical and common designations for the same conditions. The third expresses an external characteristic of the sole of the foot which in most cases is the result of an acute attack of laminitis, or it may be produced by the gradual displacement and descent of the sole and coffin-bone without the intervention of any very active inflammatory, or other morbid process, whereby the laminal attachments have become preternaturally elongated, ewakened, and eventually separated in the anterior region of the foot. In either case it is the legitimate product of the never-to-be-sufficiently-deprecated process of sole-gouging, frogparing, and all-wall-and-no-sole-supporting errors, in preparing and applying the shoe to the foot.

SUPPORT THE SOLE.

All feet are liable to this morbid condition as long as these errors dominate the practice of horse-shoeing, and, of course, the broad, squatty foot of the heavy, cart-breed variety, is peculiarly liable to lameness from the foregoing causes. I can not, however, conceive of any foot whatever being liable to it if the sole is supported upiciards, the frog allowed to press downwards and the quarters kept wide. This principle applied to shoeing will prevent the flattest of feet from becoming convex or bulging at the sole, whether applied before or after the onslaught of laminitis. The smith can easily prevent it, and the "doctor" may readily cure it. Nothing is easier for either if the true principle of shoeing is adopted in one case, and a rational rule of practice applied in the other. "Support the Sole" should be equally the maxim of the smith and the doctor. Superadded to this, in the mind of the latter should be. force it back if it comes dorin. 
I have heard it stated by a very high authority, that it was preposterous to suppose that the coffin-bone could be re-instated in its former position when rupture of its laminar attachments had taken place. "Once there is a disconnection between the yorny and sensitive structures, there is no possibility of restoring them to their normal healthy condition;" and I thought so too until I was able to demonstrate otherwise.

It is to be regretted that the 'highest authorities' are not altogether exempt from a liability to error, as the inconsistencies of their utterances with demonstrable facts, occasionally prove. I do not say that every case of pumiced foot can be restored to normal healthy conditions, but I do say, that recent cases of displacement and descent of the coffin-bone, even after the toe of the bone has become visible, and a wide fissure exists between the bone and the wall, replacement of the bone to its proper place is not only possible, but easy of accomplishment, by simply counteracting the local causes which produced the lesion.

A DEMONSTRABLE FAC'T.

I have now to state a fact of practice which will surprise many; and were it not a fact of much practical importance and value in the treatment of such cases, I should prefer to withhold it, as I know it will be doubted by some, and scouted by others as a "coinage of the brain," etc. It is this, that when the sole has descended, and the toe of the coffin-bone has protruded through the sole, the re-instatement of the bone and the sole may be facilitated by expanding the heels, and lowering the frog, even though the foot be a flat one, and it would appear as the height of folly to do so.

\section{THE WHY AND THE WHEREFORE.}

The view which I have given elsewhere of the correlative relations of each part of the foot with its opposite, will clearly explain the "why and the wherefore" of this. I may re-state this view, thus: as the descent of the sole is always accom- 
panied by the ascent of the frog, the closing in of the quarters, and by increasing the area enclosed by the anterior and anterolateral parts of the wall; so the requisite means being taken to force the sole upwards, and to expand the quarters, the ascent of the sole is followed by a descent of the frog, the widening of the quarters, and a dininution of the space enclosed by the anterior and antero-lateral portions of the wall.

\section{COMMON SENSE SHOEING THE DESIDERATUM.}

Such is the present state of general information upon the subject of shoes and shoeing, and their relations to the production or prevention of diseases of the feet of horses, that thousands of these "noble quadrupeds" are to be found in this chronic condition, in its different stages, who are suffering an incalculable amount of misery, which for the most part, is absolutely preventable and curable by one and the same means, namely, a common-sense method of shoeing. The incurable are the old confirmed cases of pumiced foot, and I am not certain that a large percentage of these would not yield to a persevering application of the principles upon which the more recent cases are recoverable.

HOW TO SHOE THE PUMICED FOOT.

The following are Spooner's directions for shoeing a pumiced foot, which in old cases I cannot improve:

"The assistance of the leather sole and the bar shoe is called for in these cases; the former for the purpose of diminishing concussion, and protecting the sole; the latter for affording pressure to the frog, and thus enabling it to relieve the crust by supporting a portion of the superincumbent weight. Unusual care, however, is necessary in the application of the sole, and the arrangement of the tow and stopping under it, in order that there should be no undue pressure at any particular part. Equal care, too, must be exercised in driving the nails, in consequence of the thinness of the horn, and for the same reason they should not be too large, although it is necessary that they 
should be more numerous than common, on account of the greater weight of iron to be attached to the foot. If the shoes be not worn out, they should be allowed to remain on longer than the usual time."

\section{NAVICULAR DISEASE.}

CAUSES AND SYMPTOMS.

I am convinced that this disease in its pronounced and advanced form is not nearly of such frequent occurrence as it is generally supposed to be. Its prominent symptom is progression upon the fore part of the feet, and a peculiar action that betrays an unwillingness to let the posterior part come into contact with the ground. This symptom is the most easily distinguishable when the animal is going up or down hill. Upon rising ground the animal often goes as if nothing ails its feet, but as soon as it travels down-hill, it evinces a painful condition of the feet of a decided character, and a tread upon a small stone will cause it to stumble badly, and perhaps to fall. The difference also between its progression on hard or soft ground is equally manifest.

As a rule its progress and development is coincident with the gradual co-arctation or closing in of the upper or lower diameters of the hoof, and especially the lower or perhaps both in some instances, the causes of which have been fully discussed elsewhere in this work. I regard its production by accident or a false step as of very exceptional occurrence. An occurrence of this nature may cause this disease in the hind foot or feet, but it never occurs in those feet unless from accident. This condition is commonly associated with a condition of the frog that appears as if it were drawn up into the centre of the foot to be out of the way of the ground.

The temperature of the foot as a rule is increased after exertion in this disease, and, after standing in the stable for a short time, after being at an elevated temperature, I have found such feet to be abnormally cold. The blood taken from the 
foot at this time would be very black and cold, affording evidence of venous congestion. I regard unequal temperature under equal conditions as a very suspicious symptom, if not absolutely diagnostic of this disease.

\section{RHEUMATIC SYMPTOMS}

and those of this disease are so similar that one is mistaken frequently for the other. The animal appears lamer in one foot to-day and in the other to-morrow, and so on, as in rheumatism. That unrelieved pressure of the hoof upon the sensitive structures within it should produce a great variety of lesions, sometimes of the bones, especially the navicular bone, and at others of the synovial membrane; and again of the flexor tendon by weakening its attachment to the coffin-bone, and in short predisposes all the sensitive tissues to take on specific lesions, varying according to the idiopathic tendencies or proximate local causes I have not the shadow of a doubt. Cases of a purely accidental nature excepted, I cannot imagine the existence of navicular disease where there is no contraction. I believe if all feet were shod properly we should scarcely hear of a case in a few years and any hereditary tendency that might exist would be rapidly eliminated.

I have absolutely cured so many cases of diseased feet that had been pronounced by good general practitioners to be the subjects of navicular disease, that I never consider a case to be one of that character until I have had it under treatment for three or four weeks, when if I cannot have effected a very marked improvement, I consider such a case to be one of advanced and probably incurable navicular disease. Out of hundreds of such cases I have not found more than two that I could so regard. I am therefore led to consider that this latter disease is much more rare than it is generally supposed to be.

The true character of the disease will soon be revealed by the fact that some good but not much is effected by softening and expanding the foot. This process will always ameliorate when it cannot cure, and gives the animal the best possible 
chance for the beneficial application of further remedial measures.

\section{ITHE MODUS OPERANDI OF TREATMENT}

is precisely the same as in simple contraction with which morbid condition, I repeat my conviction, it will be found to be identical in a vast majority of such cases.

\section{RINGBONE.}

\section{ETIOLOGY AND PATHOLOGY.}

The following presents in brief outline my views of the etiol. ogy and pathology of this diseased condition. Abnormal contraction of the quarters; the wasted frog tissues; the elevated margins of the great sole fissure; the unnaturally upright pastern constitute the sequence of causes that produce disease in the bones of the navicular joint, of which the os coronis is the superior in point of position. Like all other morbid conditions, especially of the bony structures, there may be in some cases a constitutional tendency to their production under favoring local conditions. What more favoring conditions could be imagıned for the production of Ringbone, with or without any congenital tendency, or "Ringbone diathesis" as it is technically termed, than morbid contraction and its sequent causes?

\section{TREATMENT OF RINGBONE.}

When Ringbone is detected in its incipient stage its removal is easy and certain, first by treating the foot as for simple contraction and by promoting absorption of the newly effused bony matter around the bone. Acupuncturation of the enlargement will effect this in conjunction with the use of either the bi-chloride or the bin-iodide of mercury. See Preparations in the Appendix of Formulæ.

Any enlargement of the tissues adjacent to the superior margin of the wall of the hoof will be accommodated by the ex- 
pansion of the hoof, and thus lameness will be obviated if not present, and removed if it is, since it is the enlargement and pressure of the internal tissures against the superior portion of the hoof that mainly causes the pain upon which the lameness is dependent.

I have treated considerable enlargements in this region by the measures I have indicated with the most satisfactory results. Even the cases of confirmed and chronic Ringbone, attended with lameness, may be so benefitted by adapting nature's boot, the hoof, to the foot, that the lameness can be got rid of where the enlargements are immovable.

\section{OSSIFICATION OF THE LATERAL CARTILAGES.}

\section{ETIOLOGY AND PATHOLOGY.}

This is a morbid condition of these cartilages which is the direct effect of preternatural contraction of the quarters. These cartilages are appendages to the wings of the coffin-bone, and participate in the effects of any lateral pressure which may be exerted against those wings by the contracting and contracted quarters. As already shewn in the anatomy of these structures, they play an important part in the elastic springing arrangements of the posterior portions of the foot, and any interference with the due fulfilment of their functions, will, sooner or later, be manifested by changes in their structural condition. Many examples may be cited of ossification of cartilage in the general animal economy, which are mainly attributable to constitutional tendency, and to old age. Whatever congenital tendency may exist to this morbid manifestation, old age cannot be alleged as a pre-disposing cause in horses from four to seven years old, on whose feet they are as frequently seen as on old horses.

These are examples of a spurious exostosis as they result from the conversion of cartilage into bone, whereas a true exostosis is the production of bone from bone. Manipulation with the fingers and the fact of the predominence of heat in the 
region occupied by these cartilages will enable any one to detect this morbid process in the early stage.

\section{TREATMENT OF OSSIFIED LATERAL CARTILAGES.}

Precisely the same treatment as that indicated for Ringbone will remove both the causes and the effects, and render the animal perfectly sound again. If absolute and complete ossification has ensued, I cannot predicate such a result, but the worst cases can be immensely benefited by expanding the quarters, and giving plenty of room for these hardened tissues. Mercurial applications, too, are beneficial when the animal is not too old. See Appendix of Formulæ for the Preparations.

\section{O R N .}

CAUSES AND SYMPTOMS-THE OLD THEORY.

I used to believe in a very pretty theory concerning the cause and seat of corn until I knew better. According to that theory, the seat of corn was exactly under the wing of the coffin-bone, and the cause, vertical pressure and concussion produced by the combined weight of the animal and the freeveritcal movements of the coffin-bone, hammering and bruising the vascular structures coming between the heel of the coffinbone and the iron heel of the shoe. The elements of the theory were an active and a passive agent, and sensitive tissues suffering between them. The illustration of the theory was irresistable! An anvil, a hammer, the active agents. The iron shoe was the passive agent, the anvil; the coffin-bone represented the active element, the hammer, which was wielded by the motive power of the foot, and the sensitive structures the thing hammered and bruised between them. It seems a pity almost to spoil such a theory, but facts are inexorable; and from a logical conclusion there is no escape, if the conclusion is a sound one.

THE WRITER'S THEORY.

The facts are that the seat of corn is close to the angle of 
inflection, and the position of the wing of the coffin-bone considerably anterior to it, not directly over it; that the movements of the coffin-bone are perfectly natural and considerably raised above the senitive secreting structure of the sole at this part, and there is a febro-elastic pad between the secreting structure and the bone. Free action of the bone implies healthy action, and such action per se could not crush tissues between it and the iron shoe. If we admit that this action might become abnormal, then it would follow that the injured tissues would be those coming directly between the active and passive agents, and such is not the case, for the corn is developed nearly two inches away from the heel or wing of the coffinbone, at the spot where the walls of the angle approximate and unite to form the angle.

CONTRACTION OR LATERAL PRESSURE THE CAUSE OF CORN.

It is not, therefore, vertical pressure which is the cause of corn, but lateral pressure, although when lateral pressure, which is only another name for contraction, exists, and the free movements of the bone are impeded, morbid conditions may be set up between the bone and the sole that would contribute its quota to the general and particular causes of lameness of the animal suffering from such an interference with the free movements of his locomotive apparatus.

The lateral pressure theory, however, explains it all, and the effect of removing lateral pressure knocks the vertical pressure theory and Mr. Gamgee's no-contraction nonsense, both together, at the same time, "higher than a kite."

\section{TREATMENT OF CORN.}

I deem it sufficient proof of the correctness of the lateral pressure theory that if we reverse the condition of contraction, right opposite the angle of inflection, when corn is present; in other words, if we cut out the inner side of the angle, namely, the bar, open the heel, and expand the quarter, lateral pressure is removed. Thus the cause of the condition termed corn being removed the pain abates, and the visible evidences of 
com entirely disappear after a second or third shoeing. This, then, is the rationale of the cure for corn whether it be on one or both sides of the foot.

\section{CONCOMITANTS OF CONTRACTION.}

The cessation of lameness will depend upon the extent to which the muscles of the limb have become involved in the atrophied condition. The attachment of the expanding shoe is the same as described in contraction, the difference being in the mode of preparing the foot. The objective point in the treatment of corn is to remove the angular, and restore the rounded form of the inflection. To do this effectively and promptly, the bar must be cut down upon, freely, and the discolored horn pared away until it is not prudent to proceed further without drawing blood. The wall must be left flush to the shoe, so that when the latter is expanded, the former will go with it.

Depending upon the mildness or severity of the affection, and as before stated, the extent of atrophy of the shoulder and other muscles of the limb will be the time necessary for the elimination of this source of suffering to the unfortunate victim so many false theories.

Usually one or two shoeings are sufficient, but occasionally an unusually bad case may require several shoeings, and stimulant applications to the shoulder, frequently repeated, before corn and its effects can be completely eradicated.

NO BAR-SHOES NECESSARY FOR THE CURE OF CORN.

No bar-shoe of any kind whatever is needed in this process of treatment, and the animal's services can be utilized generally after the first few days, exercise being beneficial to the reparative processes of the muscular tissues of the shoulder.

\section{SUPPURATING CORN.}

Sometimes called "Festered Corn" or "Bastard Quittor," is but an aggravated result of the same general causes that produce the Dry Corn. The immediate cause of the suppurating 
condition is that of sand or gravel getting between the shoe and the sole, just over the seat of corn, and becoming imbedded there, working its way, aided by the weight and motions of the animal, upwards, until it effects an opening for itself upon some portion of the heel or quarter, not unfrequently penetrating through the coronary band. It then takes the name of Quittor. A Quittor from this cause has been called a "Bastard Quittor," to distinguish it from Quittors arising from other causes. This form of Corn requires in addition to other measures, a free opening below and above, but especially below, that all purulent matter may escape downwards.

\section{NOTHING IN THE WORLD}

will facilitate the cure of lesions of this nature equal to expansion of the quarters affected. Read the Article on Quittor for directions to accomplish this. Some extra poulticing may be required to soften and cleanse all the parts involved. After expansion, two or three days are generally sufficient for this purpose. Then discontinue poulticing and apply a dressing of the Compound Tincture of Myrrh and Aloes, or the Compound Tar Ointment. See Appendix of Formulæ.

Redundant granulations, when present, may be repressed with a little Chloride of Antimony applied with a feather. Occasionally, a leather sole, and but very rarely, a bar-shoe is found necessary. The worst cases give me no concern whatever, nor will they any one else, who knows the "houe" and the "why" of the process of direct dilation, as a remedial measure in such cases.

\section{TOE-CRACK AND QUARTER-CRACK.}

\section{ETIOLUGY AND PATHOLOGY.}

The difference between these morbid conditions lies only in differing localities from which they are named.

The quarter-crack has been so often referred to, in the elucidation of normal and abnormal conditions of the feet, that its 
etiology and pathology would seem to require very little comment. There are some considerations, however, connected with these morbid conditions, that render a proper appreciation of these causes of much importance in the study of the various physiological and pathological questions associated with the foot of the horse.

\section{CONTRACTIONISTS AND NON-CONTRACTIONISTS.}

Simple as the causes of these lesions appears to be, the whole veterinary profession is divided into two hostile parties, contractionists and non-contractionists; the latter adducing the quarter-crack, and some of the facts associated with its existence, as a positive and demonstrative proof of the truth of their non-contraction views. The former for want of $a$ missing link in the construction of their argument, and unable to ignore the teachings of the "early fathers" of veterinary science, believe in the contraction of the foot, functionally and otherwise, without being able to explode the fallacy which gives countenance to the opposite view.

The non-expansion seems to have been a necessary accompaniment of no-contraction doctrine, as the adoption of the latter has led to the extravagance of the former notion.

\section{SOLID PROOFS WANTED; NOT FALLACIOUS ARGUMEN'IS.}

The no-contractionists declare contraction as a morbid condition, and functional contraction and expansion an "ignis fatuus;" "a myth;" "a coinage of the brain;" "a chimera;" "a phantom of the imagination;" and so forth.

And upon what ground do they thus dogmatize upon the questions of functional and phenomenal conditions of the foot, and stigmatize as visionaries the ablest writers, upon the foot of the horse, for the last three quarters of a century? What reasons do they advance, when they ask us to reverse conclusions that rest upon the basis of fact, of universal observation and experience? Simply "this and nothing more" having even the shadow of a reason, a false interpretation of the rationale of a quarter-crack! The no-contractionists draw 
their conclusions from false premises believing them to be true. They have fallen into the very common error of reasoning from the particular to the general and mistaking exceptional and abnormal conditions for those of a natural and healthy standard.

Here is the argument as they present it: "The existence of a crack in the quarter is the invariable result of expansion; then if the result of expansion, it cannot be caused by contraction; therefore there is no such thing as contraction." This is the gist of the so-called argument against contraction in any sense as commonly understood.

\section{THE TRUE RATIONALE OF QUARTER-CRACK.}

In stating what I consider to be the true etiology and pathology of quarter-crack, I shall be at the same time exposing the illusive character of this argument. I regard the sequence of causes as follows:

Weakening the sole generally has the effect of weakening the lateral support of the quarters, which facilitates their wiring in at the lower circumferent margin, posterior to the wings of the coffin-bone. This wiring in diminishes the area of frog-pressure at the lower circumferent margin, but increases it at the upper margin, from whence the quarter-crack invariably starts.

This "wiring in," "falling in," or "contraction" of the quarters at this part, produces a gradual approximation and elevation of the margins of the great sole fissure, and therefore the whole of the frog tissues, sensitive and insensitive, become correspondingly elevated. The frog-tissues thus elevated creates a depressive force at the anterior portion of the sole, which results in preternatural expansion around the region of the toe and under certain favoring conditions the wall at the toe splits, and we have the condition called toe-crack.

\section{CENTRES OF ROTATION, OR MOTION.}

The view which dominates my own mind, and which I find it more easy to demonstrate upon the foot of the horse than to convey either in written or spoken language, has reference to 
the correlative movements and conditions of the various parts of the foot, whether they be normal or abnormal, active or passive.

The whole body has a centre of motion, around which every part of the entire system is perpetually playing and balancing itself. Like the oscillation of a weighing beam, the elevation of one end is accompanied by the depression of the other. I extend this view to each limb, and to each section of a limb, during progressive movements, and finally I carry it into the comparatively passive conditions and relations of the various parts of the foot, whether functionally employed or otherwise.

\section{CORRELATIVE MOVEMENTS.}

Thus I regard the fore and hind, and the upper and lower parts of the foot, as having a counter-balancing and reciprocating effect upon each other. Each and every part has its opposite. Whichever part is elevated, its opposite is depressed; and whichever is expanded, its opposite, or correlative, is contracted. In one respect, at least, there is a three-fold relation of this nature in the foot of the horse due to the peculiarities of its structure. For example, contraction at the lower margin of the posterior quarters, not only produces expansion at the margin of the quarters where the quarter-crack takes place, but causes expansion at the toe where toe-crack occurs.

Thus the same cause that starts a crack in the hoof, on its upper border posteriorly, starts it on its lower border anteriorly, that is to say, at the toe.

\section{RATIONALE OF TREATMENT.}

Conversely if you take a foot with a quarter or toe-crack, and expand the lower posterior quarters, the upper posterior quarters will become contracted in its marginal outline, and the edges of the crack will approximate, and if kept expanded they will not separate, and the crack will disappear, not by the positive union of its edges, but by the process of growth from its respective secreting organs. This is equally true of 
the crack at the toe. Judicious mechanical expansion of the quarters will close a toe-crack, as well as a quarter-crack, in the most effective manner, no fissure made by knife or firingiron being necessary to prevent the extension of the crack. In this case "the cause being removed, the effect ceases."

\section{A SINE QUA NON.}

The application of the shoe in Quarter-crack is precisely the same as in Simple Contraction, but there is a difference in the preparation of the foot. The bar and posterior sole should be cut down upon freely, and the heel, on whichever side the crack exists, should be opened in order to allow the affected quarter to open out well under the pressure of the dilator. It is also a sine qua non that a nail should be got in posterior to the crack, and if the crack extends from the top to the bottom of the quarter, one nail-hole should be punched so as to admit of a nail passing through the wall transversely to the line of the fracture.

\section{AN EXPLODED FALLACY.}

The inner quarter is the most subject to fracture as it is always the thinnest and weakest portion of the whole wall, and therefore the first generally to contract upon its lower, and to yield to the lateral pressure upon its upper margin. Some attribute the extra liability of the inner quarter to fracture, to the fact that its position is nearer or more under the centre of gravity than the outer. The analysis of the causes I have given, leaves this hypothesis out in the cold. I have no use for it in this place. It has done duty for a learned reason long enough, and has been relegated by me long since to the limbo of exploded fallacies. The causes can be fully demonstrated, and what is of still greater consequence, easily removed, without its, to me, questionable influence.

I have some respect for the teachings of nature in anatomical construction, and for myself am satisfied that if nature had designed the inner quarter to sustain more weight than the outer, she would have made the inner quarter the stronger instead of 
the weaker of the two. The relative strength of the inner and outer quarters have an obvious relation to their capacities for resisting lateral, rather than those of sustaining vertical pressure. These have been so fully discussed elsewhere, that I need not extend their discussion further here. I deem it to have been conclusively shown that contraction is primarily, and expansion secondarily concerned in the production of fissures in the various parts of the hoof, and that those who assert to the contrary are not yet sufficiently instructed in, or have not fully investigated the economy of the foot of the horse.

THE QUARTER BEFORE-THE TOE BEHIND.

Fissures in the quarters of the hind feet are very rare; the toe is the most frequent seat of this lesion. The motive forces are chiefly concentrated in the toe of the hind foot; consequently this part is subjected to greater strain than the toe of the fore foot where these conditions exist in a much less degree, and hence the greater frequency of toe-fissures behind than before. A powerfully predisposing cause in all cases is a brittle and unyielding condition of the horny wall.

THE CAUSE-PAR EXCELLENCE.

The proximate, exciting cause, in all cases is, par excellence a morbid contraction of the hoof at points that obstruct the functional expansion and contraction of the quarters, and causes a morbid expansion of parts that are not designed to expand, except in a very minor degree.

\section{WHAT TO DO, AND WHAT NOT TO DO.}

A few further observations may supplement the treatment already indicated.

A very severe crack in the toe or quarter may require a rivet or a nail to keep it sufficiently close while growing down; although of hundreds of such cases, I have never met with but one that required it during the last five years. 
Remove foreign substances before closing the fissure; but on no account bevel the edges of the fissure, nor introduce the knife or cautery into the fissure, nor make any internal incision at the extremity of the crack, nor use a ligature of any kind; but simply approximate the edges by gradual expansion of the quarters, and keep on a shoe that you can expand whenever the case appears to require it, and to keep the crack closed while it is growing down and out.

Removing the external exposes the internal edges to atmospheric influences. The latter are apt to become dry and curl up, and set up a new source of irritation if they should happen to be unprotected for a day or two, and may prolong the period assigned for the cure indefinitely. The hoof should be poulticed for a few days prior to and following the operation.

Rapid obliteration of the crack can be best promoted by keeping the coronary ligament stimulated. (See Hoof Stimu ulants in the Appendix of Formulæ and the whole hoof in a moderately moist condition.) In a few weeks, even the coronary ligament, if ruptured, will have become united, and a new and continuous circle of horn will have formed, and in from nine to twelve months, depending on the care taken of the case the whole of the crack will have disappeared and an entirely new foot of normal dimensions will have taken the place of the old one. I can cure a majority of all cases within a fortnight, and an acute professional examiner not previously aware of the existence of a crack in the quarter, would have to make a very close examination to detect it, and it would escape the notice a less acute one altogether.

\section{FALSE QUARTER. SHELLY FOOT. SEEDY TOE.}

\section{FALSE QUARTER}

is the result of an injury to the coronary ligament, which may be caused by a solution of continuity of the ligament as a consequence of severe Quarter-crack, or the ravages of a Quittor, or other severe injury to the ligament in that region. It may be 
so slight as to present a mere line resembling a fissure, or the whole quarter may be an imperfectly formed one from the selfsame cause, namely, interruption or suspension of the process of secretion, by which the fibrous portion of the wall is secreted. We may have, therefore, the semblance of a crack without the reality of one; or a part, or the whole of the quarter in a weak, soft, and almost yielding condition, that can barely afford protection to the laminated structures, and besides, is ill-calculated to sustain the strain imposed upon it by those structures to which it should give support, and from which it derives what little strength or substance it possesses.

\section{TREATMENT.}

If but a mere line resembling a crack is present it is of little moment, excepting that if the causes and conditions that produce Quarter-crack, are present, this line being the weakest part, a crack through this line is liable to occur at any time. This may always be prevented, by counteracting the causes and removing the conditions referred to, by the judicious application of the Dilator, as this, by expanding the area of the bearing surface toward the ground, prevents the internal frog-tissues from pressing unduly upon the lateral cartilages and the coronary band.

If, however, the secreting properties of the ligament have been destroyed, by local lesions or the application of powerful caustics, as is sometimes the case, there is no cure for such a condition, but it can be palliated by removing the bearing of the shoe completely from the affected quarter and distributing it over every other part of the foot.

\section{SHELLY FOOT.}

is a condition of the external wall of the foot in which the outer fortion appears more like a scale or shell, and doubtlessly results from an imperfect secretion of the horny matrix that agglutinates together the fibrous constituents of the wall. That lack of healthy development may be, and usually is the result 
of but a slight degree of abnormal contraction in the quarters, I think needs no labored effort to prove. Regular nailing is very difficult of accomplishment in such a foot. In such feet, the point of the nails should enter the wall at the inner edge, taking a more oblique direction outwards, and not be driven quite so high up as usual; thus giving them a short and firm grip. When the expansion of such feet is intended, Clips as directed in the treatment of Simple Contraction should be used. Under these conditions the new growth of the wall, whether aided or not by stimulating liniments to the coronary secreting structure, will grow down sound, healthy and strong, and the edge of the wall will no longer chip off under the nails, like a piece of mahogony veneer, which is the characteristic of a Shelly Foot.

\section{SEEDY TOE. SPECIAL CHARACTERISTICS.}

This diseased condition of the foot is of much more frequent occurrence in England than in America; I presume for the reason that granite pavements and macadamized roads are in more universal use in the former than the latter country. It is closely allied in its characteristics to the condition called Shelly Foot, yet it has some distinctive peculiarities about it of which the name Seedy Toe is the more expressive designation. It is mainly on the front of the foot that it commits its ravages, and usually begins at the toe. That, like the general Shelly condition of the foot, it is due mainly to defective secretion of the horny matrix which binds the fibres of the wall into a tough and compact mass, and that this is a result of a morbidly contracted condition of the quarters, I cannot entertain a doubt. This view derives support from the fact that nearly, if not, all toe-cracks commence at the same spot as the seedytoe, and, therefore, that the same class of causes may produce the different effects, accordingly as they may be governed by different external conditions. Contraction of the quarters will produce an elevation and disuse of the frog. Disuse of the frog throws more weight upon the front part of the foot, and if the horny sole be weakened as it usually is, depression of the 
sole must follow, causing an undue lateral strain outwards upon the horny wall which is felt most at the toe; and in addition to this the toe is further weakened by the nick for the toe-clip of the shoe, rendering the foot, especially at the toe, peculiarly liable to concussive influences.

I prefer this view of the origin of these cases to the parasitic hypothesis, still, deeming it quite possible that its ravages subsequent to its disorganization may be ascribed to parasitic action. It may be regarded as a species of $d r y$-rot similar to the $d r y$-rot of wood. There is this difference between Shelly-foot and Seedy-toe; in the former it is a thin external layer of the wall that is separated, while in the latter it is the inner or laminated layer that is separated from the body of the wall.

\section{THE GENERAL TREATMENT}

should consist of shoeing the foot in accordance with common sense principles so as to promote the growth of a sound, healthy foot, and this can only be done effectively by restoring the lost functions to the heels, the sole and the wall, by the judicious use of the Dilator. It is advisable to explore the extent of the separated portions, to remove the debris, and arrest any further extension of the separation by injections of oil of tar, turpentine or carbolic acid. Measures of absolute cure must look to the displacement of the old conditions by the substitution of new and better ones, and the production of new and normally fashioned feet. Stimulating applications to the coronet and keeping the hoof under the conditions of moisture and exercise, will promote this end in the shortest period of time that is possible. A run at grass or the freedom of a loose box is almost essential in such cases. 


\section{GREASE (SCRATCHES); CHAPPED HEELS; CAN- KER; THRUSH.}

The

\section{ETIOLOGY AND PATHOLOGY}

of all these diseased conditions are substantially of the same nature. They are diseases of the various secreting structures of the foot, or of its immediate connections. The fetid fluid emanations from these structures, are the perverted and vitiated secretions, which under healthy conditions were requisite for the fulfillment of certain appropriate functions, in providing for the wear and tear of the horny tissues in the latter cases, and of keeping the skin of the heels supple and soft in the former case.

FATTY FOLLICLES AND THEIR FUNCTIONS.

It may not be known to every one of my readers that the entire skin of the animal is kept in a supple condition by an oily secretion which is formed within the skin, through the means of the sebaceous glands, or fatty follicles, and that those parts where there is the greatest amount of motion in consequence of their contiguity to joints, and therefore, liability to stretch, the skin is thinnest, and the fatty follicles are clustered together in the greatest number. In no part of the body are these follicles exposed more to deleterious influences than at the heels. Here they are more exposed to wet and cold, and the effects of accumulations of mud, and neglect; and remoteness from the centre of circulation, than at any other part of the system, and here the motions of the foot and their immediate contact with horn-structure require that they should be kept in the highest state of efficiency.

\section{CROWDING AND DWARFING THE TISSUES.}

That the mildness or malignancy of the diseases depend much upon local and constitutional causes, the result of neglect and bad stable management, cannot be questioned. 
That the chief cause, both predisposing and exciting, is to be attributed to a morbid contraction of the foot, acting mainly upon the posterior part, I think, is equally unquestionable.

Persistent undue contraction of the quarters not only croweds the secreting structures of the horny sole and frog, but involves the sub-cutaneous tissues adjacent to the heels in the general crush.

Crowding of the secreting structures of the foot is no more conducive to healthy exercise of function and healthy nutrition than crowding in other spheres of observation, such as trees in a garden, or plants in a bed. The Chinese custom of encasing the feet of their female children in shoes of iron, has the same effect in kind upon the human foot as the hardened hoof and its iron appendage has upon the foot of the horse.

\section{DIFFICULT TO MISUNDERSTAND.}

I should think the etiology and pathology of these affections difficult to misunderstand, but lest they should not be, I will glance at the chain of causes which connects faulty shoeing with Grease, Canker and Thrush; weakening the sole generally, and opening the heels leads to the falling of the first anteriorly, and the closing in of the quarters posteriorly. The two most important functions of the foot at first are partially, and eventually, totally suspended by the injudicious use of the paring-knife alone. Those usually removed portions should be the solid points of resistance for the spring of the sole within the foot, and the expansion of the quarters when the weight of the animal descends during motion.

\section{THE MACHINERY IS OUT OF GEAR.}

The abnormal pressure created by the altered structure and functions of the horny tissues, produces vascular excitement and inflammation of the tissues subjected to the pressure, which communicates itself by sympathy with, and to, adjacent and subjacent tissues. All the secreting structures in, and around the foot, are affected in a greater or less degree, de- 
pending on various constitutional and other local causes. The stomach, lungs, brain and feet are known to have an intimate connection with each other in certain pathological conditions; and bad stable-management is known to have a powerful influence in producing a bad state of things about both feet and heels. I repeat then, the fetid emanations of Grease or Scratches, are the perverted and vitiated secretions of the Sebaceous follicles around the heels; those of Thrush, of the secreting vessels of the Frog, and those of Canker of the secretories of the sole.

\section{BAD ENOUGH AT THAT.}

There is an important difference hetween Thrush and Canker. The vitiated secretions of the former have a chance of escape through the central frog-fissure, while those of the latter have no way of escape whatever. They therefore remain, and by their eminently corrosive action destroy the connection between the sensitive and insensitive soles, extending by degrees all over the sole. Occasionally the laminated structures become involved in the cancerous onslaught, when it becomes a very serious affair, but when it is confined to the sole, it is bad enough at that.

TREATMENT OF GREASE OR SCRATCHES.

Dilation is nine-tenths of the cure. Mild measures may do for mild cases, conjoined with better stable management. In the Appendix will be found several formulæ that in such cases are used with good effect. Where, however, there is pain, inflammation, swelling, and lameness as there frequently is, and possibly a deep crack or fissure in the bend or cup of the heels, softening the feet with poultices and expanding the quarters constitutes nine-tenths of the cure, The pressure of the quarters removed, the inflammation subsides; the tissues resume their normal size, and having "room and verge enough," the parts quickly resume their healthy functions, lameness disappears and "all serene" is the word once more. The Appendix will furnish medicinal agents that will quickly heal any broken surface of the skin. 
TREATMENT OF THRUSH.

Before I understood the importance of judicious Dilation, I have seen bad cases of Thrush that were deemed incurable and have known them to be destroyed on that account. Since that time I have found every case of Thrush, however bad, that I have met with, susceptible of an early and absolute cure by that process alone, conjoined, of course, with poulticing. Dilalating the quarters will widen the space wherein the frog should find an easy and roomy bed. Give a wasted or thrushy frog room to develop itself and it will soon do so, and a plump healthy-looking frog will soon be seen taking the place of the puny, puckered up, putrid pest of the past.

I cannot imagine an incurable case of Thrush if I have but the means of softening and expanding the foot which is the subject of it. Those who wish to employ medicable measures will find the best known, in the Appendix.

The Dilator and the poultice I regard as the radical remedy for the present, and the positive preventive for the future.

\section{THE ALL-IMPORTANT ADJUNÇT.}

A discharge from the cleft of the frog is not always a result of Thrush. An accidental puncture or wound in that region, from some other cause may be the origin of it. But whatever may be the nature of the injury, there is no more useful adjunct to be found in the removal of all diseased conditions of the foot, than careful and circumspect dilation of the quarters.

\section{TREATMENT OF CANKER OR FOOT ROT.}

\section{SOME CURES CONTRARY TO ALL EXPECTATION.}

Canker, for reasons already stated, is not so readily disposed of as Thrush, especially in its worst forms and advanced stages. Yet I have cured some cases that were so badly cankered that I feared the whole foot would become detached, from the almost universal presence of the "leprous distillment,"-the can- 
cerous emanations. My first object is to arrest the progress of decomposition, and, therefore, of separation of the laminal attachments, and of the connections of the horny and sensitive soles. Under ordinary circumstances it is always difficult to get antiseptic agents to act in a direct manner upon the decomposing tissues within the foot.

In this case it is necessary to pare down the sole pretty freely, to make two, three, or more small orifices for the entrance of the antiseptic agents and the evacuation of the imprisoned products of decomposition.

The quarters should be expanded slightly, even where separation has taken place, for the same reasons that apply to the sole. The foot should be saturated with antiseptics as early as possible, as decomposition must be arrested before re-organization of the tissues can take place. The best antiseptic stimulants I have found to be that of bi-chloride of mercury found in the appendix.

This and a charcoal poultice, will remove all fotor from the foot, and promote a healthy healing action in the affected parts After a few days of this treatment, pressure-genial pressuremust be procured upon the sole by the animals own weight and the judicious packing of the sole with cotton-batting, saturated with stimulant dressings. (See Appendix.)

After a week the shoe should be re-set, redundancies of horn removed, a new diagnosis instituted, and measures taken accordingly upon the same general principles I have laid down. Usually a strong leather sole made of boot-makers sole leather and packing, and drawing on the shoe somewhat tightly, to create pressure all over the sole will be necessary to promote the cure. Usually a newly formed hoof will displace the old shell, and then it is only a question of time and judicious shoeing when the "old shall have passed away and all shall have become new." 


\section{ATROPHY OF THE FOOT. DRY-ROT .}

\section{CONTRACTION BOTH CAUSE AND CONSEQUENCE.}

This is a condition of the foot of the horse occasionally met with. The atrophied foot is usually perceptibly smaller than the comparatively sound one. Such a foot is a "miserable apology" for a foot, and is commonly accompanied by an atrophy of all the pectoral, shoulder, and brachial muscles, in connection with the atrophied foot. Contraction is both a cause and consequence of this state of things. Each has reacted in the production of the other. It is not by any means an incurable condition. The same general principles as are applied to contraction will remove atrophy of the foot when there is no bar in the absolute disorganization of the foot-tissues.

Giving the tissues room to expand and grow will restore the lost functions of nutrition if any thing will. If expansion of the foot will not effect this, nothing will. No treatment will avail the muscles that move the leg if the foot is disordered. Get the foot well, and developement of the muscular tissues named will follow. It may, however, require months of judicious exercise, and external stimulation, to restore them to their normal capacity and action.

\section{ACCIDENTAL INJURIES TO THE CORONARY LIG-} AMENT FROM TREADS, BRUISES, CALKS,

\section{AND QUITTORS}

are most frequent in the winter when the necessity exists for Sharp Calks to the shoes. They sometimes end favorably, and at others become the most intractable of injuries, leading to the destruction of the animal. Pain, lameness, and irritative fever, are the usual accompaniments of these ailments. 


\section{A CALK UPON THE INSTEP}

I have found the most troublesome to treat, from the circumstance that the tendon of the extensor pedis passes over that part and is often lacerated just where it is inserted into the superior process of the os pedis. In such cases the bone frequently gets involved with the tendon, Caries supervenes, and separation of the tendon from the bone would necessarily follow. Such cases may then be considered incurable. When they occur near the quarters they are less dangerous, but they sometimes take on the

\section{CHARACTERISTICS OF QUITTOR.}

The suppurative matter that forms in these tissues is of a very acrid nature, and it eats its way, when it has no way of escape, forming burrows or sinuses in various directions, not unfrequently causing a detachment of the hoof from its connections with the sensitive tissues.

\section{A REMARKABLE RESEMBLANCE.}

I have known a mere tread, giving no external evidence of injury to the feet beyond the gait and manner of moving its leg, almost peculiar to an injury in this particular spot. I say almost, because the movement very closely resembles that of a horse with Stringhalt. It is raised from the ground much higher than usual, and is placed upon it again with as little flexion of the foot as possible. Such cases as these are commonly neglected until too late to effect a cure. The intention, in all cases of this nature, should be to prevent or arrest suppuration.

The chances of safety for the animal depend upon the fulfillment of this condition. The most powerful antiseptics are indicated in the advanced stages. The less powerful may be sufficient in the earlier stages. 
where any inflamimation of the tissues has taken place, and lameness is produced, is the use of the Dilator. Soften by poulticing, and expand the foot as early as possible, and the congestion and inflammation which is aggravated by the unyielding nature of the horny wall, will receive no aggravation from that cause; there will be room for the temporary enlargement of the softer tissues, and the work of reparation will go on uninterruptedly. The practitioner who becomes acquainted with the process of expansion of the foot will experience comparatively little difficulty in the treatment of any of these diseases that admit of a cure.

The shoe used for expanding should have heel-calks proportionately high to the requirements of the case, in order to give relaxation and rest to the tendons and ligaments of the leg. The lesser injuries of this kind yield readily to the application of a mixture of equal parts of carbolic-acid and glycerine. Cases of a somewhat severe nature may require the application of a softening poultice to the affected part, until the inflammation has subsided, and subsequent healing, by healing unguents. I particularly caution against the common practice of rasping the quarters thin, and cutting down, or lowering the wall at the quarters. These are often Fatal MEAsUres.

Get on a shoe and EXPAND THE QUARTERS. The results will suprise you by its rapidly beneficial action.

\section{T E T A N US-L O C K - J A W.}

\section{ETIOLOGY AND PATHOLOGY.}

From "Druitt's Surgery" I have derived the texts for a series of observations regarding the influence of pressure and other causes, upon nerves, and nerve-force, which may prove servicable in our endeavor to elucidate the etiology and pathology of the diseases of the foot of the horse, an organ pre-eminently exposed, and susceptible, to influences of this nature. 
"Tetanus may originate in some disorder of the blood, or nerves, without a wound, when it is called idiopathic. That which is caused by a wound is traumatic." As the foot of the horse is so frequently the subject of the traumatic variety of tetanus, and is especially exposed, and susceptible, to disorders of the blood, and nerves, from pressure of its horny envelopement, may we not, more frequently, regard the blood and nerve disorders of this organ as the source at least of some of the idiopathic forms of this disease met with in veterinary practice? And further, may we not, with possibly good results in all cases of supposed idiopathic tetanus, proceed to treat the feet in the same manner that I shall recommend for adoption in all cases where traumatic tetanus is distinctly traceable to a wound of the foot?

"Tetanus may be caused by wounds and external injuries of every description, but especially by lacerated and punctured wounds of the hands and feet; wounds irritated by foreign matters, or in which nerves are exposed.

"It is probable, however, that in most instances some concurrent or predisposing cause, in addition to an external injury, is required to produce tetanus. Of such causes, the best established are, first, an irritable state of the gastro-intestinal mucous membrane ; and second, exposure to cold, damp, nightair, especially during warm weather.

"The same causes, cold and visceral irritation, which predisposes to the traumatic, may of themselves produce the idiopathic tetanus."

\section{MYSTERIOUS INTERTRANSMUTATIONS OF DISEASE.}

If the veterinary pathologist will here recall the doctrines and facts relating to the sympathy that exists between the skin, the mucous membranes of the lungs, and the abdominal viscera, and then add those of the feet to this list of sympathetic tissues, he will not find it difficult to perceive the feasibility of the view I have entertained for some time, namely, that in certain conditions of the nerve structures, and forces, of the foot 
of the horse, induced mainly by external causes, the principal of which is undue pressure exerted by its horny investment, there exists a predisposing cause to visceral irritation, both thoracic and abdominal, and thence to the skin,-or the order of causation may commence with the skin or either of the visceral structures, and end in the feet through the medium of the excito-motory or the sympathetic system of nerves, or, perhaps, both conjoined; and that thus, those mysterious intertransmutations of disease, termed metastasis, may in some rational manner be accounted for.

\section{THE FACTS OF PATHOLOGY}

indicate an intimate connection between the external skin and the internal mucous membranes. Cold in the former produces functional derangement in the latter, and vice versa. Functional derangements of the latter will produce manifestations of disorder in the former. The removal of the cause or causes in one, will induce a cessation of the effects in the other.

Let it also be remembered that the foot is made up of the same materials as enter into the composition of the skin and we shall have no difficulty in conceiving of the sensitive structures of the foot,-its secreting papillæ, and its whole nervous organization, as involved in the general mutual sympathy that exists between the external skin and all internal mucous membranes.

CONCURRENT OR PREDISPOSING CAUSES.

Moreover, the legs, and especially the feet of horses, being the furthest situated from the nerve and circulating centersthose parts, and particularly the feet-are more exposed and liable to the effects of a cold and humid atmosphere than other parts nearer the centers of circulation and of nerve force. Add to these considerations the fact that the iron appendage to the horse's foot is a rapid conductor of heat, and that in very numerous instances horses have to stand upon a cold, 
stone pavement, which circumstance, in conjunction with a thin weak sole, and probably an acclivity of the floor of the stall to stand against rather than upon, more fatiguing in its effects than a moderate amount of ordinary labor, and I think we have reasons, many and sufficient, for regarding a disordered condition of the blood and nerves of the feet as a frequent source of visceral irritation and per consequence, of many cases of idiopathic tetanus.

With such "concurrent or predisposing causes" in almost perpetual existence to diseases of the nervous system, and to maladies of the visceral organs,-and the tegumentary system together with their sympathetic relations, is it any wonder that cases of idiopathic tetanus should arise out of these morbid conditions, without the stimulus of an external injury, or that traumatic tetanus should be.so frequently the sequela of a puncture in the foot?

Since the adoption of this practice I have never known a case of tetanus to supervene upon an injury of this nature when I have had charge of the treatment from the beginning. Several cases of tetanus that have been placed under my charge, in mules and horses, after the tetanic spasms have set in, and known to have had a recent wound in the foot-have come out right, but I attribute this result to the process of cutting down upon the wound, applying narcotic poultices and above all to the free use of the dilator, rather than to any constitutional measure of treatment.

AN INVALUABLE ADJUNCTIVE MEASURE.

If general facts accord with my own experience, punctured wounds of the foot are the most frequent source of tetanus. Before I practiced dilation of the foot I have known some cases to terminate unfavorably under ordinary treatment, and some to take a considerable period to get well-and an occasional one eventuated in tetanus, from which I never knew one to recover. 
Since practising dilation my estimate of the value of this process of treatment as an adjunctive measure in all cases of wounds and injuries to the fect, even in cases where tetanic symptoms were fully manifested, may be learned from the following statement :

In all cases of injury to the feet placed in my charge for treatment, I soften and dilate the quarters, more or less, according to circumstances and the nature of the case. I practice this general measure upon the principle that, in any case, it can do no harm, and in some cases it may prevent tetanus - the constant dread of the veterinary practitionerfrom supervening. Its direct benefits, in the majority of cases, however, are so plainly manifest in facilitating the healing processes-in conjunction with purely medicative measures of treatment, that I have but little or no confidence in any plan of treatment without it.

\section{STRINGHALT.}

\section{A MYSTERIOUS MALADY.}

I propose to record some observations which I have made in the course of my experience upon a somewhat barren topic. This subject has engaged the pens and baffled the acumen of such pathological investigators as Professors Spooner and Sewell, and Percival, Blaine, Youatt, Goodwin, and Busteed, of New York, besides some other of lesser note.

I do not suppose that the small item of observation which I wish to record will amount to anything more than a suggestion, or clue, which others as well as myself may follow out who may have opportunities for experiment and observation. The paucity of the information we possess as to the true origin and seat of this malady and its supposed absolute remediless character, may sufficiently excuse the smallness of the donation.

Writes Professor Varnell, "There is a mystery about the malady, which, for the present, is darkened over with a heavy mist, that requires considerable research to clear away." During 
my noviciate at the Royal Veterinary College, it was my privilege to witness numerous dissections of Stringhalt subjects, and presumably to learn all that was then known upon the etiology and pathology of that disease.

\section{NOTES AND QUERIES.}

The following is the substance of some of the notes which I took of the lectures by Professor Spooner upon this subject. They may prove interesting to the student of hippedo pathology. There is a vital contractile force in involuntary muscles which is entirely independent of, and distinct from the force which is subservient to the influence of the will. Mechanical pressure alone would produce pain. Stringhalt as a rule only affects the hind extremities, although Professor Spooner has seen an instance of a peculiar jerking action of one fore-leg, which he considered to be a true case of Stringhalt.

\section{PECULIAR MECHANISM OF THE HOCK-JOINT.}

The mechanical construction of the astragalo-tibial articulation, the principal articulation of the hock joint, explains in some measure the jerking action peculiar to, and diagnostic of, this disease. One effect of the peculiarity of this construction may be observed when a horse lies down. The hock joints are flexed to a certain extent, and then the animal falls down suddenly. He cannot, if he would, let himself down gradually, and his rising from the ground is always with a sudden springing movement, or jerk. This peculiar mechanical contrivance can be equally well observed in the dead subject, by dissecting away" everything but the lateral ligaments of the joint which hold the articulatory surfaces of the joint in close apposition. The joint movements being effected by the hands, they will be found to move in one direction with a jerk and snap movement. The mere mechanism of the movement is therefore readily understood in this manner. From this mechanical peculiarity it is deduced that the power or force that acts, as the natural 
balance or controling force in natural and healthy action, is more or less overcome or destroyed altogether in a condition of disease, and this apparently spasmodic action becomes involuntary and permanent. It is thence inferred, that this controling force has its origin in the substance of the muscles that antagonize the muscles that lift and extend the foot. These are the gastrocnemii muscles whose powerful tendon passes over the point of the hock.

Thence, it is inferred that weakness or partial paralysis of these latter muscles, or any portion of them, would allow of that jerking action of the joint to go partially or wholly unantagonized, or unregulated. The peculiar jerk which indicates Stringhalt is involuntary in its character, and there is no evidence of pain to the animal or uneasy motion to the rider. It is not a lameness therefore which is a consequence of pain. Professor Spooner has known cases in which after a severe run with the hounds, the symptoms have been more severe for a time. In most cases Stringhalt comes on gradually, but it does sometimes make its appearance suddenly.

\section{DOES STRINGHALT CONSTITUTE UNSOUNDNESS ?}

Undoubtedly, it is a disease, and therefore unsoundness. Is it due to an exalted action of nerve force, or to the opposite condition? In other words, is it due to spasm or paralysis? $\mathrm{Mr}$. Spooner at one time believed it to be due to the former cause, but he now ascribes it to the latter.

\section{PROFESSOR SPOONER'S HYPOTHESIS.}

The following is the hypothesis upon which his later view is based. Muscular tissues possess a capacity for storing nerveforce. During rest these tissues accumulate this force which forms a reserve supply for extraordinary occasions of speed, etc. That muscular tissues are not immediately deprived of the power to act, even when the main supply is as it were cut off. This is considered proved by the muscular contractions which are observable after death, and also by the muscular 
movements which can be excited by galvanism soon after death. That it is a nerve-affection is admitted by all writers on the subject, but what part of the nervous system is the precise locale of the disease is a problem that yet remains to be solved.

\section{PERCIVAL'S OPINION}

is shown in the following quotation. "Those who suppose it to be a muscular affection, mistake, I conceive, the effect for the cause. I choose rather to refer its seat to the spinal marrow, or to the nervous trunks passing between it and the affected muscle." Professor Spooner was not disposed to dogmatise upon a question upon which so little light could be thrown by anatomical investigation. Lesions of the medulla spinalis and of the larger branches of the nerves had frequently occurred when there was no evidence of Stringhalt, and a dissection of the worst cases of Stringhalt had revealed no evidence whatever of a lesion of the nervous trunks or branches.

\section{MICROSCOPICAL RESEARCH}

had also failed to reveal any abnormality of structure. That the disease resulted from a functional disturbance of nerve-force, he thought there could be no doubt whatever. He had found on one occasion a spicula of bone pressing against a nerve in the spine; on another a small abscess pressing against the nerve. He had also found a thorn imbedded in the nerve of a subject of Stringhalt, but as he had found thorns so frequently in other than Stringhalt cases, he attached no importance whatever to this latter circumstance.

\section{PROFESSOR SPOONER'S FINAL JUDGMENT}

of the matter was that the true explanation, if ever it could admit of verification would be that of a partial paralysis of the nerves of the gastrocnemii muscles. These muscles are so arranged that they antagonize or check any undue action each of the other, and thus produce easy and harmonious move- 
ments. But a partial paralysis of the nerve-force of one muscle or set of muscles would permit of an irregular and exalted or spasmodic action on the part of its opposing or antagonistic muscle, or set of muscles. Now the antagonists of the extensor muscles are the gastrocnemii, and hence spasmodic irregular nervous action of the extensors, aided by the

\section{PECULIAR PHYSIOLOGICAL ATTRIBUTE}

of the hock joint already explained, constitutes the affection known as Stringhalt.

\section{DR. BUSTEED'S BELIEF.}

I must not omit to allude to the view taken of the matter by Dr. Busteed, of New York. This observer locates the malady in the astragalo-tibial articulation, where he has found appearances of an ulcerated condition. I do not think, however, the facts and observations upon which Dr. Busteed founds his hypothesis, sufficiently numerous, to characterise them as anything more than suggestions as to a possible cause in some occasional instances.

\section{PROFESSOR SPOONER'S STRICTURES.}

Professor Spooner has stated in his lectures that the apparently abnormal condition observed by Dr. Busteed is by no means uncommon in horses which have shown no tendency whatever to Stringhalt, or lameness of any kind whatever. His explanation of the phenomenal appearance observed by Dr. Busteed is, that arising from severe and protracted labor, or some other cause, there may be a deficiency of synovia in the joint, which would induce attrition in the deep sulcus where this lesion is always found; and that the articular cartilage which is worn away by this attrition being non-sensitive, no inflammatory action ensues, as a rule, admitting possibly of some exceptions. Besides this, inordinate pressure upon the parts deprived of articular cartilage, would produce molecular ab. 
sorption; and finally finding this connection so frequently in horses, both with and without Stringhalt, or even a noticeable lameness of any kind whatever, he negatives

\section{DR. BUSTEED'S CLAIM AS A DISCOVERER}

of the true cause or causes of Stringhalt. The seven isolated cases, which took twenty-three years to observe and record, even in the absence of other explanatory facts, certainly would not afford sufficient grounds for such a claim.

\section{EXPERIMENTAL FACTS.}

The mite of observation which I wish to contribute to the etiology of Stringhalt may be gleaned from the following observations: In the course of practice, when operating for the removal of lameness in the fore feet, I have occasionally had a case that was the subject of Stringhalt. Whenever I have had such a case, I have experimented by softening and expanding the foot of the affected limb; and I have never so experimented without perceiving some benefit from the operation. From these experiments I have been led to think it possible that one of the causes of Stringhalt at least may have its origin in MECHANICAL PRESSURE upon the nerves of the foot, excited, either by the entire hoof, or by some particular portion of it.

\section{A CURIOUS COINCIDENCE.}

If anything more than a very slight injury be inflicted upon the tendon of the Extensor Pedis, particularly at the point where it is inserted into the superior process of the os pedis, by the tread of a sharp calk or by any other accident, the suffering is more severe than when it is inflicted elsewhere upon the tendon, because of the inflammation causing an outward pressure against the superior margin of the wall of the hoof, and because the movements of progression seriously aggravates the lesion. If any doubt should exist as to the precise locale of the hurt, the peculiar manner in which the animal lifts its foot 
and places it again upon the ground in walking indicates unmistakably the precise seat of the trouble. This peculiar manner always reminds me of Stringhalt, it is so very similar to the peculiar jerk in the latter complaint.

I have in former years had much trouble with such cases, and have known some to become absolutely incurable.

Pressure from contraction of the hoof can be excited around its superior circumferent margin upon this very same tendon of the extensor pedis of the hind leg. Too much growth of horn at the toe from keeping the shoes on too long would also produce pressure against the Extensor tendon, and pinch or press it against the Superior process of the pedal bone just at the point of its insertion into that bone. I have been called to examine cases of inscrutable lameness where half a dozen veterinary surgeons had located the source of the lameness in as many different places, but when I had located the possible source of the lameness in the instep, at the very part I have indicated, and after lowering and shortening the toe, elevating the heel, and softening and expanding the hoof, the lameness has all disappeared in two or three days.

Szinging around the circle, as I have done, I have lost the run of my Stringhalt cases, and, therefore, I cannot say if after the lapse of time any of them were permanently benefitted or were susceptible of absolute cure. Here is a case probably, like some others, that falsify the notion, that when causes are removed the effects will cease. Habit, we all know, becomes a second nature, and I deem it likely that the habit of jerking up the leg in action has become of too fixed a nature to be entirely removed even after the original active-cause has ceased to operate.

THE WRITER'S SUGGESTION.

Adopting this view, it is easy to conceive that, supposing pressure upon the nerve-filaments of the foot to have produced Stringhalt, and after it had existed for years, when that pressure has been removed, that habit has much to do with the continuance of the irregular action; in this manner I regard 
the condition termed knuckling. I can readily remove the cause, but I cannot so soon dispose of its effects. The ligaments of the fetlock joint have become elongated and adapted to the requirements of the habit, and an absolute cure on account of this habit is tedious and difficult. Even so, I think, the ligaments of the hock-joint and the tendons of the muscles engaged in the Stringhalt movements, have become adapted by gradual and persistent abnormal tension to the perverted action of the muscles. Certainly, there is nothing in this view of the possible cause of Stringhalt to conflict with the views of Professors Spooner, Percival, and others who considered it a disease of the nervous system, but who probably never extended their inquiries beyond the leading trunks and branches, not suspecting that it may have been caused by irritation of the peripheral nerve-fibrillæ in the remote region of the foot. This view, I think, may derive some countenance from the fact that tetanus is also a disease of the nervous system, and that the most frequent cause of this complaint is in connection with injuries to the feet. See the Article on Tetanus. 


\section{SUMMARIZED STATEMENT OF THE AUTHOR'S THEORY.}

\section{SUMMARY OF CHANGES.}

In this summary of changes that take place in the form and functions of the foot of the horse may be perceived the conditions out of which not only Laminitis, and Navicular Disease, but every other specific lesion of the foot may arise.

\section{INCIPIENT CONTRACTION}

produces impaired action, by undue lateral pressure of the wings of the coffin-bone, impairment of natural action being in proportion to the intensity of pressure.

\section{ADVANCED CONTRACTION}

causes undue pressure upon the lateral cartilages besides the pressure on the wings of the coffin-bone. The rotary and other movements of the foot within the hoof are thus impeded; attrition first, and subsequently, inflammatory action in the tissues, eventually leading to

OSSIFICATION OF THE LATERAL CARTILAGES.

\section{LAMINITIS}

both chronic and recent, is the necessary sequent of an unsupported sole, by causing abnormal straining and morbid elongation of the laminæ. These causes gradually weaken the laminal attachments, and very frequently lead to their disconnection in what is commonly called Founder, and descent of the coffin-bone, producing the condition termed 
both chronic and recent, is the product of contraction, which is associated with an ascended frog and uired in quarters. The result is a loss of substance and functions in the frog-tissues, and concussion to the bony constituents of the foot, whereby other specific lesions of the tissues composing the joint are directly or indirectly produced.

\section{RINGBONE}

is also the result of concussion, occasioned by the diminution or destruction of the elastic properties of the foot, induced in the first instance by contracted quarters, and a predisposing conformation of the pastern joint.

\section{CORNS}

are the products of lateral pressure, which gradually converts the naturally rounded inflection at the junction of bar and wall into an angular one; the vascular and nerve-filaments becoming crushed between the sides of the angles near its point; pressure on the nerves producing the pain and lameness; and the rupture of the vessels causing extravasation of their contents into the horny sole at this spot.

\section{QUARTER-CRACK}

is invariably the result of that inverted order of things, whereby the quarters are contracted, which prevents their due expansion, when weight is thrown upon the foot in motion; and are expanded where they ought rather to contract; and hence the hoof splits from internal lateral pressure exerted in the wrong place.

\section{TOE-CRACK}

is caused by the tendency of the toe to expand, when and where it ought not to, in consequence of its reciprocal relations to the heels and quarters. 
FALSE-QUARTER, SHELLY FOOT, SEEDY-TOE, SCRATCHES, THFUSH OF THE FROG, AND CANKER OF THE SOLE.

These morbid conditions of the foot of the horse, are the products of perverted, or vitiated secretions, arising from partial or total suspension of the secreting organs; the general cause of which being an unduly contracted hoof, and the particular and proximate cause, direct pressure upon the organ or organs more immediately involved.

\section{GENERAL ATROPHY OF THE FOOT}

is the result of the same general cause, acting more equally over the whole of the foot, namely, morbid contraction, interfering with the vital processes of development, of nutrition, or of both.

ALL ACCIDENTAL AFFECTIONS OF THE FEET, SUCH AS TREADS, BRUISES, INJURIES FROM CALKING, QUITTORS, SUPPURATING CORNS, PICKING UP NAILS IN THE STREET, INJÜRIES FROM PRICKING, STABBING, CROWDING, ETC.,

IN SHOEING

are all greatly aggravated and intensified by a morbidly contracted condition of the horny structures, which is proved by the fact, that softening and expanding those structures facilitates the healing process in all of them in a most remarkable degree.

CERTAIN CONSTITUTIONAL COMPLAINTS, AS TETANUS, PNEUMONIA, PLEURISY, GASTRITIS, ENTERITIS, GASTRO-ENTERITIS,

AND SKIN AFFECTIONS.

are known to have most important sympathetic and other relations with the internal tissues of the foot. Again, light has been thrown on these relations by the process of mechanical dilation of the quarter, showing, that in a morbid contraction of the horny textures lies the germ of many unsuspected maladies of the horse. 
SWEENY, OR ATROPHY OF THE MUSCLES OF THE SHOULDER, THE CHEST AND THE ARM.

is the almost necessary concomitant of an injury of any kind to the foot. But rarely is this condition due to any direct injury to the shoulder. The best proof of which is, that while the foot is affected, no measure of treatment will effectually remove the morbid conditions of the shoulder, etc., but as soon as the foot is easy, the muscles which govern its action gradually recover their tone and normal dimensions.

CERTAIN ABNORMALTIES AND IRREGULARITIES OF ACTION, SUCH AS STUMBLING, POTTERING, DAISY-CUTTING, SHORT GAIT, BRUSHING, INTERFERING, SPEEDY-CUTTING, KNEE-STRIKING, HIGH: SPEEDY-CUTTING, DROPPING, SKIPPING, HITCHING, HOBBLING, BROKEN-GAIT, OVER-REACHING, GRABBING, CLICKING, FORGING, HAMMER-AND-PINCERING, STRINGHALT

and the rest, can all be modified, and most of them completely changed to normal action, by simply softening and expanding the feet; proving beyond a peradventure, that morbid contraction in some degree or form, is $a$ cause, if not the cause of these abnormalties and irregularities of action. 


\section{CONCLUSION.}

Such a theory, and such a treatise as this book presents, Professor Gamgee declared, ten years ago, had not then appeared "in either the earlier or later times."

The Theory, as I have placed it before the reader, is the necessary sequence of the practical measures that accompany it. It is the result of a large number of operations upon every description of foot, and every variety of the foot-affections of horses. It is based upon no isolated cases, but an accumulation of facts ; facts of practice, experience, and demonstration.

There is nothing far-fetched, or unreasonably conjectural about this theory. It meets every requirement. It is simple, intelligible, and demonstrable.

It is in harmony with the facts of practice, and each is the complement of the other. What more is needed?

I found the practical measure a rough-and-ready one of very limited application, and it has revealed pathologicol secrets to my apprehension, which, as far as I am aware, have been vouchsafed to no other. I now regard it as the key to a science, the true nature of which, when it becomes sufficiently understood, and generally applied, will constitute a boon of no mean order to the equine race itself, and will, I verily believe, enhance in an eminent degree, the value of its services in the general interests of mankind. 


\section{APPENDIX OF FORMULA.}

POULTICES AND POULTICES BOOTS.

Equally important as mechanical dilation, is the process of softening the horny textures of the foot when they are hard and unyielding. To soften effectually the author recommends before all other means and appliances, the use of the

LEATHER POULTICE BOOT.

The best softening agent is flax-seed meal, wrought to the proper consistence by boiling, or hot water, in which a little soap, or lye, or washing soda has been dissolved. Success or failure almost exclusively depends upon the attention given to the softening process.

An occasional bad case of Quittor, Canker, Thrush, Scratches and other diseased conditions where there is much fotor and offensive discharges, may require the use of an

ANTISEPTIC POULTICE.

To the common poultice may be added any one of the following Antiseptic agents:

r. Solution of Chloride of Zinc, I drm. to $1 / 2$ pint water.

2. " Carbolic Acid, I oz. to $x / 2$ pint water.

3. " Corrosive Sublimate, I drm. to I pint of , hot water.

4. Chloride of Lime, in powder, 2 or $3 \mathrm{oz}$.

5. Charcoal, in powder, 2 or $3 \mathrm{oz}$.

6. Yeast, $1 / 2$ pint.

Sometimes there is much pain and inflammation of the soft tissues of the foot and of the tendons and ligaments of the leg 
in connection with it. In severe cases of this nature, it may be desirable to apply to the foot or leg, or to both, a

NARCOTIE AND ANODYNE POULTICE.

To the common poultice may be added any'one of the following ingredients, or even any combination of them :

7. Tincture of Arnica, 2 or $3 \mathrm{oz}$.

8. “ Aconite Root, 2 or $3 \mathrm{oz}$.

9. " "Wormwood, 2 or 3 oz.

Iо. " Camphor, 2 or $3 \mathrm{oz}$.

I . " Opium, 2 or $3 \mathrm{O} z$.

12. Extract of Belladonna, $\mathrm{I}$ oz., dissolved in warm water.

I3. " Hyoscyamus, I oz.

I4. Boiled Hops make a cheap and excellent anodyne agent in a poultice, as also

15. A decoction of Wormwood.

\section{FOMENTATIONS.}

When fomentations appear desirable, as in acute sprains of tendons and ligaments, from Nos. 7 to 13 , either singly, or a combination of them in about equal proporitions, added to an equal or double quantity of hot water, may be used with the very best effects. A rest for the foot in the form of a high heeled shoe is a most important requirement in these cases; and if there is much swelling and inflammation around the region of the coronary ligament, an expanding shoe should be placed on the foot, and the hoof slightly expanded. The soothing and discutient effects of moderately hot water are not to be overlooked. Nos. I 4 and 15 are both powerfully soothing and anodyne in their effects upon painfully inflamed tissues. 


\section{LOTIONS.}

I6. MERCURIUS CORROSIVUS LOTION.

Corosive sublimate, I drachm,

Hot water, I pint.

Useful in the reduction of ring-bones, bone-spavins, splents, side-bones, thickened tendons, etc. For these purposes it should be applied with friction of the hand for a day or two, morning and evening, or until soreness is produced; when its application should be discontinued, the parts oiled, and washed with soap and water daily until the soreness is removed, when the process should be repeated until the object is attained.

I have found this the most useful of all antiseptic and stimulant lotions in Quittors and other ulcerous affections of the foot, such as Grease, Thrush, Canker, etc.

I7. CHLORIDE OF ZINC LOTION.

Chloride of Zinc, $1 / 2$ ounce,

Water, I pint.

A very useful antiseptic stimulant in Quittors, and other ulcerous affections.

\section{IS. ARNICA LOTION.}

Tincture of Arnica, 2 ounces, Water, I pint.

Good in all kinds of injuries from sprains, bruises, contusions, pricks from nails, blows, fractures, dislocations, etc.

The undiluted tincture may be applied with advantage after cutting down upon Corns of a severely painful nature.

19. ARNICA AND ACONITE LOTION.

Tincture of Arnica, I ounce,

Tincture of Aconite Root, I ounce,

Water, I pint. 
Good in the same category of complaints as the last. I prefer to use it moderately hot in very painful and acute cases, keeping the affected parts constantly wet by means of a linen bandage, and giving support to the limb by means of a highheeled shoe, at the same time carefully expanding the quarters where the soft-tissues are highly inflamed and create an evident pressure against the horny textures of the foot.

\section{RHUS TOXICODENDRON LOTION.}

Tincture of Rhus Tox., I ounce, Water, I pint.

I have known this to remove sore and weak ankles when other applications have failed.

After the feet have been expanded, this lotion facilitates the removal of soreness and old rheumatic symptoms from the joints, the best of any, in conjunction with the frequent application of hot water.

\section{GOULARD LOTION.}

Goulard's Extract, 2 drachms, Water, I pint, Spirits of Wine, 2 ounces.

This is an excellent cooling and soothing application where the tissues have become inflamed by severe labor, or from the effects of stimulating applications when injudiciously employed. Keep the parts constantly moist with it by means of a linen bandage.

22. NITRATE OF LEAD LOTION.

Nitrate of Lead, I drachm,

Distilled water, I pint.

Deodorizing and Cooling in Greasy ulcerous sores. 
23. ACETATE OF ZINC LOIION.

Acetate of Lead, I ounce,

Sulphate of Zinc, I ounce,

Water, I pint.

A favorite formula with some, for the cure of Scratches, and for its cooling and repellant properties in general.

\section{LINIMENTS AND EMBROCATIONS.}

Applications of the above nature are sometimes more convenient to use than fomentations, and are preferred by many to lotions. They are especially useful in sprains and bruises, and in cases of rheumatism and enlargement of the pastern or knee joints.

They will be found as useful in the human as in the equine patient.

\section{CHLOROFORM LINIMENT.}

Chloroform,

Tincture of Camphor,

" " Opium,

Of each $2 \mathrm{oz}$.

Olive Oil or Glycerine,

\section{CAMPHOR LINIMENT.}

Camphor, I ounce,

Spirits of Wine, 4 ounces,

Glycerine, 4 ounces.

26. CAMPHOR AND FUSEL OIL LINIMENT.

Spirits of Camphor, 2 ounces,

Fusel Oil, 2 ounces,

Water of Ammonia, 2 ounces,

Tincture of Opium, I ounce,

Tincture of Aconite, I ounce. 
27. CAMPHOR AND CANTHARIDES LINIMENT.

Camphorated Oil, 4 ounces,

Tincture of Cantharides, 2 ounces,

Oil of Turpentine, 2 ounces,

Acetic Acid, I ounce.

\section{CAJEPUT EMPROCATION.}

Oil of Cajeput, 2 ounces,

Camphor, I ounce,

Almond Soap, 2 ounces,

Alcohol, I pint.

Dissolve the soap and camphor in the alcohol first, in a warm bath when nearly cold, add the cajeput oil, shaking the mixture well together until quite cold. This is especially good in deep-seated rheumatism and lumbago.

\section{LINIMENTS AND SALVES.}

For wounds, faruncles, treads, calks, grease, cracks, ulcers, etc., in the region of the foot.

29. CARBOLIC ACID LINIMENT.

Carbolic Acid, I part,

Glycerine, I part,

Olive or Lard Oil, 4 parts.-Mix.

3O. CARBOLIC ACID SALVE.

Carbolic Acid, I ounce,

Lard, 8 ounces,

Add a little wax in warm weather. A crystal of magenta will give color. 
31. LEAD AND BINC SALVE.

Acetate of Lead, $1 / 4$ ounce,

Oxide of Zinc, $1 / 4$ ounce,

Lard, 4 ounces.-Mix.

32. ALUM AND ZINC SALVE.

Alum, I part,

Carbonate of Zinc, 3 parts,

Lard, 4 parts.-Mix.

33: ALUM AND SULPHUR SALVE.

Powdered Alum, I part,

Sulphur, 2 parts,

Lard, 3 parts.

34. LINIMENTS FOR CANKER AND THRUSH.

Pine Tar, 4 ounces,

Molasses, 2 ounces,

Sulphuric or Nitric Acid, $1 / 2$ ounce.

35. Subacetate of Copper, 4 ounces,

Honey, $1 / 2$ pound,

Spirits of Wine, 2 ounces,

Nitric Acid, 2 ounces.

Melt the two first ingredients over a slow fire, and when cooling add the two last.

Apply by means of pledgets of tow or cotton, dipped in either mixture, and procure genial pressure upon the sole, by means of careful packing, a stout leather sole, and a highheeled shoe somewhat "drawn on" to the foot by judicious nailing. 


\section{POWDERS FOR SCRATCHES, CANKER AND THRUSH.}

They should all be reduced to the finest powder, and thoroughly mixed and sifted through a very fine sieve, before application. These powders are also good for wounds generally, and especially in joint wounds, where there is an escape of synovia, it is desirable to coagulate.

36. Carbonate of Zinc, 4 parts, Alum, I part.

37. Alum, 4 parts, Armenian bole, I part.

38. Burnt Alum,

Dried Sulphate of Iron,

Myrrh.-Equal parts.

39. Sulphate of Zinc, 2 ounces, Oxide of Zinc, I ounce.

40. Alum, I drachm, Charcoal, $1 / 2$ ounce.

4I. Burnt Alum, Sulphate of Zinc,

Armenian bole

White lead,

Yellow Resin,

Charcoal.-Of each 2 ounces. 
POWDERS FOR CLEANING FOUL ULCERS, AND REPRESSING REDUNDANT GRANULATIONS IF THE FOREGOING ARE NOT SUFFICIENTLY POIVERFUL.

42. Acetate of Copper,

Acetate of Lead.-Equal parts.

43. Sulphate of Zinc,

Alum.-Equal parts.

44. Red Precipitate, Burnt Alum.-Equal parts.

45. Red Precipitate, Verdigris,

Calamine.-Equal parts.

46. Powdered Quick Lime.

\section{QUITTOR DRESSINGS.}

These should be injected into the sinuses when practicable. On no account rasp or cut away the quarter of the wall affected, but carefully expand it, and cause the affected parts to be thoroughly permeated with the dressing by applying to them pledgets of tow or cotton saturated with the medicinal agent.

47. Bi-chloride of Mercury, I drachm,

Water, nearly boiling, I pint.

Dissolve in any vessel but a metal one.

48. Chloride of Zinc, I drachm, Water, I pint.

49. Sulphate of Zinc, 2 drachms, Water, I pint. 
50. Bi-chloride of Mercury, $1 / 2$ ounce,

Hydrochloric Acid, T/2 ounce,

Liq. Plumbi Diacetatis, I r 2 drachm,

Spirits of Wine, I ounce.

5 I. Sulphuric Ether, I part,

Iodine, 6 parts.

52. Corrosive Sublimate, $1 / 2$ ounce,

Diacetate of Lead, r ounce,

Rectified Spirits of Wine, 4 ounces.

\section{BLISTERING APPLICATIONS.}

For Splents, Spavins, Ringbones, Side-bones, or Bony Enlargements, Thickening of the Tendons, and the Skin, etc.

53. Corrosive Sublimate, I drachm,

Boiling water, I pint.

Prepare and use as before directed.

54. Iodine, I drachm,

Strong Alcohol, I ounce.

Paint over the enlargement with a small brush every two or three days as long as necessary.

55. Biniodide of Mercury, I part, Lard, 7 parts.

The size of a hazel nut to be rubbed on daily. When tender or Scurf is produced, wash the part, and re-apply the Ointment as often as it is found necessary.

56. Corrosive Sublimate, I drachm,

Tincture of Iodine, I ounce,

Oil of Turpentine, I ounce,

Finely powdered Cantharides, $1 / 2$ ounce,

Finely powdered Euphorbium, 1/2 ounce,

Hog's lard, r/2 pound. 
Remove the hair with scissors. Apply with friction. The second day apply oil or lard. The fourth day wash off the scurf and repeat the process until the purpose is effected.

RLISTKRING APPLICATIONS FOR THE CURONET.

Should such, however, be deemed necessary, no better can be found than

No. 56 .

The effects of this blistering compound are not severe, but its potency may be lessened to any desired extent by the addition thereto of hog's lard.

No. $5^{6}$ is a peculiarly valuable preparation, from the fact that the horse will not bite or gnaw the parts to which it is applied. It is also a useful external stimulant to the muscles of the shoulder, breast and arm, in the condition termed Szeeeny.

\section{H O O F D R E S I GS.}

\section{THEIR USE AND ABUSE.}

The writer's views are opposed to the indiscriminate and constant use of Hoof-dressings of whatever character or class upon feet that are perfectly sound, properly shod at regular and proper intervals of time, and otherwise well cared for by being kept clean, dry and cool, while standing in the stable. Greasy, unctuous applications to such feet that obstruct the perspiratory exhalations are, to him, an especial abomination. A small roll of damp cloth, lying loosely around the fetlock, and resting on the skin just over the coronary ligament, will do more to keep the horny wall cool and sufficiently moist than anything whatever that may be applied to the external surface of the wall.

Under morbid conditions, when it becomes necessary to promote the growth of the wall, stimulating applications should be applied to the secreting organs, rather than the secreted structures. Any mild stimulant dressing applied around the cor- 
onet about every other day, or as often as it can be done without blistering the skin, is sufficient to promote the growth of the wall, always provided, the coronary secreting ligament has plenty of room for the due exercise of its functions. This is essential to the growth of perfectly sound horny substance.

The sole and the frog structures are secreted differently from that of the wall. The same conditions of plenty of room for development and the free exercise of functions are just as essential in the former, as in the latter structures. When the full natural dimensions of the outer wall has been obtained by judicious expansion, then, and not till then will the sole and frog become developed, and this they will rapidly do under the influence of their own natural stimulus, namely, exercise; which may be aided by an occasional mild stimulant, dressing or stopping applied to the sole and frog.

Only under a morbid condition of the foot and the plea of ignorance of anything better that can be done can the continued use of Hoof dressings and the water and mud baths be justified.

\section{HOOF DRESSINGS.}

STIMULANT DRESSINGS FOR THE CORONARY LIGAMENTS.

57. Strong Water of Ammonia, I part, Sweet Oil, 4 parts.

58. Cod Liver Oil, Kerosene Oil.-Equal parts.

59. Turpentine,

Camphor,

Sweet Oil.-Equal parts. 
SOFTENING AND STIMULANT STOPPINGS FOR THE SOLE AND FROG.

6o. Soft Soap, 4 ounces,

Pine Tar, I pound,

Flax Seed Meal, 2 pounds.

6r. Common Axle Grease, i pound,

Pine Tar, I pound,

Flax Seed Meal, 2 pounds.

62. Pine Tar, I pound,

Tallow, I pound,

Flax Seed Meal, 2 pounds.

To be worked into a stiff paste, and applied only to the sole and frog after thoroughly cleansing and drying the foot.

\section{HOOF OINTMENTS OR SALVES.}

After long continued poulticing, it may be necessary to discontinue its use. Every part of the hoof, and an inch or two above it, may then be anointed occasionally with any of the following preparations, for the purpose of keeping up the emollient effects already attained:

THE THREE T OINTMENT.

63. Tar,

Tallow,

Turpentine.-Equal parts.

THE T. H. T. OINTMENT.

64. Tar,

Honey,

Tallow.-Equal parts. 
SPOONER'S HOOF OINTMENT,

65. Tar, I pound,

Palm Oil, I/2 pound,

Oil of Turpentine, I ounce,

Sulphuric Acid; I ounce.

Melt the two first; when cooling add the two last.

BOURGELAT'S HOOF OINTMENT.

66. Yellow IVax,

Olive Oil,

Lard,

e

Veal Suet,

Honey,

Turpentine.-Equal parts.

Colored with ivory black.

FLESH AND HOOF OINTMENT.

67. Resin, 4 ounces,

IVax, 4 ounces,

Honey, 4 ounces,

Lard, 8 ounces,

Turpentine, I 2 ounces.

Melt together the four first; when cooling add the last and stir till cold.

FLESH AND HOOF SALVE.

68. Resin, 2 pounds,

Linseed Oil, I pint,

Coal Oil, I pint,

Balsam of Fir, 4 ounces,

Spirits of Turpentine, 2 ounces,

Glycerine, 2 ounces,

Carbolic Acid, 2 ounces.

Dissolve all the ingredients together very carefully. 


\section{CONSTITUTIONAL TREATMENT.}

Severe injuries to the Feet of Horses are sometimes attended by a disturbance of the system variously designated as Systemic Fever, Irritative Fever, Sympathetic Fever, Traumatic Fever, Acute Inflammatory Fever, etc. The pulse runs high, the respirations are rapid, the breath and tongue hot, the skin hot and cold by turns, the urine high-colored and scanty, the bowels constipated, and the appetite impaired. These are the principal phenomena to be observed in this class of Fevers, and, of course, the intensity of the symptoms will accord with the severity of the disturbing causes. These sympathetic manifestations constitute an index to the more or less serious character of the injury. As the wound improves these symptoms subside.

In all foot-wounds, as well as those of the knee and the ischium, the vigilance of the experienced veterinarian keeps him constantly on the alert for the possible supervention of Tetanus or Lock-jaw.

Some discrimination is needed in the treatment of the constitutional symptoms already referred to. If the systemic disturbance be slight the case may be left to nature. If at all pronounced, internal remedies become requisite. Such cases divide themselves into two classes, sthenic and asthenic; the first denoting strength, the last, the lack of it. Cases of the first class are those in which the patient may have been in robust health before the infliction of the injury. He might have been in good or even high condition; or the system may have been gross from over feeding, or there may have been but a slight loss of blood from the injury, and the pulse, it may be, has increased in frequency to 70,80 or 90 per minute, with a 
full, strong and firm beat. Such cases call for depletive measures. In other words a purgative or laxative dose of aloes, and an occasional dose of the chlorate or nitrate of potash will be both desirable and necessary.

Cases of the second class in which the animal has lost much blood, and the pulse is quick, thin and thready, and there is prostration and trembling, and the vital powers feeble, require an opposite course of treatment; repletive rather than depletive measures should be resorted to.

The use of stimulants, such as Brandy, Wine, Beer, Aromatic Ammonia, \&c., which arouse rather than depress the vital powers, are then indicated.

If the animal is very weak, they are best given in gruel, if otherwise, diluted with water. If constipation is present, it should be overcome by frequent enemata of warm soapy water.

In both classes of cases when there is much pain, sedatives may be given with propriety, such as Aconite, Arnica, Belladonna, Hyoscyamus, Rhus Tox., and Opium.

It has been a favorite practice with me to administer the same kind of medicine internally as that I have been using externally.

\section{Doses.}

The doses of the medicines alluded to in the foregoing brief notice, are as follow :

I. Aloes in Solution.-Barbadoes Aloes 3, 4, 5 or 6 drachms in powder, according to size, age, and requirements of the patient. Place in a pint bottle, and add thereto halfpint of warm water in which a little Washing Soda or Saleratus has been dissolved. Shake up well, and administer.

2. Aloes in Ball.-Barbadoes aloes, same as before, but made into a very stiff paste with a little common soap. 


\section{8}

3. Nux Vomica.-After the action of the aloes has subsided the bowels may be kept tolerably regular by Powdered Nux Vomica half-drachm, morning and evening, given in a little water, or on the feed.

4. Chlorate of Potash.-One or two drachms morning and evening may be given on the feed, or in the drinking water, or the animal may be dosed with it dissolved in a few ounces of water.

5. Nitrate of Potash. - Same as the last.

6. Aromatic Ammonia.-The best stimulant when procurable, 4 to 6 drachms in a pint of cold water, twice daily.

7. Brandy in 2 or 3 ounce doses, suitably diluted with water.

8. WINE.-Same as the last.

9. Ale and Beer may be obtainable when other stimulants are not. These may be given in pint doses, without dilution. The addition of a little powdered Ginger or Cayenne Pepper, or both, would be an improvement.

io. Aconite.-Tincture of Aconite Root, 5 or ro drops, either placed on the tongue or given in water or gruel, should be given at intervals suitable to the requirements of the case. This agent must be discontinued as soon as any glucking noise is heard in the throat.

II. ARniCa.-Give the Tincture in one drachm doses, 2 or 3 times a day in 2 ounces of water.

I2. Belladonna is a favorite sedative with me in the following formula: 
Strong Solution of Acetate of Ammonia, I oz.,

Nitric Ether,

Tincture of Belladonna, - - - 2 drms.,

Cold Water, - $\quad$ - $\quad$ - $\quad$ - $\quad$ - $\quad$ - $1 / 2$ pint.

Morning and evening till the violent symptoms abate.

I3. Hyoscyamus.-The same quantity of the tincture may be substituted for the Belladonna in the last formula. Is a favorite recipe with some.

14.-Rhus Tox.-This is an internal homeopathic remedy of great value in wounds of the tendons, ligaments, and ligamentous structures. Rheumatic symptoms usually yield to this agent when properly used and understood. ro drops of the Mother Tincture may be given in $\mathrm{I}$ or 2 ounces of water 3 or 4 times a day with the best effects.

15. Tincture of Opium.-This old-time remedy must not be over-looked. It has rendered good service to mankind, and I use it occasionally with the best results, as follows:

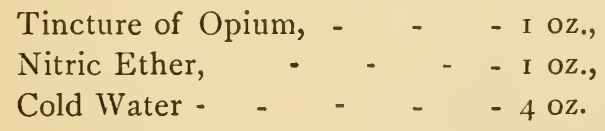




\section{GLOSSARY.}

Abdomen. The belly.

Abdominal. Belonging to the belly.

Abnormal. Contrary to the natural condition.

Absorbent. Sucking up or absorbing.

Absorption. Sucking up.

Abyss. Depth.

Accessory. Muscles that assist the action of larger ones.

Acclivity. A slope or ascent upwards.

Action. A faculty or function of the body.

Acumen. Quickness of perception.

Ad infinitum. To infinity.

Adjunctive. Assisting other remedies.

Adult. Arrived at maturity.

Egis. A shield.

Affection. Synonomous with disease.

Agglutination. A glueing or joining together.

Aggregate. The sum, or whole of several particulars.

Ala. A wing. Applied to parts from their resemblance to wings.

Amateur. A lover.

Ancemia. Deficiency of blood.

Analagous. Applied to things different in their nature, but similar in function.

Anatomy. The dissection of organized bodies.

Animal-economy. All matters relating to animal life.

Anodyne. Medicines which assuage pain.

Articular. Belonging to a joint.

Articulation. A joint.

Astragalus. The principal bone of the hock joint.

Astragalo-tibial. The articulation formed by the astragalus and tibia.

Atrophy. Wasting, or emaciation. Defect of nutrition.

Attrition. Rubbing against, and wearing by abrasion. 
Apex. The point or top of a thing.

Artery. A vessel conveying blood from the heart.

Archiform. Having the form of an arch.

Arcolar. Containing areolic or small spaces.

Aponeurosis. Expansion of a tendon or tendons into a fibrous membrane. Anastomosis. The communication of branches of vessels with each other. Albuminous. Having, or of the nature of albumen.

Antiphlogistic. Treatment intended to subdue inflammation.

Aeupuncture. Puncturing with needles.

Antiseptic. Preventing putrefaction.

Analysis. The process of separating a compound substance into its constituents.

Brachial. Belonging to the arm.

Bursa. A bag, or purse.

Bursa Mucosa. A serous bag for secreting a substance (Synovia), to lubri. cate tendons and joints rendering their motion easy.

Basement membrane. The undermost or fundamental membrane.

C

Calcareous. Belonging to lime.

Caliber. The diameter of a tube. The compass of mind.

Capillary. Belonging to hair. Hair-like. Applied to a minute system of vessels which connects the arteries and veins.

Caries. An ulceration of bone.

Carpus. The knee joint.

Cartilage. Commonly called gristle.

Centre of gravity. That point of a body, by which, if it were freely suspended, all the parts would be equally balanced.

Centre of motion. The same.

Centre of rotation. The same.

Cervical. Belonging to the neck.

Circulus Arteriosus. The artery which runs round the foot.

Circumferent. The line including and surrounding a thing, and forming a circle.

Chorion. A membrane involving the fotus.

Chronic. Long-continued; opposed to acute.

Co-arctation. A straightening, or pressing together.

Commissure. Applied to the fissures of the frog.

Compression. Flattening in a lateral direction. 
Concussion. A violent shaking.

Conforination. The natural form of a part.

Congener. Belonging to the same kind or race.

Congenital. From birth; born with.

Congestion. An unnatural accumulation of the usual contents of any vessels or ducts.

Cohesive. Sticking together.

Constitution. The general habit of the body.

Contraction. The act of contracting, drawing together, or shrinking, the state of being contracted.

Concavity. An internal rounded surface.

Convex. Bent down on every side of a body.

Connective tissue. Tissues that connect the different muscles, etc.

Conical. Cone-shaped.

Coronal. Resembling a crown.

Coronary. Applied to a ligament that encircles a part like a crown.

Corneous. Horny.

Correlative. Having, or indicating a reciprocal relation.

Cranial. Belonging to the cranium or skull.

Cuboid. Resembling a cube.

Cuticle. The epidermis, or scarf-skin.

Depletion. The use of means acting through the constitution in checking inflammation.

Diametrically. Directly opposite.

Diagnosis. The recognition of a disease by its symptoms.

Diathesis. A particular state or disposition.

Dilatation. An enlargement or expansion.

Dilation. The same.

Dilatator. Applied to instruments that enlarge or expand.

Dilator. The same.

Disease. Any departure from the state of health.

Dislocation. Displacement of a bone of a movable articulation from its natural place.

Disintegration. Breaking down of structures, or destruction of function. Dorsal. Pertaining to the back.

Economy. System.

Emollient. Softening.

Empirical. Belonging to an empiric or quack.

Empiricism. Quackery. 
Engorgement. A state of vascular congestion.

Enteritis. Inflammation of the bowels.

Epidermis. The external covering of the body. The cuticle.

Equine. Relating to the horse.

Etiology. The causes of disease.

Expansibility. The capability of being expanded.

Expansion. The increase of bulk or of surface, of which natural bodies are susceptible.

Extensor. An extender.

Extravasation. The effusion of a fluid out of its proper vessel or receptacle. Exfoliation. Shedding off in flakes.

Exostosis. Morbid growth of bone from bone.

Excreta. Applied to matters voided from the animal system.

Excito-motory. Exciting motion. A peculiar attribute of the spinal system of nerves.

Epithelial. The cuticle covering a mucous membrane.

Effluvia. Noisome exhalations perceived by the sense of smell.

Exudation. The oozing of fluids through the vascular walls.

Endosteum. The lining membrane of bones.

Etymological. Relating to the derivation of a word

Equilibrium. Equality of weight.

Exhalents. Vessels that exhale or send out vapors.

\section{$\mathrm{F}$}

Facilis decensus avernus. The road to evil is easy.

Fascia. A tendinous expansion.

Fibre. A minute thread or filament.

Fibrilla. Extremely fine threads only seen through the microscope.

Fibrin. Coagulable lymph.

Fibrinous. Having or partaking of fibrin.

Fibro-cellular. Both fibrous and cellular.

Fibro-elastic. Both fibrous and elastic.

Filament. A delicate thread-like substance.

Fissure. A deep depression.

Follicles. Little bags.

Foramen. A hole or opening.

Foramina. Plural of foramen.

Fragilitas. Ossium. Brittleness of bones.

Frustum of a cone. A cone with its apex cut off.

Fulcrum. A stay, or prop.

Function. A power or faculty by the exercise of which the vital phenomena are produced.

Functional disease. Where the function of an organ is vitiated, but its structure remains natural. 
Gastric. Belonging to the stomach.

Gastritis. Inflammation of the stomach.

Gastro-intestinal. Belonging to the stomach and intestines.

Gland. An organ for secreting or separating some particular fluid from the blood.

Globular. Of a round form like a globe.

Glutinous. Gluey, adhesive.

\section{$\mathrm{H}$}

Hallucination. Mental error, or foolish imagination.

Haversian Canals. Canals in bones first described by Haver.

Hereditary. Transmissible from parents to offspring.

Heterogeneous. Opposite by nature. Of different kinds.

Hiatus. An opening.

Hippedopathology. Pertaining to the diseases of horses' feet.

Histology. The doctrine of the minute or ultimate structure and composition of organized bodies.

Homologue. The same organ in different animals.

Homogeneous. Of the same kind, or quality throughout.

Horizontal. On a level.

Humeral. Relating to the arm.

Hygiene. The science of health.

Hyperamia. Excess of blood in a part.

Hypertrophy. Excessive growth, thickening, or enlargement of an organ.

Hypothesis. A supposition.

\section{I.}

Idiopathic. Arising spontaneously.

Inflammation. A state of disease characterized by redness, swelling, heat and pain.

Inflection. Bent, or curved inwards.

Intermittent. Disappearing and returning again at intervals.

Interosseous. Between bones.

Interperiosteal. Between periosteal membranes.

Intertransposition. Transposition between parts or organs.

Intertransmutation. Changes between parts or organs.

Ipse Dixit. Dogmatic assertion.

$\mathrm{L}$

Lamella. A thin plate of some substance.

Lamelle. Plural of lamella.

Lamellar. Having thin plates. 
Lamellated. The same.

Lamina. A thin plate, a layer of some substance.

Lamine. Plural of lamina.

Laminal. Consisting of thin layers.

Laminated. The same.

Laminitis. Inflammation of the laminæ.

Lateral. On, or near the side.

Lesion. Injury, hurt. or wound.

Ligament. A gristly substance which unites bones at their extremities.

Ligamentous. Of, or belonging to a ligament.

Locomotive. Changing place.

Lymph. The contents of lymphatic vessels. A product of inflammation. Lymphatics. Absorbents or vessels containing lymph.

M

Malformation. Deviation from the natural form of an organ. Matrix. A place where anything is generated or formed.

Membrane. An expanded sulsstance for the purpose of enclosing parts or organs.

Medullary. Pertaining to marrow.

Metacarpal. Beyond the knee-joint.

Metastasis. Change of disease from one part to another.

Metastastic. Relating to metastasis.

Modus operandi. Mode of operation.

Molecule. The smallest part of matter conceivable.

Molecular. Consisting of molecules.

Mollities Ossium. Undue softening of bone.

Morbid. Diseased.

Motory. Giving motion.

Mucus. The fluid secreted by mucous membranes.

Mucous membrane. The surface of the nostrils, mouth, windpipe, stcmach and bowels.

\section{$\mathrm{N}$}

Narcotic. Inducing sleep.

Navicular. Having the appearance of a small boat.

Naviculare, Os. The navicular bone.

Necrosis. Ulceration of bone.

Neuralgia. Pain in a nerve.

Neurotomy. Division of a nerve.

Nidus. A nest.

Nomenclature. The proper arrangement and application of names.

Nosology. Classification of diseases. 
Oicult. Secret, hidden, unknown.

Octogenarian. Eighty years old.

Ocular. Known by the eye.

Oleaginous. Of an oily nature.

Organ. Natural instrument.

Organism. Organic structure.

Os. A bone.

Os. Naviculare. The navicular bone.

Ossification. Cohversion into bone.

Osseous. Of a bony nature.

Palliative. Mitigating, not removing.

Parasitic. Living at another's expense.

Paralysis. Loss, or diminution of the power of voluntary motion.

Parieties. The walls, or sides of a cavity.

Par excellence. By way of eminence.

Papilla. Minute termination of a nerve.

Papilla. Plural of papilla.

Papillated. Having papillæ.

Pathology. A consideration of the nature and effects of diseases.

Pedal. Belonging to a foot.

Pectoral. Belonging to the breast.

Pendulous. Hanging, not supported below.

Perichondium. A membrane covering a cartilage.

Periosteum. Membraneous covering of a bone.

Peripheral. Towards the circumference.

Perspiratory. Causing, or pertaining to perspiration.

Phenomenon. In pathology, a morbid condition.

Phenomena. Plural of phenomenon.

Physiology. The natural constitution of things.

Pigment. Color.

Plantar. Belonging to the sole of the foot.

Plexus. A little net-work of vessels or nerves, or of both.

Pneumonia. Inflammation of the lungs.

Post mortem. After death.

Precursor. Forerunner, harbinger.

Predisposing. Rendering susceptible to any condition or disease.

Primary. Original, first.

Prognosis. Knowledge of a disease.

Proximate cause. The immediate existing cause of a disease.

Pulmonary. Belonging to the lungs.

Pyramidal process. Process resembling a pyramid. 
$\mathrm{R}$

Receptaculum Chyli. The expanded portion of the thoracic duct.

Resilience. The act of springing or leaping back.

Reiicular. Like a net.

Rationale. Explanation of causes.

Sebaceous. Fatty glands that secrete fat.

secerning. Separating or dividing.

Secretion. The same.

Secretories. Organs that secrete.

Sentient. Susceptible to sensation.

Sensory. Imparting sensation.

Sequela. A consequence, or sequel.

Serous. Having, or full of serum.

Serum. The watery portion of the blood.

Silicious. Having silicia in its composition.

Sinus. A cavity, hollow, or depression.

Sine qua non. A necessary condition.

Solar. Relating to the sole of the foot.

Solution of continuity. Division of the skin or other textures by a blow, a cutting instrument, or ulceration.

Spinal. Belonging to the back bone.

Squamous. Scaly.

Stellate. Pointed, or radiated, like the emblem of a star.

Sthenic. Having strength, a robust condition of body.

Stimulus. That which rouses or excites the energy of a part.

Strictuxe. Term for contraction.

Styptic. Having power to stop bleeding.

Sub-acute. Less acute.

Sub-cutaneous. Lying under the skin.

Sub-structure, The under structure.

Suffraginis os. The suffraginis bone. Large pastern bone.

Suigeneris. Of its own kind.

Sulcus. A groove, furrow, or trench.

Suppuration. A gathering of matter, festering.

Sympathy. That intimate connection between one part of a body and the rest.

Synovia. Commonly called joint-oil. 
Tegument. In general, the skin.

Tegumentary. Pertaining to the skin.

Temperament. Peculiar constitution of the body.

Temperature. Sensible heat.

Tendon. The gristly termination of a muscle.

Tendinous. Relating to a tendon,

Tetanus. Lock-jaw.

Textures. In anatomy, animal structures and substances.

Theory. A doctrine, scheme, or speculation.

Therapeutics. The science of applied remedies for the cure of diseases.

Thoracie. Relating to the thorax.

Thorax. The chest.

Tissue. See textures.

Tortuous. Twisted, winding.

Tone. Healthy condition of muscles, etc.

Tonics. Medicines which increase the tone of muscular fibre.

Translucent. Penetrable to some extent by luminous rays.

Traumatic. Belonging to a wound.

Tumour. A morbid enlargement from whatever cause.

Vaginal. Belonging to a sheath.

Vasa vasorum. The very minute arteries and veins by which the substance of larger vessels is supplied with nourishment.

Vascular. Having, or belonging to vessels.

Venesection. Bleeding from a vein.

Vermicular. Having the appearance of the progression of a worm.

Vesicular. Belonging to, or having vesicles.

Villus. Applied to small conical projections that secrete the various horn textures.

Villi. Plural of villus.

Viscera. The contents of the large cavities of the body, as the heart, lungs, stomach and intestines, etc.

Visceral. Relating to those organs.

Visual. Exercising the power of sight.

Vitiated. Perverted, injured, deteriorated.

Virisection. The cutting into living animals. 


\section{SPECIAL NOTIFICATION.}

Dr. J. B. Coleman hereby notifies the owners of valuable horses throughout the American States that, upon invitation, he will proceed to any readily accessible locality within the States for the purpose of giving instructions in his methods of treating the various foot-diseases of the horse. His instructions include demonstrations upon the feet of horses suffering from maladies that are usually deemed incurable, such as the supposed Navicular Disease, Laminitis, etc. Horses having tender feet, or are the subjects only of Contraction, Corns, and Quarter-Crack; it will be shown by actual demonstration are readily and quickly curable. He will stay sufficiently long in one locality to thoroughly induct his pupils into the whole rationale of the causes and treatment of foot diseases, than which, fully understood, nothing can be more simple and rational; more perfectly adapted to accomplish the ends in view, or more easily acquired; and a correct knowledge of which is of immeasurable value to owners of first-class stock.

A general knowledge of these principles and processes will save millions worth of horse-stock from sacrifice or destruction; which means millions saved to individual and national gain.

The author can save, and show others how to save, ninetyfive per cent of all cases of so-called incurable diseases; and cure rapidly, in a few weeks at most, the worst cases of QuarterCrack, Corn, and Contraction. Such important information as this should no longer be kept secret. What would not some horse-owners give if their horses could be prevented from Interfering, Speedy-cutting, Knee-hitting, and other Irregular Actions, so as to dispense with boots and pads? That this is readily effected, is as demonstrable as that one and one make „two. The author enters into his work con amore, and strives 
to make every one of his pupils as expert as himself, and more so, if possible.

He feels confident that not one of his pupils has ever regretted the outlay of the small fee, for instruction, small in comparison to the value of the information imparted, or part with the latter if he could, for twenty times the amount.

\section{DR. J. B. COLEMAN,}

Post Office Box 34,

Chicago, Ills. 


\section{TESTIMON I A LS.}

"HOW TO MAKE A BOOK."

The writer prefers to depend upon the merits of his work for its extended sale and the employment of his personal services, both as a teacher and practitioner, than to the ad captandum mode of operations implied in the display of a large number of laudatory testimonials, while the desired and paid for information is non est inventus.

This is the general character of a book published a few years since, whose title page would lead the purchaser to imagine that a great secret was to be the equivalent for his five dollars; but instead of which he purchased a work that would have been better entitled, "A Collection of Letters and Extracts from Newspapers upon the Merits of a Method of Treatment for Horses' Feet; " but the rationale of which method could only be imparted after a fee of from one hundred to five hundred dollars has been duly paid and pocketed. The amount of disappointment and profane swearing which has been occasioned by the sale of that book and its purchaser is not edifying to dwell upon.

"THE PLAY Without THE PART, OF HAMLET."

The writer of this work believes that it will not belie the promises of its title page; that it will not create disgust and disappointment; that it will not be a mere collection of letters laudatory of a system with the system omitted; the play of Hamlet with the part of Hamlet left out, but that it will supply the long sought-for information; the loudly-expressed want of all horse-owners of every class and description; the most humane and successful of all systems of treatment for the diseases of the feet of horses. 
The writer is indebted to his friends, AdDison Doughty and MAjor AnTHony, of this city, for a knowledge of the fact that his plans of treatment, besides its other merits, is a very large factor in the development of speed in the trotting horse, by its prevention, and correction, if present, of irregular action; so much so that the usual upholstery work of boots and pads can be very largely if not entirely dispensed with. This fact alone enhances the value of his special treatment immensely; and with the endorsement of the two foregoing names, he can afford to smile at the rabid hostility manifested by some socalled veterinarians and blacksmiths of this city, who cherish bar shoes and cripples, as institutions, or sources of profit of which, whoever dares to look doubtfully or speak lightly, should be immolated instanter.

\section{UNEXCEPTIONABLE TESTIMONY.}

It were easy for the writer to make a book of the letters and testimonials he has received, or may ohtain, if he so desired, eulogistic of himself and his system. He hopes, however, the two following letters from well-known practical horsemen of Chicago, will be sufficient to satisfy the very proper desire some may entertain for testimony of this character, before they entrust valuable property into the hands of any one, of whose professional skill they are not themselves personally cognizant.

\section{LETTER FROM ADDISON DOUGHTY, ESQ. \\ Training Stable, 404 IVebster Avenue, ? Chicago, Ill., January 2 I, 1876.}

\section{Dr. Coleman :}

Dear Sir:-I am happy to bear testimony to the extreme value and importance of your methods of treatment for the various diseases to which the foot of the horse is liable. since becoming your pupil, the knowledge of these methods 
has been of immense advantage to me, as I have been enabled thereby to improve the speed of several otherwise fast horses, and notably that of "Woodford" and "Pinkie," in a remarkable degree. I have cured many cases of contraction, corn, and quarter-crack, since then, by these means, such cases giving me no trouble whatever. I have made a remarkable cure of a mare, the short history of which was this: She had been badly foundered, had been five or six weeks in the hands of a doctor who had abandoned her as incurable-as the coffinbones of her fore feet had become visible through the horny soles. I bought her for experimental purposes at a very low price. I have succeeded in re-instating the coffin-bones in their natural position, the feet are growing down sound, the mare being meanwhile perfectly free from the suspicion of lameness. As this statement may be doubted by some, any one doubting, or requiring any reference as to your capabilities in the premises, can have this statement verified by writing to me upon the matter. I would say that you have my most unqualified endorsement as a perfect master of all matters pertaining to the foot of the horse and its diseases. If your forthcoming work contains the information I have derived from your personal instructions, it will be an invaluable boon to horsemen, and a blessing to horses of every class, from the trotter to the streeter.

I further take pleasure in saying that I have good reasons for reposing confidence in your ability in the treatment of the constitutional maladies of the horse; and I can say as much on behalf of my friends, whose very valuable animals you have treated with perfect success.

In conclusion, I would add the expression of my opinion, that if your views and methods of shoeing both sound and lame horses were widely disseminated and generally adopted by horsemen, veterinary surgeons, and shoeing-smiths, diseases of the feet of horses would become exceedingly rare in a very short time. 


\section{LETTER FROM R. C. ANTHONY.}

\section{Boarding and Sale Stable, i33 Michigan Ave, ? Chicago, Ill., January 24, I 876 .}

\section{Dr. J. B. Coleman,}

Dear Sir :-In compliance with your request for my opinion as to the value of the special modes of treatment which you practice and teach, I have to state that of nearly fifty cases that you have treated for me, or that I have treated after receiving your instructions, I cannot recall a single instance of want of success in the treatment. They were all cases of foot diseases in some form or another, the greater part I should say. were those of contraction, corns, and quarter-crack. Some were believed to have been navicular disease, but whether they were or not they became sound. One was a case of canker in which the sole and nearly the whole of the crust had separated, yet the canker was arrested and a new foot grown out, and the life of a valuable animal saved, which, I think, would have been impossible by any other means than those you adapted. Your clear insight into the general and particular causes of every malady that affects the foot of the horse, and above all your simple, rapid, painless and effective cure of cases usually deemed incurable, or of doubtful cure, such as Navicular Disease, Acute and Chronic Founder, and badly contracted feet, stamps you, in my estimation, as a genius in all that pertain to the foot of the horse whether in health or disease.

No one can appreciate this statement until they have been instructed by you in this special branch of horse-knowledge. I can safely recommend all horse-men, no matter what they know already, to avail themselves of your personal instructions upon this subject, feeling assured they will not be disappointed, nor regret the outlay. It is important that horse-men should be made aware of the very marked influence your treatment has over all irregular action, such as hitching, broken-gait, interfering, etc. Nothing conduces more powerfully to regulate and perfect action, and to the development of speed than the 
treatment you advise. My mare, 'Pet,' a short time ago, could not be driven by any but myself without getting her gait 'mixed up' and her fore shoes picked off. Your treatment which is simplicity itself, has changed all that.

You further desire my opinion upon the quality of the work which you are about to publish upon the foot of the horse. IVhat I have seen of it in manuscript; what I know of the information to be obtained from veterinary works in general; and my experience in horse-matters generally, enables me to say that it will be the best and most advanced work of its kind ever given to the public. Its utility to horse-men will be of the most valuable character, and I predict that we shall hear of greater achievements in speed than have hitherto been recorded, when the principles and practice it inculcates in regard to the preservation of sound feet, and the restoration of diseased ones, come to be widely appreciated and carried into effect.

R. C. ANTHONY. 


\section{THE DILATOR.}

The high price charged for a patented instrument of this nature which possesses no special advantage to make it a sine qua non, and the loss of time, trouble, and expense involved in getting one made by the ordinary blacksmith, has led the author of this work to have an instrument manufactured which is equally effective as the patented instrument, and can be sold at a much less price.

It can be supplied, plain, for $\$ 3.00$.

Silver or Nickel plated, in leather case, for carrying in the pocket, $\$ 6.00$. 


\section{THE BOOK AND THE INSTRUMENT.}

Until agents, who are wanted everywhere, have been appointed for the sale of the book and the instrument, they can only be obtained from the author.

The book will be mailed free, to any address in the U. S., upon the receipt of three dollars.

The instrument will be sent, by Express, to any address in the U.S., upon the receipt of three or six dollars respectively.

The book and the instrument will be sent together, by Express, upon receipt of stated prices.

Booksellers ordering the book, or the instrument, or both, may deduct ro per cent. for commission, but pre-payment is a pre-requisite of the order being attended to.

Post Office Orders should be made payable and all communications addressed to

DR. J. B. COLEMAN,

$$
\begin{aligned}
& \text { Post Office Box } 34, \\
& \text { Chicago, ILl. }
\end{aligned}
$$




\section{NOTICE TO HORSE OWNERS.}

As many horse-owners of Chicago and elsewhere may desire to be informed where, and by whom the foot-diseases of the horse can rationally and successfully be treated upon the principles and methods of treatment advocated in this work, the author has pleasure in presenting the cards of two gentlemen who are thoroughly indoctrinated with the author's views and processes of treatment, and have effected some very remarkable cures themselves, and into whose care horses of value may be safely sent from any distance for special treatment with perfect confidence.

The Horse-Shoers, whose cards are presented, have also been instructed in the author's theory and practice of shoeing the feet of both sound and lame horses. They have been his chief coadjutors in his practice in Chicago, upon the feet of all kinds of horses, whether of much or little value, and he can endorse them as skillful and efficient workmen. 


\section{ADDISON DOUGHTY,}

BOARDING.

\section{BREAKING AND TRAINING}

\section{S TA B L ES S,}

Nos. 402, 404, 406 and 408 Webster Ave.,

\section{OIFIOAGO, III.}

N. B.-Open for the reception of horses for the special treatment of foot diseases, upon Dr. Coleman's rational, radical and safe methods of cure.

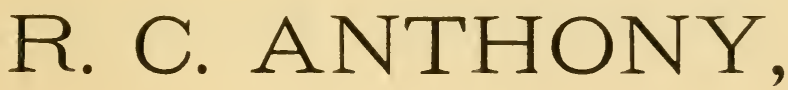

\section{Boarding and Sale Stable,}

No. 133 Michigan Avenue,

CHICAGO, ILL.

H orses crippled by contracted quarters, corns and quarter-crack, may be consigaed to him for treatment, and an absolute cure guaranteed in from seven to thirty days, upon

DR. COLEMAN'S METHOD OF TREATMENT. 


\section{JAMES MADDEN,}

\section{PRACTICAI}

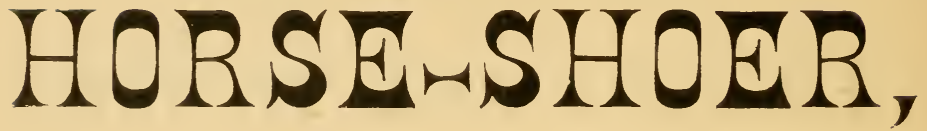

\section{Rear of 43 14th Street,}

(Between Michigan and Wabash Avenues,)

\section{CHICAGO, ILL.}

His long general experience as a Horse-Shoer, together with the particular experience which he has gained under the instructions and directions of Dr. Coleman, for the removal of all the diseased conditions of horses' feet, and especially for the quick cure of Contraction, Corn, Quarter-Crack, Quittors, etc., and the prevention and cure of Interfering, enable him to promise absolute satisfaction to the owners of horses requiring his services.

N. B.-All horses shod under his own superintendence, and none but the most skillful workmen employed.

\section{MICHAEL KEADY,}

PRACTICA L

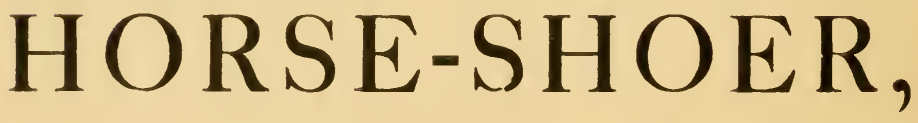

702 Larrabee Street,

(Near Lincoln Avenue.)

All kinds of Interfering and all Contractions, Split Hoofs and Corns guaranteed to bo cured by Dr. Coleman's method of treatment. 







\footnotetext{
Webster Family Library of Veterinary Medicine Cummings School of Veterinary Medicine at Tufts University 200 Westiboro Road North Grafton, MA 01536
} 

